\title{
Wake Effects in a Fayette 95-IIS Wind Turbine Array
}

\author{
R. L. Simon \\ D. F. Matson \\ J. M. Fuchs
}

Fayette Manufacturing Corporation

Tracy, California

Prepared under DOE/SERI Cooperative

Agreement No. DE-FC02-85CH10252
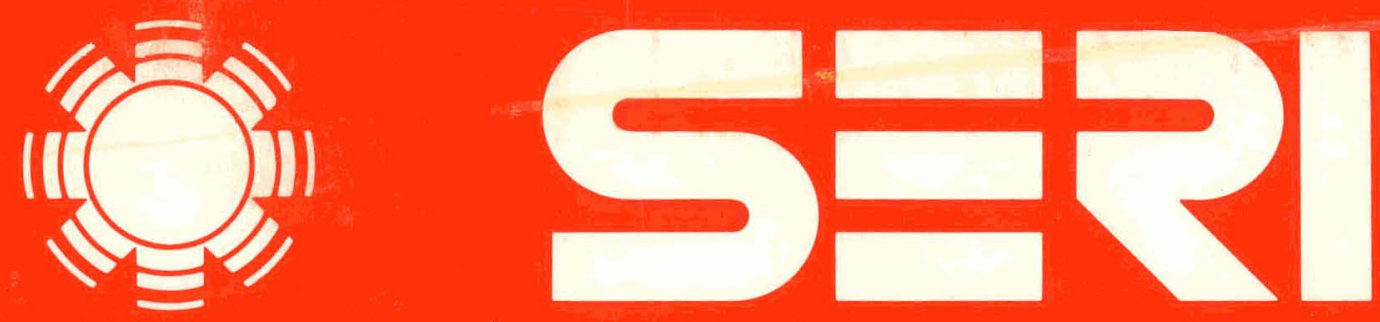

Solar Energy Research Institute

A Division of Midwest Research Institute

1617 Cole Boulevard

Golden, Colorado 80401-3393

Operated for the

U.S. Department of Energy

under Contract No. DE-AC02-83CH10093 


\section{DISCLAIMER}

This report was prepared as an account of work sponsored by an agency of the United States Government. Neither the United States Government nor any agency Thereof, nor any of their employees, makes any warranty, express or implied, or assumes any legal liability or responsibility for the accuracy, completeness, or usefulness of any information, apparatus, product, or process disclosed, or represents that its use would not infringe privately owned rights. Reference herein to any specific commercial product, process, or service by trade name, trademark, manufacturer, or otherwise does not necessarily constitute or imply its endorsement, recommendation, or favoring by the United States Government or any agency thereof. The views and opinions of authors expressed herein do not necessarily state or reflect those of the United States Government or any agency thereof. 


\section{DISCLAIMER}

Portions of this document may be illegible in electronic image products. Images are produced from the best available original document. 


\title{
Wake Effects in a Fayette 95-IIS Wind Turbine Array
}

\author{
R. L. Simon \\ D. F. Matson \\ J. M. Fuchs \\ Fayette Manufacturing Corporation \\ Tracy, California
}

September 1987

SERI Technical Monitor: W. Bollmeier

Prepared under DOE/SERI Cooperative Agreement No. DE-FC02-85CH10252

\section{Solar Energy Research Institute}

A Division of Midwest Research Institute

1617 Cole Boulevard

Golden, Colorado 80401-3393

Prepared for the

\section{U.S. Department of Energy}

Contract No. DE-AC02-83CH10093 


\section{NOTICE}

This report was prepared as an account of work sponsored by the United States Government. Neither the United States nor the United States Department of Energy, nor any of their employees, nor any of their contractors, subcontractors, or their employees, makes any warranty, expressed or implied, or assumes any legal liability or responsibility for the accuracy, completeness or usefulness of any information, apparatus, product or process disclosed, or represents that its use would not infringe privately owned rights.

\section{Printed in the United States of America \\ Available from: \\ National Technical Information Service \\ U.S. Department of Commerce \\ 5285 Port Royal Road \\ Springfield, VA 22161}

\section{Price: Microfiche A01}

Printed Copy A04

if Codestis

Codes are used for pricing all publications. The code is determined by the number of pages in the publication.

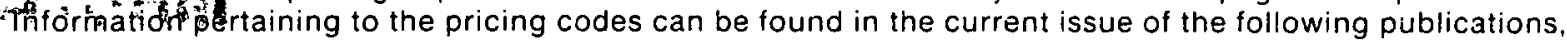
which are generally available in most libraries: Energy Research Abstracts. (ERA); Government Reports Announcements and Index (GRA and I); Scientific and Technical Abstract Reports (STAR): and publication. NTIS-PR-360 available from NTIS at the above address. 


\section{PREFACE}

This report summarizes the findings of a field measurement program that studied wake effects on energy production and wind velocity within a wind farm array operated by Fayette Manufacturing Corporation. This array included 35 turbines that were operated under specially designed sequences of scenarios.

This was one of several studies, funded by the DOE Federal Wind Program as part of the SERI Cooperative Field Test Program (CFTP), to address array wake effects through direct measurements. It complements past measurement studies funded by DOE and others of wakes behind individual turbines and theoretical techniques developed to estimate array wake effects with numerical models.

In addition to the innovative nature of the technical approach, the project also resulted in a positive, productive interaction between the government and private sectors in addressing the current needs of the wind industry.

The success of this project was the result of the combined efforts of many people. Walter Thompson, Fayette's contractual representative, provided invaluable administrative and overall. support. Steve Smialkowski, Glen Johnson, and George Berasi designed, built, tested, and installed the data acquisition system, often working late hours to ensure that it would be available for summer 1986. Rich Castro, Fayette Meteorological Department, assisted in anemometer deployment and calibrations. Fayette operations personnel, headed by Bob Keech and Larry Barr, kept the turbine array and data acquisition system operating with high reliability.

Dr. Larry Wendell of Battelle Pacific Northwest Laboratory and Mr. Alan Miller, formerly of Battelle, are thanked for their participation at various stages of the project--notably in its design and analysis and in the preparation of the final report. Mr. Warren Bollmeier, SERI CFTP Manager, and other SERI and DOE staff are also acknowledged for their administrative and technical support.

Two of the authors, Richard Simon and David Matson, are consulting meteorologists who have worked with Fayette for four years. The other author, Jerry Fuchs, supervises Fayette's Metenrolngiral Department. 


\section{SUMMARY}

A group of 35 Fayette Manufacturing Corporation 95-IIs wind turbines on the Castello Ranch in Altamont Pass, California, was investigated to quantify array wake effects (losses in energy production due to operation of upwind turbines) and the factors influencing them. Approximately 65 hours of field measurements were made in summer 1986, with turbine energy production and wind velocity data recorded for various scenarios of array operation. Customized software and hardware were developed and installed by Fayette to facilitate these measurements.

There were three primary rows of turbines used for the analysis, each row containing seven turbines. Array spacing was uniformly 2.8 rotor diameters between adjacent turbines in a row and either 10.4 or 11.1 rotor diameters between rows. This spacing is more open than that of most commercial wind farms.

During half of the measurement program, 21 primary turbines and adjacent "buffer" turbines were operated in alternating scenarios of all rows running and only selected rows running. These row-by-row scenario tests were used to evaluate whether wake effects even existed in the array (they did), which was initially of some concern because of its open spacing. In the other half of the measurement program, more subtle features of the wake phenomenon were investigated by bringing small numbers of turbines on 1 ine in a sequenced mode.

The existence of wake effects was fairly well established. Relative energyproduction losses averaged $6 \%$ at the second row, when the first row was operating, and $7-8 \%$ at the third row, when the first two were operating. Apparently, then, the impact of the first row on the third (at a 21-rotordiameter distance) was minimal.

Ambient wind speed did not appear to affect the relative wind speed pattern within the array due to wakes, but because of the shape of the performance curve, it did affect relative energy production losses (particularly for the low-RPM mode of machine operation):

The influences of ambient atmospheric conditions, such as stability, turbulence, and shear on the array wakes, were also investigated by testing over a range of the conditions available during a typical 24-hour day at the test site. None of these variables showed any significant effect on the degree of wake-induced energy losses.

The lack of a relationship between turbulence intensity and wake effects is noteworthy in that previous researchers and numerical modelers have postulated that there would be one. Also conflicting with these past concepts was the lack of a cumulative increase in turbulence throughout the array--anemometers at 8 and 9 rotor diameters downwind of particular turbine rows showed the same turbulence levels regardless of whether the upwind rows were operating or shut down.

While the results of this study apply only to this specific array and type of wind turbine, the methodology could be applied to study wake effects at other wind farms. 


\section{TABLE OF CONTENTS}

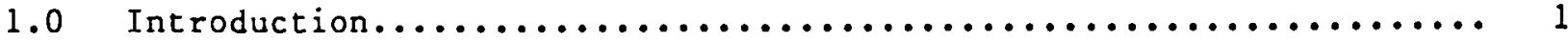

2.0 Study Methodology................................ 3

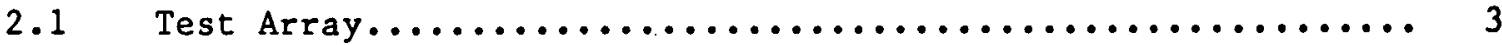

2.2 Historical Wind and Energy-Production Patterns at the Test

Monitoring Equipment and Instrumentation.............. 7

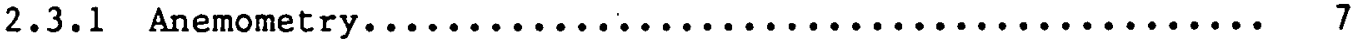

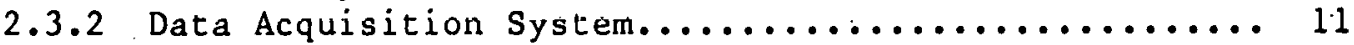

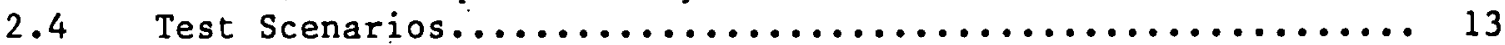

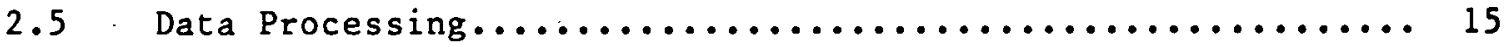

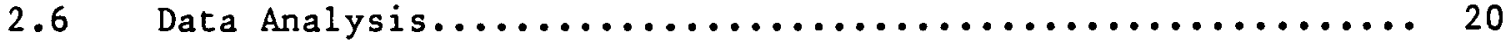

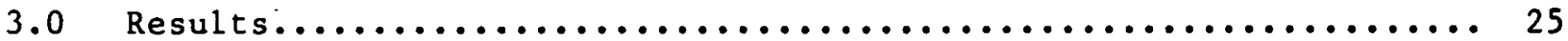

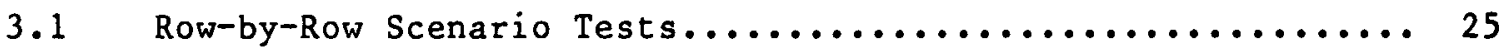

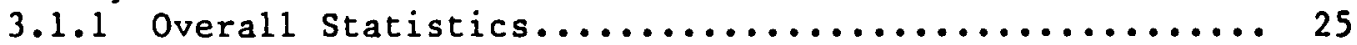

3.1 .2 Ambient-Wind-Speed Influences................ 27

3.1.3 Vertical-Shear Influences..................... 31

3.1.4 Turbulence-Intensity Influences................ 31

3.1 .5 Diurnal Influences........................ 35

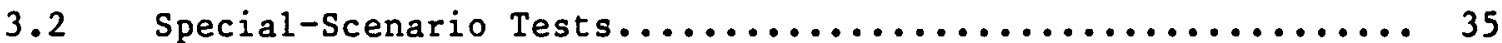

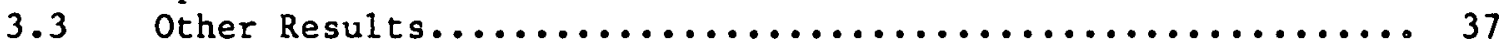

3.3.1 Wind Shear at Anemometer Tower B.............. 37

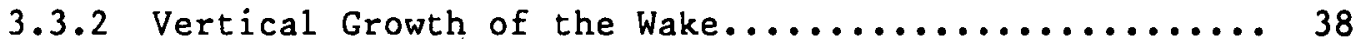

3.3.3 Special Comparison of Anemometers B $(80 \mathrm{ft})$ and $\mathrm{C} \ldots \ldots 38$

4.0 Conclusions and Recommendations...................... 41

$5.0 \quad$ References..................................... 43

Appendix A: Sample Operational and Analysis Graphics for an Individual 15 -minute Test....................... 44

Appendix B: Mean Energy-Production and Wind-Speed Data for the

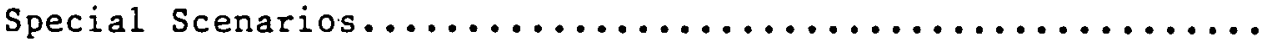


SEP

$\operatorname{STR}-3186$

LIST OF FIGURES

Figure

$\underline{\text { Page }}$

2-1. Location of Wake-Effects Test Array on the Costello Ranch....... 4

2-2. Fayette 95-IIS Performance Curve.

5

2-3. Mean Wind-Speed Patterns across the Test Array at $45 \mathrm{ft}$ above Ground (Spring 1986)......................... 8

2-4. Schematic of the Data Acquisition System................. 12

$2-5$. Wake Test Scenarios................................ 14

2-6. Row 14 Equivalent Mean Wind Speed vs. Anemometer A Mean Wind Speed (Low-RPM Mode)

23

2-7. Row 14 Equivalent Mean Wind Speed vs. Anemometer A Mean Wind Speed (High-RPM Mode)............................. 24

vi 


\section{LIST OF TABLES}

Table

2-1. Control Anemometer Wind-Speed Data (April 27-June 2, 1986)...... 7

2-2. Observed Daily Energy-Production.Ratios to Primary Turbines

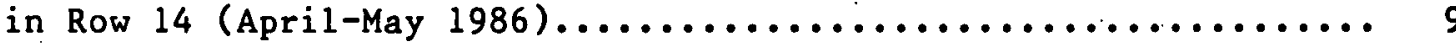

2-3. Meteorological Towers Used in the Wake Study............... 10

2-4. Number of 15 -Minute Test Runs...................... 16

2-5. Wake Study Test Status Codes......................... 18

2-6. Frequency Distribution of Test Status Codes by Scenario Type..... 19

2-7. Correlation of Row 14 Turbine Energy Production with Anemometer A Wind speed............................ 21

3-1. Mean Energy Production (Row-by-Row Tests)................. 26

3-2. Mean Wind Speeds Measured by Anemometers A-D (Row-by-Row

Tests)........................................ 28

3-3. Significance Level of Energy Production and Mean-WindSpeed Differences (Row-by-Row Tests).................... 29

3-4. Mean Energy Production and Wind Speed as a Function of Anemometer A Wind-Speed Class (Scenario A Tests)............ 30

3-5. Mean Energy Production as a Function of Vertical Shear Class (Scenario A Tests)............................. 32

3-6. Mean Speed Turbulence Intensity...................... 34

3-7. Mean Energy Production as a Function of Speed Turbulence Intensity Class (Scenario A Tests).................... 34

3-8. Mean Energy Production as a Function of Time-of-Day Class (Scenario A, Low-RPM Tests).................... 35

3-9. Analysis of Scenario G Sequence (Low-RPM Mode).............. 37

3-10. Mean Wind-Shear Ratios (Anemometer Tower B)............... 38

3-11. Frequency Distribution of Mean Wind-Shear Ratios (Row 14

Turbines Shut Down)............................. 38

3-12. Analysis of Wake Effects at $110 \mathrm{ft}$ (Anemometer Tower B)........ 40

3-13. Relative Mean Wind-Speed Losses due tó Rúw 14 wakes........... 40 


\subsection{INTRODUCTION}

Commercial wind farms generally consist of quasi-orthogonal arrays of wind turbines. Developers like to locate as many turbines as possible on a specific property; however, if they are packed too closely, rotor wakes impinge on downwind turbines and reduce their energy production.

In the past, there have been two methods for assessing wake effects:

- Theoretical--Numerical modeling has been used to estimate array wake loss factors. Researchers such as Eberle (1981) and Lissaman et al. (1982) have developed flow models that simulate rotor-induced wake turbulence into the mean flow. As currently written, these models assume a flat terrain, uniform turbine characteristics, and a uniform ambient wind velocity entering the grid. Such perfect conditions rarely apply, of course.* Another drawback is that the models have not been verified on an operating turbine array (at least not in publicly available literature).

- Direct Measurements--A number of investigators have studied wakes behind individual turbines (e.g., Baker and Walker, 1985; Buck and Renne', 1985; Doran and Packard, 1982; Renne' and Buck, 1985). Many of these studies have been funded by the U.S. Department of Energy (DOE). The drawback to this approach is that there is no established, verified method of predicting array energy losses from the individual wake data.

This study was one of several new DOE publicly-funded studies to examine array wake effects in an operating wind farm with direct measurements.

A group of 35 Fayette 95-IIs turbines in Altamont Pass, California, was chosen for this study. This array (discussed further in Section 2.1) had several desirable attributes:

- Turbines were on a relatively flat terrain (hilly terrain complicates the analysis).

- This is an orthogonal array with uniform hub height and uniform spacing between adjacent turbines in the rows. Spacing between rows varied slightly.

- There is relatively high turbine availability.

- Fayette had already developed a dedicated command/data acquisition system.

- There are no turbines upwind in the prevailing (southwest) direction for over 2000 feet, ensuring wake-free flow at the upwind edge of the array.

The field measurements were conducted from August 12-October 11, 1986. Before these tests, an evaluation of winds and energy production across the array was made under normal operating conditions (Section 2.2).

*The code is being rewritten to cover more realistic conditions under as-yetunpublished studies ( $\mathrm{S}$. Veenhuizen, United Industries Corp., personal communication). 
The study methodology is discussed in section 2.0 and the results in Section 3.0 


\subsection{STUDY METHODOLOGY}

The basic methodology used to examine array wake effects was to operate the turbines in a series of various scenarios, measuring their energy production as well as wind velocity at strategic locations. Test segments for each individual scenario lasted 15 minutes, followed by several minutes of starting up or shutting down some of the turbines prior to the next test segment.

This section describes the array, instrumentation, and the procedures used to conduct the study.

\subsection{Test Array}

The test array is located on the Castello Ranch in the eastern portion of Altamont Pass, California (Figure 2-1). There are 35 Fayette model 95-IIS wind turbines (see the performance curve of Figure 2-2) * 1aid out in an orthogonal grid on a small plateau rising about $100 \mathrm{ft}$ above the surrounding terrain and oriented perpendicularly to the prevailing west-southwest flow. The plateau is not perfectly flat, but elevation changes are gradual. The difference in elevation between the highest and lowest turbine within the array is only $40 \mathrm{ft}$; in comparison, the rotor diameter (RD) of the turbines is $36 \mathrm{ft}$. There are no turbines upwind of the array for at least $2000 \mathrm{ft}$, ensuring that the ambient flow is free of embedded wakes.

The rotors are mounted on $80-\mathrm{ft}$ guyed towers. The three rows in the test array are oriented along an axis of 335 degrees, or perpendicular to a wind direction of 245 degrees. The lateral spacing of towers within rows is uniformly $100 \mathrm{ft}$ ( $2.8 \mathrm{RD})$, the minimum possible due to guy-wire considerations. Spacing among the three rows does vary: it is $375 \mathrm{ft}$ ( $10.4 \mathrm{RD})$ from Row 14 (the most upwind) to Row 15, and $400 \mathrm{ft}$ ( $11.1 \mathrm{RD}$ ) from Row 15 to Row 16 (the most downwind). This spacing was dictated by property setback requirements; had there been a fourth row, the spacing would have been $7 \mathrm{RD}$, which would be too close.

The typical spacing of many commercial wind farms is $2 \times 8$ or $2 \times 10$ RD, so the turbine rows in the Fayette test array are spaced further apart than those of most arrays in the industry.

There were three classifications of turbines within the array:

- Twenty-one "primary" turbines (seven per row), the group for which wake effects were analyzed.

- Ten "buffer" turbines to the immediate north and south of the primary array. Their purpose was to help ensure uniformity across a given row of primary turbines (so that no unwanted conditions leaked in horizontally due to turbulence or a mean wind direction not exactly perpendicular to the row orientation).

*Note that the Fayette rotor operates in $10 \mathrm{w}-\mathrm{speed}(80 \mathrm{rpm})$ and high-speed $(120 \mathrm{rpm})$ modes. 


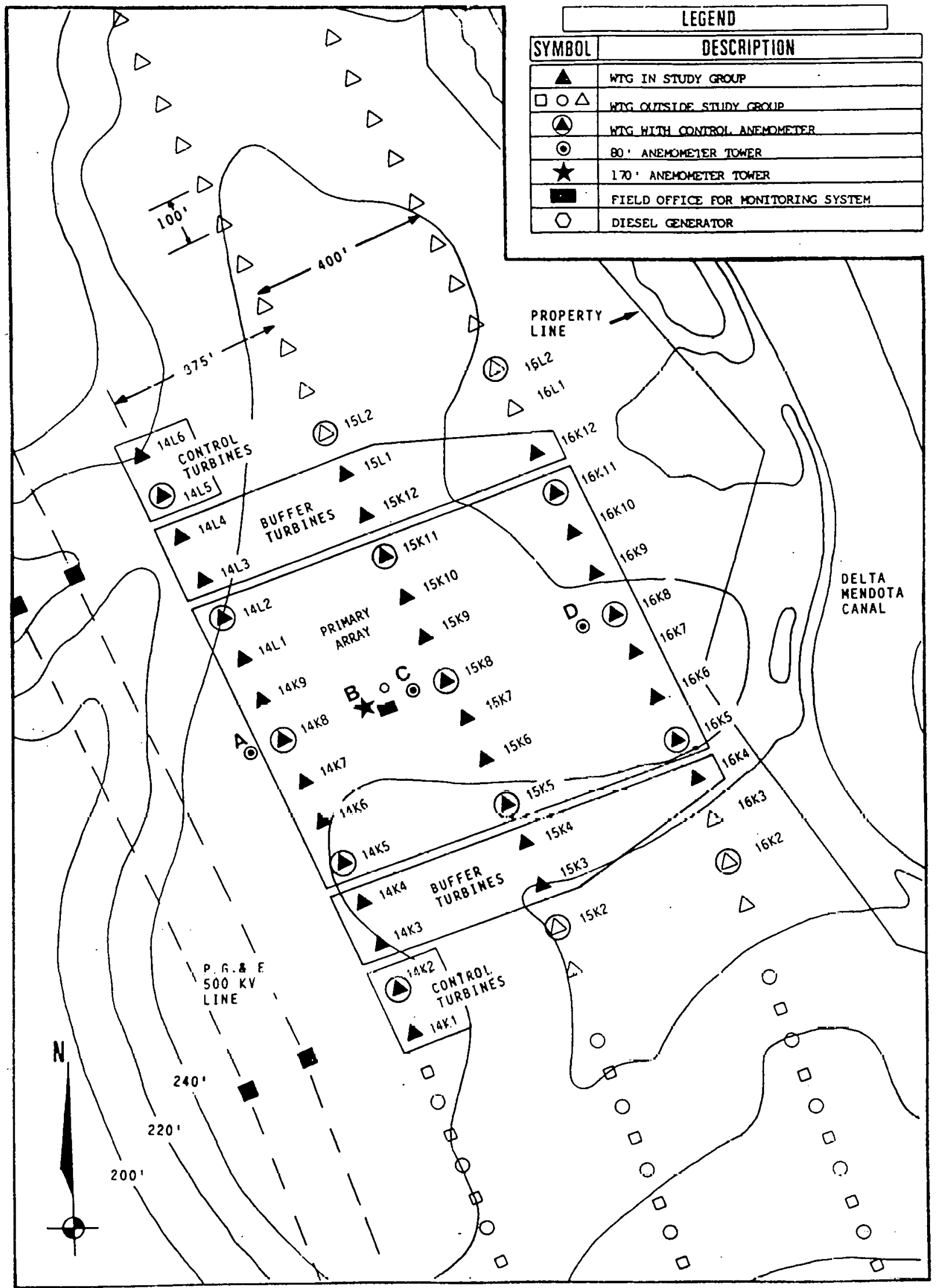

Figure 2-1. Location of Wake-Effects Test Array on the Castello Ranch 


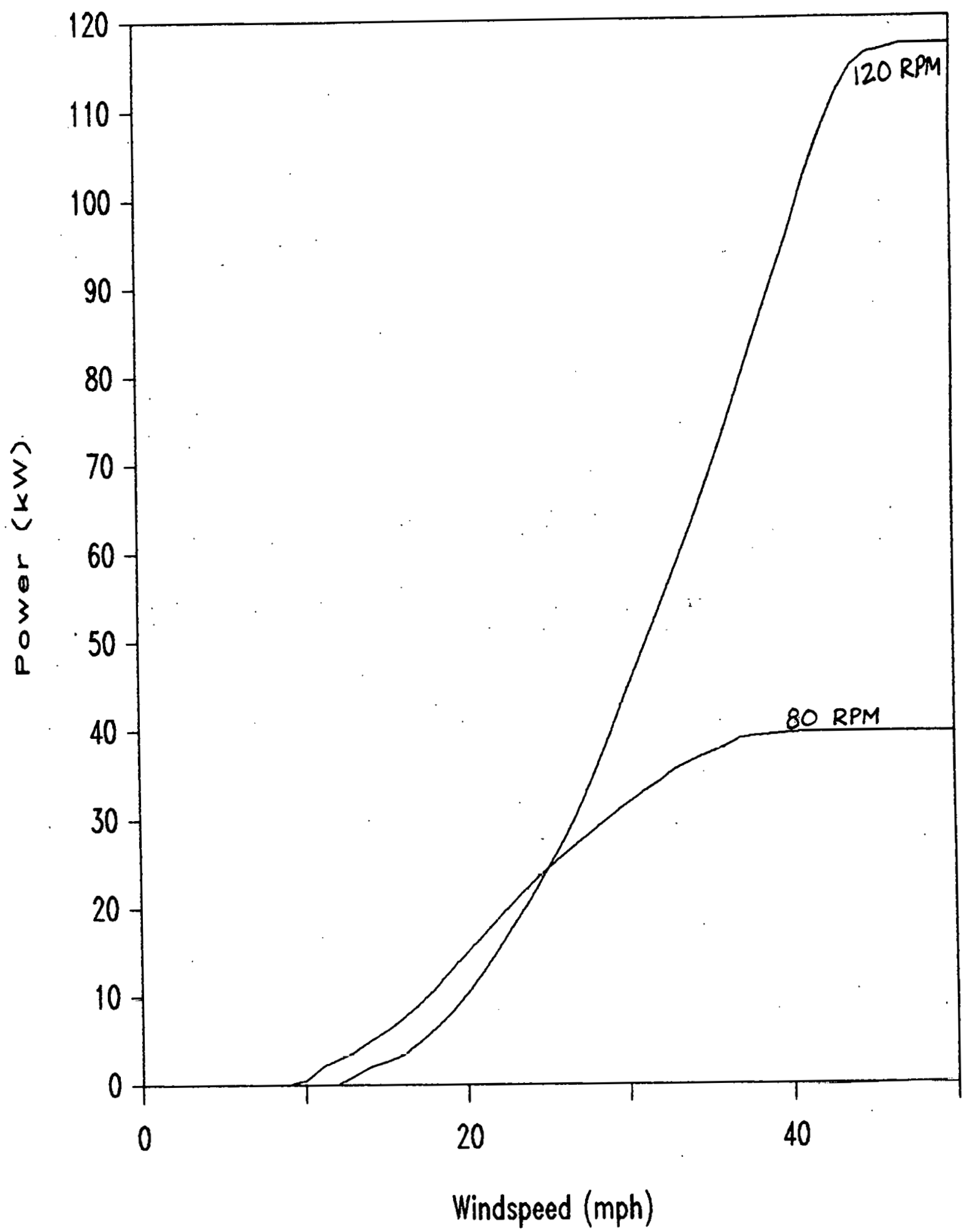

Figure 2-2. Fayette 95-IIS Performance Curve 
- Four statistical "control" turbines to the immediate north and south of the buffer turbines in Row 14. The control turbines operated during all the test scenarios, whereas the primary and buffer turbines were subject to being shut down. The scenarios are described in section 2.4 .

\subsection{Historical Wind and Energy-Production Patterns at the Test Array}

Wind-speed and energy-production data were collected at the test array before the wake tests to document typical conditions during normal operation of the wind farm.

Control anemometers mounted on every third turbine tower at the $45-\mathrm{ft}$ level (t'igure 2-1) were used to measurc winds from Apri1 27-June 2, 1986. This porind was dominated by west-southwest flow, the same direction for which the wake tests were conducted several months later. There were tive control ane= mometers in each row. One row was sampled each week on a rotating basis, by means of five wind run data loggers built by Wind Engineering Consultants and NRG Systems. The loggers were moved from row to row each week. Thus, two weekly mean speed readings were obtained from each anemometer over the sixweek period. All mean speed data were normalized by the simultaneous mean speed at Fayette's permanent Castello-13 anemometer site located just upwind of the array at the 40-ft level. Table 2-1 lists the normalized weekly mean speed data; Figure 2-3 plots them on a site map and shows the location of the Castello-13 anemometer.

These data show a strong relationship between elevation and mean wind speed. Sites in lower-lying areas were $10-15 \%$ less windy than the higher portion of the plateau. Note that the two normalized weekly mean speed values for a given site differed 1ittle, generally less than $2 \%$, indicating a consistent wind pattern across the test site.

Energy-production patterns across the primary array were analyzed for the period from April 5 to May 6, 1986. Turbines were operaced exclusivily in the low-speed mode during that time, and daily energy production was recorded manually. Because of some low-wind periods and maintenance problems, there were only 10 days with sufficient energy production and data quality to be included in the analysis (Table 2-2).* Mean (primary) row energy production decreased downwind through the array, but the separate contributions of wake effects and terrain cannot be discerned solely from these data.

The "control" turbines at the south end of Row 14 operated inconsistently, but those at the north end of Row 14 provided sufficient data for analysis. Note that these two turbines produced only $78 \%$ as much energy as the primasy tur. bines in the same row. Furthermore, the standard deviation of the daily mean production ratios (to primary turbines in Row 14) was substantially greater for the two control turbines than for Rows 15 and 16 . Ihis is important to note, hecause the rationale for having statistical "control" turbines is that their energy production is well correlated with that of the primary array; however, these data suggest a relatively poor correlation.

*The energy production of kow 15 exceeded that of Row 14 on two days (April 15 and May 1). Thus, the energy-production patterns can be quite variable in light wind days. 
Table 2-1. Control Anemometer Wind-Speed

Data (April 27-June 2, 1986)

\begin{tabular}{|c|c|c|c|c|c|c|c|}
\hline $\begin{array}{l}\text { Wind tur- } \\
\text { bine control } \\
\text { anemometer }\end{array}$ & Week & $\frac{\mathrm{C}-13 *}{\mathrm{~V}(\mathrm{mph})}$ & $\begin{array}{l}\text { Sitel } \\
\text { C- } 13 \\
\bar{V} \text { ratio }\end{array}$ & Week & $\begin{array}{c}\mathrm{C}-13 \\
\overline{\mathrm{V}}(\mathrm{mph})\end{array}$ & $\begin{array}{l}\text { Sitel } \\
\text { c-13 } \\
\bar{v} \text { ratio }\end{array}$ & $\begin{array}{r}\text { Overal1 } \\
\text { ratio } \\
\text { to } \mathrm{C}-13\end{array}$ \\
\hline $\begin{array}{l}14 \mathrm{~K} 2 \\
14 \mathrm{~K} 5 \\
14 \mathrm{~K} 8 \\
14 \mathrm{~L} 2 \\
14 \mathrm{~L} 5\end{array}$ & $\begin{array}{c}4 / 21-28 \\
" 11 \\
" 1 \\
" 1\end{array}$ & $\begin{array}{c}19.4 \\
11 \\
" 1 \\
" 1\end{array}$ & $\begin{array}{c}0.926 \\
0.984 \\
\text { N/A } \\
\text { N/A } \\
0.827\end{array}$ & $\begin{array}{c}5 / 12-19 \\
" 1 " \\
" 1 \\
"\end{array}$ & $\begin{array}{c}15.5 \\
11 \\
11 \\
11\end{array}$ & $\begin{array}{l}0.914 \\
1.013 \\
1.046 \\
0.977 \\
0.819\end{array}$ & $\begin{array}{l}0.92 \\
1.00 \\
1.05 \\
0.98 \\
0.82\end{array}$ \\
\hline $\begin{array}{l}15 \mathrm{~K} 2 \\
15 \mathrm{~K} 5 \\
15 \mathrm{~K} 8 \\
15 \mathrm{~K} 11 . \\
15 \mathrm{~L} 2\end{array}$ & $\begin{array}{c}4 / 28-5 / 5 \\
" \\
" 1 \\
"\end{array}$ & $\begin{array}{c}11.7 \\
11 \\
" 1\end{array}$ & $\begin{array}{c}0.880 \\
0.946 \\
1.015 \\
1.046 \\
\text { N/A }\end{array}$ & $\begin{array}{c}5 / 21-27 \\
5 / 19-27 \\
" 1 \\
" 1\end{array}$ & $\begin{array}{c}17.6 \\
18.3 \\
" 1 \\
11\end{array}$ & $\begin{array}{c}0.902 \\
0.972 \\
1.031 \\
1.053 \\
\text { N/A }\end{array}$ & $\begin{array}{r}0.89 \\
0.96 \\
1.02 \\
1.05 \\
\text { N/A }\end{array}$ \\
\hline $\begin{array}{l}16 \mathrm{~K} 2 \\
16 \mathrm{~K} 5 \\
16 \mathrm{~K} 8 \\
16 \mathrm{~K} 11 \\
16 \mathrm{~L} 2\end{array}$ & $\begin{array}{c}5 / 5-12 \\
11 \\
11 \\
11 \\
" 1\end{array}$ & $\begin{array}{c}15: 2 \\
" 1 \\
" 1 \\
" 1\end{array}$ & $\begin{array}{l}0.903 \\
1.021 \\
0.991 \\
0.928 \\
0.964\end{array}$ & $\begin{array}{c}5 / 27-6 / 2 \\
" \\
" \\
"\end{array}$ & $\begin{array}{c}23.4 \\
" 1 \\
" 1 \\
" 1\end{array}$ & $\begin{array}{l}0.911 \\
1.013 \\
0.977 \\
0.928 \\
0.975\end{array}$ & $\begin{array}{l}0.91 \\
1.02 \\
0.98 \\
0.93 \\
0.97\end{array}$ \\
\hline
\end{tabular}

$* \mathrm{C}-13=$ Castel10-13 anemometer, shown on Figure 2-3.

\subsection{Monitoring Equipment and Instrumentation}

This section discusses the software, hardware, and instrumentation used to conduct the wake study.

\subsubsection{Anemometry}

Four meteorological towers (labeled A-D in Figure 2-1) were installed to support the wake tests. Tower locations, heights, and instrumentation are given in Table 2-3. Each tower had a specific purpose.

Tower A was upwind of the test array and provided the best representation of the "upwind" ambient wind conditions. Towers $C$ and $D$ were in front of but as close as possible to Rows 15 and 16 without being affected by their turbines. All three of these towers were $80 \mathrm{ft}$ tall (hub height). 


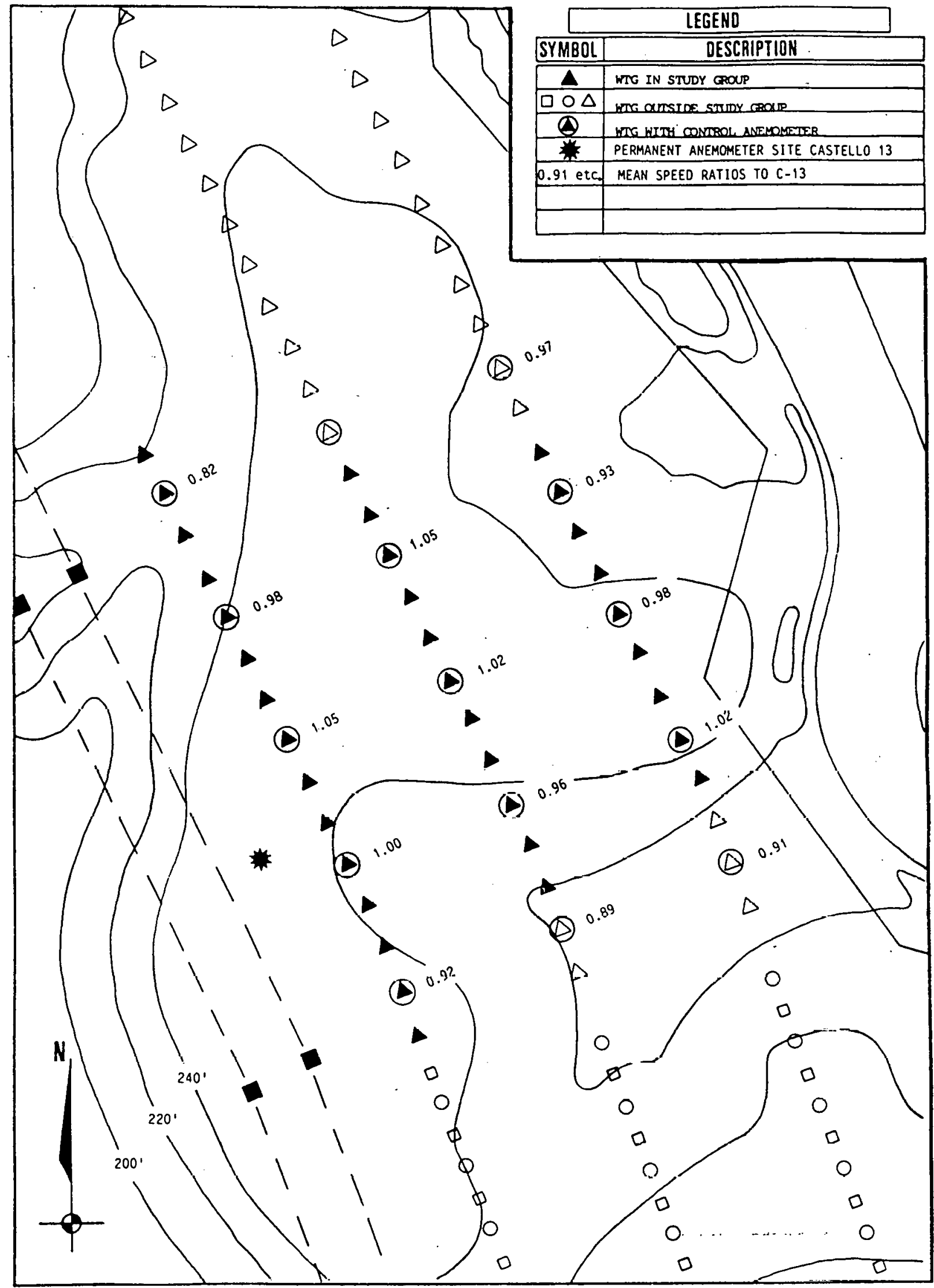

Figure 2-3. Mean Wind-Speed Patterns across the Test Array at $45 \mathrm{ft}$ above Ground (Spring 1986) 
Table 2-2. Observed Daily Energy-Production Ratios to

Primary Turbines in Row 14 (April-May 1986)

Energy production ratio

Mean energy production

Date (kWh) per turbine, Row

North control

Row 15/Row 14 Row 16/Row 14 turbines/Row 14*

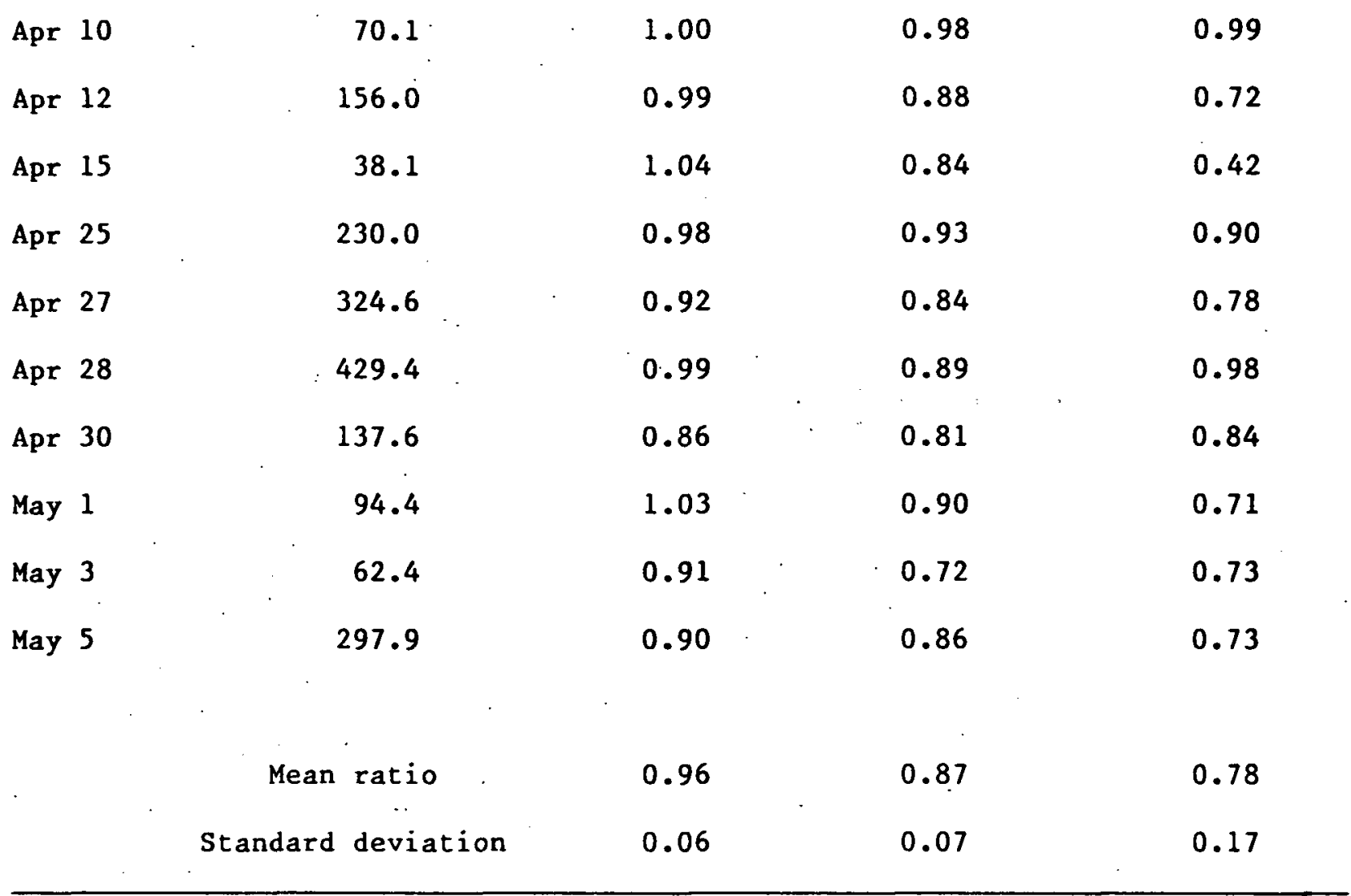

*North control turbines are 14L5 and 14L6 (see Figure 2-1).

Note:

Past experience and studies have shown consistent performance from machine to machine. During the test period, the wind turbines were monitored for variations in output. For example, bug accumulation on the blades was not experienced and did not impact test operations or the test results.

Sufficient energy production or data quality was defined as no more than one missing or invalid daily energy-production value, with the exception of turbine 15K6, which was inoperative during the entire test period. Data from this turbine were not included in the analysis. 
Table 2-3. Meteorological Towers Used in the Wake Study Tower Location Height $(f t)$ Type

Instrumentation A $\quad 2$ RD upwind of
turbine $14 \mathrm{~K} 8$

B

5 RD dowinwind of turbine $14 \mathrm{~K} 8$

C $\quad 2$ RD upwind of turbine $15 \mathrm{~K} 8$

D . 2 RD upwind of turbine $16 \mathrm{~K} 8$
80

170

80
Telephone pole

Rohn 45-G, guyed
RM Young model 06002 cup and vane assembly at $80 \mathrm{ft}$

RM Young model 06002 at 80 and $170 \mathrm{ft}$; Maximum 40 cups at $80,110,140$, $170 \mathrm{ft}$

NRG tall tower KM Young model 06002 at $80 \mathrm{ft}$

NRG tall tower RM Young model 06002 at $80 \mathrm{ft}$

Tower $\ddot{B}$ was $170 \mathrm{ft}$ tali: Its primary purpose was to provide information about winds above the array. Historical wind records elsewhere in Altamont Pass have sometimes shown negative wind shears (speed decreasing with height): If and when such conditions occurred over the test array, there would be a reduction in the capacity of the atmosphere to "destroy" wakes by recharging the flow with momentum from above. This could exacerbate wake-induced energyproduction losses within the array compared to "positive" vertical shear profiles.

For the 170-ft level of Tower B to be impacted by Row 14 wakes, the vertical wake growth angle would have to be at least 21.4 degrees. This is extremely unlikely to occur, so it was concluded that the $170-\mathrm{ft}$ level always represented ambient conditions. Intermediate measurement levels of 110 and $140 \mathrm{ft}$ were chosen to investigate the levels at which the vertical growth of the wake could be detected.

The RM Young cup anemometer has a miniature dc tachumeter generator whose output analog voltage is directly proportional to the wind speed. Its distance constant is $8.9 \mathrm{ft}$. The vane utilizes a conductive plastic potentiometer and has a damping ratio of approximately 0.39 . Wind velocity was sampled every second from these sensor pairs during tests.

Maximum Type 40 three-cup anemometers were mounted on all four levels of the 170-ft tower. This anemometer is a lightweight plastic unit with a miniature ac generator that produces a sine wave voltage proportional to wind speed. The Maximum anemometers were coupled to NRG wind run loggers, from which 15-minute mean speed data were obtained.

Considerable problems were noted with the RM Young wind vanes from the beginning of the wake study; however, before the postcalibrations the test engineer assumed that correcting the linear offsets to the raw input data could resolve the problems. Indeed, the postcalibrations revealed up to 
20- to 40-degree errors for all potentiometers in the southwest quadrant. Unfortunately, the revised wind directions, which were adjusted for these errors, did not produce the consistent readings that were expected. After consultations with Fayette's test team and the DOE technical monitor, it was decided that an analysis of the wind direction data was not feasible.

Instead, quality of the overall results was assured by confirmation of the wind direction for all test segments. This was accomplished by observation of turbine orientation before, during, and after each test segment. While these observations were qualitative, they were accurate quantitatively as well. For example, the test engineer could observe the vanes on top of the test turbines to ascertain the wind direction to within $5-10^{\circ}$. The test team believed that the overall results were not affected by this level of inaccuracy.

There were also some inconsistencies between the RM Young and Maximum 40 anemometers that were both located at the $170-\mathrm{ft}$ level of anemometer tower $B$. The RM Young sensor cables were fully shielded, but cables for the Maximum sensors were not electrically shielded above $80 \mathrm{ft}$ (nor were those at 110 and $140 \mathrm{ft})$. Based on a detailed assessment of the vertical shear profile characteristics between adjacent levels, it is believed that the Maximum sensor at the $80-f t$ level read accurately (it agreed exactly with the RM Young unit), but at each higher level it was reading progressively higher than the RM Young anemometers.

The Maximum anemometer/NRG wind run loggers were compared with a boom test before and after the wake study test period. All four sensors were mounted on a boom $12 \mathrm{ft}$ above ground on Tower B. Four hours of test data were collected (16 15-minute means) in winds of 15-25 mph. " The sensors all agreed to within $1 \%$ of each other.

\subsubsection{Data Acquisition System}

A monitoring and control system was designed and built for this study by Ca1 Delta, Inc., a Fayette subsidiary. The relationships among its individual components are shown schematically in Figure 2-4.

Control/monitor modules were placed in each turbine control enclosure. The modules were connected to a data collection interface and from there to a Sperry IT computer. [The interface and computer were housed in a trailer located between anemometers $B$ and $C$ (Figure 2-1)]. Information traveled in both directions--data collected in the field were sent from the turbine modules to the computer; the computer sent commands to the turbine modules. Commands included start-up and shut-down of turbines, store data, send data, and seop sending data.

Energy production, control anemometer wind speed, and rotor RPM were sampled every second and processed by the turbine modules to yield sequential, oneminute, energy-production data (to the nearest $0.1 \mathrm{kWh}$ ), mean speed, and mean RPM. This information was stored in the module until the end of that test and then transmitted to the computer. Wind speed and direction were polled by the computer every second from the RM Young sensors on the four anemometer towers. 


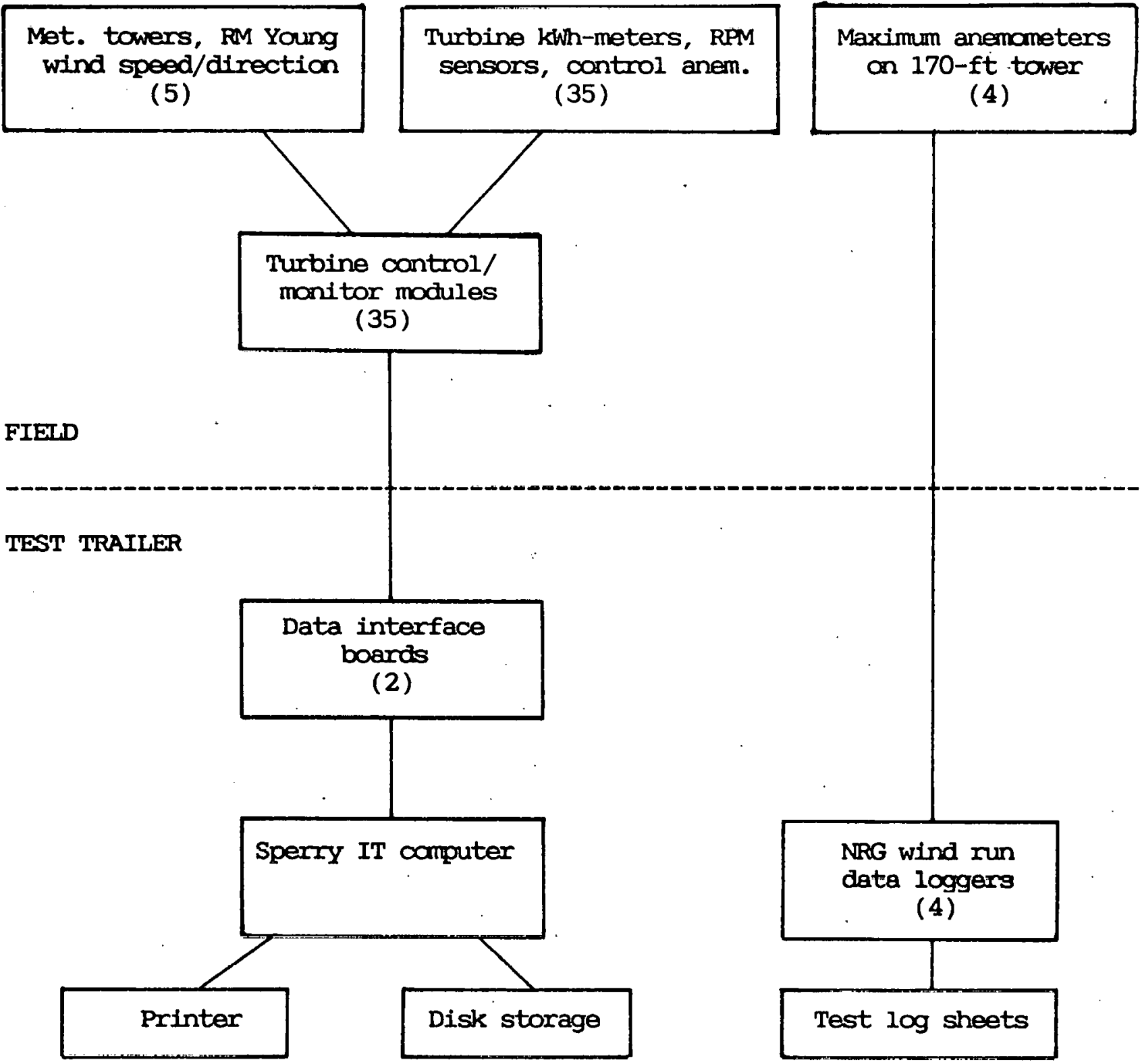

Figure 2-4. Schematic of the Data Acquisition System 
The RM Young anemometer data were displayed and updated on the terminal screen every second. Turbine RPM data were also displayed continuously on the same screen during tests and updated every 15 seconds. These displays gave the operator a real-time appraisal of conditions across the array, which proved quite valuable in terms of quality assurance and certain remedial maintenance procedures.

A typical sequence of events for conducting the wake tests was as follows:

- Operator reaches site, starts diesel generator, brings computer on line

- Communication status with turbines and anemometers is determined; remedial action taken to correct any deficiencies

- The first test scenario is selected, RPM data monitored on screen until scenario setup is completed

- Test is started via typed command, initial wind runs and other pertinent information are entered in the log

- Test runs for 15 minutes, operator monitors conditions and aborts test, if necessary

- Final wind run counts are entered into $\log$ at end of test; meanwhile, computer is polling data from the field and creating a formatted data file on the hard disk

- Data file is scanned for completeness and broad accuracy (more thorough editing is done much later, away from the site)

- A new test scenario is chosen, and the cycle repeats until testing is completed for the day.

Samples of screen displays, the log sheet, and the data file created for a typical test (非52) are given in Appendix A.

\subsection{Test Scenariog}

Ten operating scenarios or scenario sequences were used for the wake tests (Figure 2-5). Scenarios A-D are referred to as "row-by-row" scenarios because all (primary and buffer) turbines in a given row were either operating or shut down together. Scenarios E-J are referred to as "special" scenarios, in which small numbers of turbines are added sequentially in a series of three subscenarios (five for Scenario E).

Each row-by-row scenario and each special subscenario lasted 15 minutes, during which time energy-production and wind-velocity data were recorded (Section 2.3). The time required to change from one scenario to the next was about five minutes.

The majority of the row-by-row scenario tests were done in the first half of the field measurement phase of the study. They were the most appropriate for determining whether wake-induced losses in energy production even existed, initially of some concern because of the openness of the array. The scenarios 

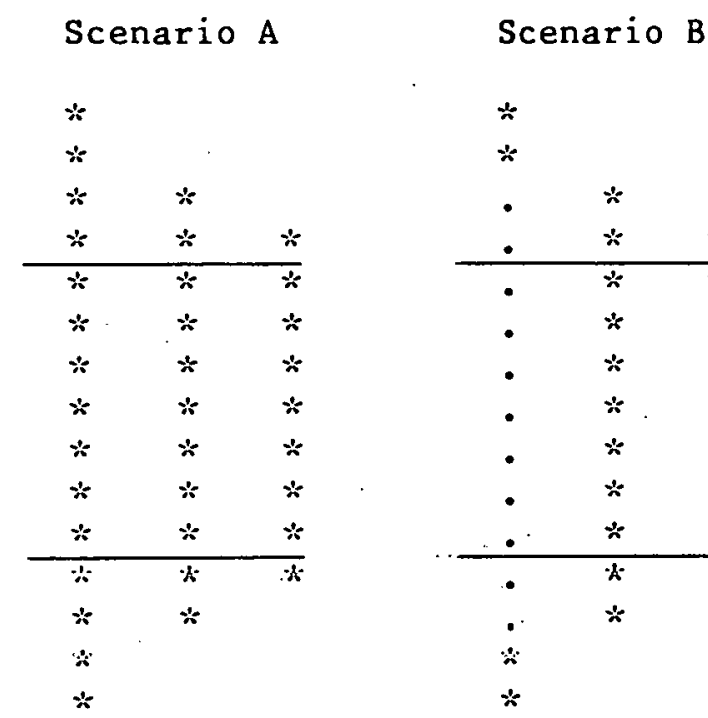

Scenario $\mathrm{C}$

Scenario D
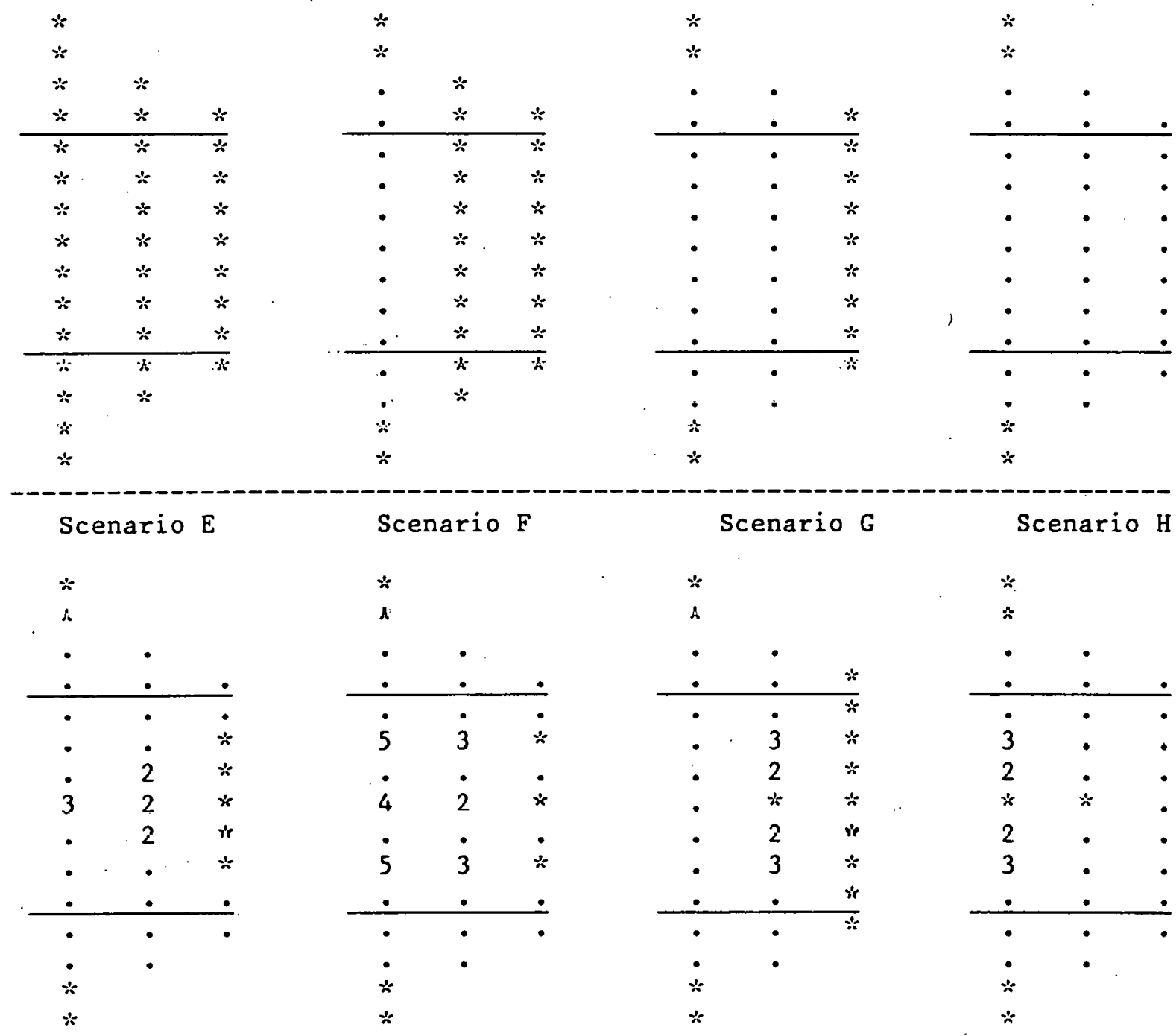

Scenario $\mathrm{F}$

Scenario G

Scenario $\mathrm{H}$

\section{Scenario I}

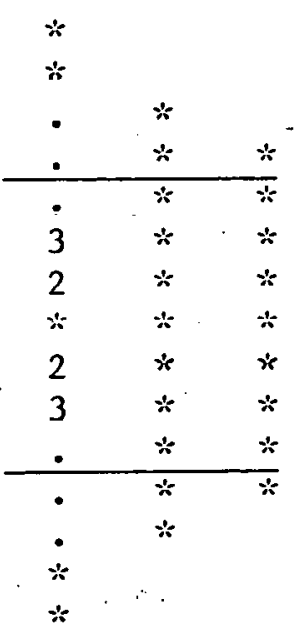

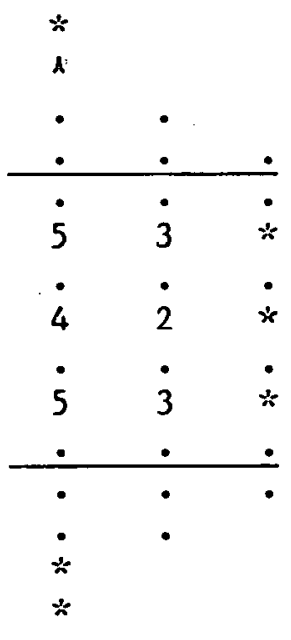

\section{Scenario J}

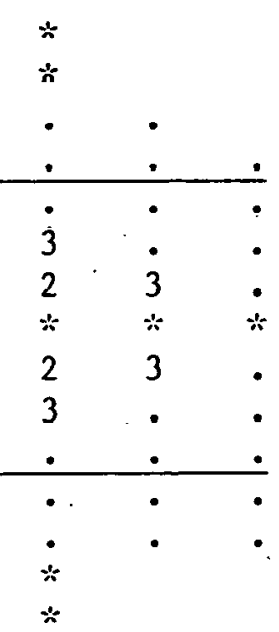

\section{KEY}

Array format is identical to geographic layout. (Figure 2-1).

* = Turbine operating during

$*$ = scenario (A-D) or entire sequence of scenario ( $E-J$ )

. = Turbine not operating during scenario

2,3 , etc. = subscenario in which turbine begins operating. It remains on during rest of scenario.

Figure 2-5. Wake Test Scenarios 
were typically alternated between $A$ (all rows operating) and either $B$ or C (one and two rows shut off, respectively).

" $A$ " scenarios were further classified as bracketing Scenarios B or $C$ if they were within two test numbers of each other. The rationale for the bracketing subclassification comes from the analysis methodology. In the discussion of results, Scenario $B$ and $C$ test data are compared against the Scenario $A$ test data bracketing them. These comparisons are much more meaningful when the individual tests composing one scenario match those of another as closely as possible in time, because aggregate background meteorological conditions will then be virtually identical.

The special scenarios were designed to investigate the subtler details of the wakes. There was no particular order for running these scenarios, except that the subscenarios within each scenario were always run in sequence.

As noted earlier, the Fayette rotor operated at either 80 or $120 \mathrm{rpm}$. In the normal operating procedure, turbines automatically switch from one to the other at wind speeds between 23-27 mph, but for this testing, the turbines were programmed to run at one speed on1y for a given day. It was not known if the rotor speed would influence array wake loss factors, so all tests were further categorized by low-RPM or high-RPM mode.

The meteorological criteria for conducting tests were wind speeds greater than $15 \mathrm{mph}$ at Anemometer $A$ and wind directions of 215-275 degrees. Since winddirection data were not being properly recorded, the test operator made this determination by visual inspection.

The initial strategy was to collect 15 hours of row-by-row tests and then 32 hours of the special-scenario tests. As it turned out, 32 hours of each type of test were collected. Table 2-4 presents the joint frequency distribution by scenario type, turbine RPM mode, and Anemometer A wind-speed category. The sampling was well spread across the range of wind speeds encountered by the array under normal operating conditions.

\subsection{Data Processing}

The Sperry IT computer in the test trailer created a data file after each test and stored it on its hard disk. The files included a header record, sequential one-second wind velocity data from the $R M$ Young sensors, and the sequential one-minute turbine energy-production, RPM, and control anemometer mean speed data. (A sample hard copy of the file appears in Appendix A).

These files were examined by the operator immediately after each test to check for data recovery and spurious values. Any problems were noted on the log sheet.

The storage capacity of the hard disk was approximately 80 tests. Periodically, these files were copied onto floppy disks and taken to Fayette's Tracy office and recopied onto another Sperry IT. Two backup copies of all test data files were made on magnetic tape. After the creation of these backup files had been verified, the original files in the test trailer computer were deleted to make room for new test data. 
Table 2-4. Number of 15-Minute Test Runs

Anemometer A Wind Speed (mph)

\begin{tabular}{cccccccc} 
& \multicolumn{8}{c}{ Anemometer A Wind Speed (mph) } & Row \\
\cline { 2 - 7 } Scenario/RPM & $10-15$ & $15-20$ & $20-25$ & $25-30$ & $30-35$ & $35-40$ & Tota \\
\hline A Low & $\cdot$ & 6 & 18 & 12 & 4 & 1 & 41 \\
A High & - & 1 & 3 & 6 & 12 & 3 & 25
\end{tabular}

\begin{tabular}{|c|c|c|c|c|c|c|c|}
\hline $\begin{array}{l}\text { B Low } \\
\text { B High }\end{array}$ & . & $\begin{array}{l}5 \\
.\end{array}$ & $\begin{array}{l}5 \\
3\end{array}$ & $\begin{array}{l}7 \\
5\end{array}$ & $\begin{array}{l}2 \\
4\end{array}$ & i & $\begin{array}{l}19 \\
14\end{array}$ \\
\hline $\begin{array}{l}\text { C. Inw } \\
\text { C High }\end{array}$ & $\begin{array}{l}1 \\
.\end{array}$ & 5 & $\begin{array}{l}2 \\
2\end{array}$ & $\begin{array}{l}5 \\
4\end{array}$ & $\begin{array}{l}1 \\
6\end{array}$ & $\begin{array}{l}1 \\
2\end{array}$ & $\begin{array}{l}15 \\
14\end{array}$ \\
\hline $\begin{array}{l}\text { D Low } \\
\text { D High }\end{array}$ & $\dot{\bullet}$ & : & $\begin{array}{l}1 \\
\bullet\end{array}$ & - & : & • & $\begin{array}{l}1 \\
\text {. }\end{array}$ \\
\hline $\begin{array}{l}\text { E Low } \\
\text { E High }\end{array}$ & $\dot{.}$ & $\begin{array}{l}4 \\
.\end{array}$ & $\begin{array}{l}8 \\
-\end{array}$ & $\begin{array}{l}4 \\
3\end{array}$ & . & $\begin{array}{l}3 \\
\text { - }\end{array}$ & $\begin{array}{r}19 \\
3\end{array}$ \\
\hline $\begin{array}{l}\text { F Low } \\
\text { F High }\end{array}$ & $\dot{.}$ & . & $\begin{array}{r}10 \\
2\end{array}$ & $\begin{array}{l}5 \\
7\end{array}$ & i & : & $\begin{array}{l}15 \\
10\end{array}$ \\
\hline $\begin{array}{l}\text { G Low } \\
\text { G High }\end{array}$ & . & $\begin{array}{l}1 \\
.\end{array}$ & $\begin{array}{l}7 \\
3\end{array}$ & $\begin{array}{l}5 \\
3\end{array}$ & $\begin{array}{l}5 \\
3\end{array}$ & • & $\begin{array}{r}18 \\
y\end{array}$ \\
\hline $\begin{array}{l}\text { H Low } \\
\text { H High }\end{array}$ & • & • & $\begin{array}{l}3 \\
3\end{array}$ & $\begin{array}{l}5 \\
-\end{array}$ & $\begin{array}{l}1 \\
3\end{array}$ & - & $\begin{array}{l}9 \\
6\end{array}$ \\
\hline $\begin{array}{l}\text { I Low } \\
\text { I High }\end{array}$ & . & $\begin{array}{l}3 \\
\text {. }\end{array}$ & $\begin{array}{l}9 \\
8\end{array}$ & $\begin{array}{l}1 \\
1\end{array}$ & $\begin{array}{l}3 \\
\text { - }\end{array}$ & . & $\begin{array}{r}16 \\
9\end{array}$ \\
\hline $\begin{array}{l}\text { J Lüw } \\
\text { J High }\end{array}$ & $\dot{\bullet}$ & $\begin{array}{l}j \\
1\end{array}$ & $\begin{array}{l}1 \\
3\end{array}$ & 6 & $\begin{array}{l}2 \\
.\end{array}$ & - & $\begin{array}{r}12 \\
4\end{array}$ \\
\hline Total & 1 & 29 & 90 & 79 & 47 & 12 & 258 \\
\hline
\end{tabular}


The next data processing step was to print out various statistics useful for thorough editing and interpretation. There were two pages of printouts for each test data file:

- One page showed the minimum one-minute mean RPM data for each turbine (this was used to see if turbines that were supposed to be on-line were in fact on-1ine for 15 minutes) and the number of records in each anemometer data file (should be 900 ).

- The other page listed individual turbine energy-production and mean windvelocity data for the complete 15-minute period (see sample, Appendix A).

From these printouts, one could assess the reliability of the data and identify questionable records. The questionable data could then be examined more closely by returning to the raw data file. Adjustments or corrections to the files were made in some cases where there was some justification in doing so:

- If an energy production record was missing or garbled and the turbine was known to have actually worked properly, an estimated value was substituted based on the corresponding mean value of the two adjacent turbines. This was also done occasionally when the turbine didn't work properly and there was no impact on downwind rows.

- If a turbine had operated at the wrong RPM, its energy production value was adjusted using the effective wind speed based on the performance curve (Figure 2-2).

- Energy-production data were deleted if they were not zero and the turbine was known not to have worked.

- Obviously "bad" wind-speed data were deleted, and the mean speed was calculated for the remaining data. Rarely did more than two values need to be deleted (out of 900 ).

- The entire test was deleted if there were too many problems.

The quality of the data varied for each test. A three-letter status code was assigned to each test, using the guidelines of Table 2-5. The first letter was the code for the primary array, so it was by far the most important. A summary of test status codes for each scenario is presented in Table 2-6, broken into row-by-row and special scenarios.

Codes V-Z for the primary array were deemed adequate in terms of data accuracy and completeness, and they formed the principal data base for most analyses. Eighty-nine of the 129 row-by-row tests and 93 of the "non-orphaned"r 127 special-scenario tests met this criterion.

*An orphaned test was one in which the special-scenario sequence was begun but not completed. This happened twice, because winds fell below the minimum acceptable level. 
The test data were combined into a series of data bases, each of which was designed for certain types of analysis. These data bases were streamlined in that only the specific information needed for the given type of analysis was included. This typically included test identification data (date, scenario, status, etc.), 15-minute energy-production data, and means and standard deviations of the wind-velocity data. As noted previously, the wind-direction data turned out to be unacceptable, so they were not used.

\section{Table 2-5. Wake Study Test Status Codes}

Z All worked properly; valid data

$\mathrm{Y} \leq 2$ had badly recorded data, but all worked properly; data corrected

$\mathrm{X} \leq 2$ on wrong RPM, otherwise all worked properly; data corrected Applicable for Scenarios E-J only: < 2 turbines on when shouldn ${ }^{\top} t$ have been, but no perceived impact on data

$\mathrm{V}$ Any two of $\mathrm{W}, \mathrm{X}$, or $\mathrm{Y}$ applicable

$U \leq 2$ intermittent operation; currected

$T \leq 2$ worked improperly (on/off) and impact expected on results; data estimated or corrected

$S$ Any combination of one of $W, X$, or $Y$ and one of $\mathrm{T}$ or $\mathrm{U}$

$\mathrm{R}$ Three or four of $\mathrm{T}, \mathrm{U}, \mathrm{W}, \mathrm{X}, \mathrm{Y}$ apply

Q T.ike U, V, X, Y, exrept $\geq 3$ turhines

P. Like $R$ or $S$, except $\geq 3$ turbines

N Anything worse
All worked properly; valid data

$\leq 2$ wrong RPM;

corrected

N/A

$<2$ adjusted for

intermittent operation N/A

1 turbine off-line

N/A
All ran properly

$\begin{array}{ll}\text { N/A } & \text { N/A } \\ \text { N/A } & \text { N/A } \\ \text { N/A } & \text { N/A } \\ \text { N/A } & \text { N/A } \\ \text { N/A } & \text { N/A } \\ \text { N/A } & \text { N/A } \\ \text { N/A } & \text { N/A } \\ \text { ng worse } & \text { All did not run } \\ \text { above } & \text { properly }\end{array}$
properly
Anything worse than above

*The actual code is composed of three letters in the order given in the table. Anemometer data were good enough in all cases so that no code was needed. 
Table 2-6. Frequency Distribution of Test Status Codes by Scenario Type

For Scenarios A-D

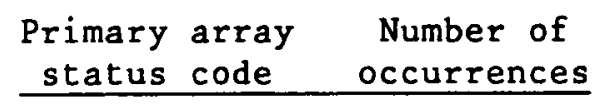

\begin{tabular}{cc} 
Z & 47 \\
Y & 24 \\
$\mathrm{X}$ & 15 \\
$\mathrm{~W}$ & N/A \\
$\mathrm{V}$ & 3 \\
$\mathrm{U}$ & 3 \\
$\mathrm{~T}$ & 20 \\
$\mathrm{~S}$ & 16 \\
$\mathrm{R}$ & 1 \\
Q, P, N & 0 \\
\hline Total & 129
\end{tabular}

$\because$

For special scenarios

Number with

Scenario Number of cases* primary code V-Z

\begin{tabular}{ccc} 
E & 21 & 15 \\
F & 25 & 17 \\
G & 27 & 25 \\
H & 15 & 14 \\
I & 24 & 13 \\
J & 15 & 9 \\
\hline & & \\
Totals & 127 & 93
\end{tabular}

*Does not include orphaned tests, as defined in this section. 


\subsection{Data Analysis}

The data bases described above were processed with spreadsheet, graphics, and other software applications packages. Much of this effort was directed toward computing mean wind and energy-production data for selected groups of tests. Statistical correlations were also used to assess relationships between certain variables. Low- and high-RPM tests were processed separately.

The results were interpreted to infer the magnitude of array wake effects and the influence of various meteorological variables that theoretically should affect wake growth and decay, such as vertical shear profile, turbulence, and ambient wind speed.

The most important analysis was the determination of wake-induced energyproduction losses from row to row, addressed by Scenarios A-C. All three rows operated in Scenario A, but Row 14 (the front one) was shut down in Scenario $B$ and Rows 14 and 15 in Scenario C. Because of this, wake effects rould not be determined directly from actual energy-production patterns. (The anemometer data could, of course, be used to assess differences in mean wind patterns for the various scenarios.)

To illustrate this point, assume that Row 14 turbines are reducing energy production at Row 15 (Scenario A). If Row 14 were shut off (Scenario B), then Row 15 production should increase--but relative to what? Independent statistical controls are needed to evaluate the increase; Row 14 production cannot be used because the row is shut down in the non-A scenarios.

Two types of statistical controls were available: actual energy production at the four "control" turbines in Row 14, and Anemometer A wind speed data. These are discussed below.

Recall that the control turbines are located to the immediate north and south of the primary/bufter array (Figure 2-1). It had been postulated in the design phase of the study that energy production at these turbines would be sufficiently correlated with that of the primary turbines in Row 14 and that the two would be essentially interchangeable (with some multiplicative factor applied). If this were true, the control turbine production data could be used to normalize and compare all scenarios and assess the relative production losses due to wakes.

Unfortunately this was not the case, as the measurements taken in spring 1986 had hinted (Section 2.2). The energy production at the control turbines was only modestly correlated with that of the primary turbines in the same row (Table 2-7). This table presents linear correlation coefficients between individual turbine production in Row 14 (expressed as equivalent mean wind speed using the performance curve in Figure 2-2) and Anemometer A mean wind speed. The correlation coefficients are nearly perfect (1.00) for turbines immediately adjacent to the anemometer, and they decay with distance. The combined correlation coefficient for all four control turbines was 0.89 for the low-speed mode and 0.68 for the high-speed mode. The standard errors of estimate for this group $(0.2-0.3 \mathrm{kWh})$ are the same order of magnitude as the apparent wake effects. Thus, the control turbines are not an appropriate indicator of conditions across the primary turbines in Row 14 , and so it was decided not to use them for this purpose. 
Table 2-7. Correlation of Row 14 Turbine Energy

Production with Anemometer A Wind Speed

Low-RPM Mode ( 31 cases)

High-RPM Mode ( 11 cases)

\begin{tabular}{|c|c|c|c|c|}
\hline Turbine* & $\begin{array}{l}\text { Correlation } \\
\text { coefficient** }\end{array}$ & $\begin{array}{l}\text { Standard error } \\
\text { of estimate ( } \mathrm{kWh})\end{array}$ & $\begin{array}{l}\text { Correlation } \\
\text { coefficient } * *\end{array}$ & $\begin{array}{l}\text { Standard error } \\
\text { of estimate ( } \mathrm{kWh}) \\
\end{array}$ \\
\hline $14 \mathrm{~L} 6$ & 0.86 & 0.32 & 0.66 & 0.37 \\
\hline $14 \mathrm{~L} 5$ & 0.86 & 0.27 & 0.63 & 0.39 \\
\hline $14 L 4$ & 0.90 & 0.20 & 0.65 & 0.45 \\
\hline $14 \mathrm{~L} 3$ & 0.85 & 0.33 & 0.70 & 0.45 \\
\hline $14 \mathrm{~L} 2$ & 0.92 & 0.20 & 0.82 & 0.29 \\
\hline $14 \mathrm{~L} 1$ & 0.93 & 0.16 & 0.93 & 0.18 \\
\hline $14 \mathrm{Kg}$ & 0.95 & 0.14 & 0.98 & 0.11 \\
\hline $14 \mathrm{~K} 8$ & 0.96 & 0.10 & 0.98 & 0.09 \\
\hline $14 \mathrm{~K} 7$ & 0.97 & 0.10 & 0.98 & 0.10 \\
\hline $14 \mathrm{~K} 6$ & 0.95 & 0.14 & 0.94 . & 0.15 \\
\hline $14 \mathrm{~K} 5$ & 0.90 & 0.18 & 0.94 & 0.15 \\
\hline $14 \mathrm{~K} 4$ & 0.88 & 0.15 & 0.93 & 0.14 \\
\hline $14 \mathrm{~K} 3$ & 0.87 & 0.22 & 0.83 & 0.21 \\
\hline $14 \mathrm{~K} 2$ & 0.88 & 0.22 & 0.71 & 0.22 \\
\hline $14 \mathrm{~K} 1$ & 0.82 & 0.25 & 0.52 & 0.33 \\
\hline $\begin{array}{l}\text { Two north } \\
\text { controls }\end{array}$ & 0.86 & 0.28 & 0.65 & 0.38 \\
\hline $\begin{array}{l}\text { Two south } \\
\text { controls }\end{array}$ & 0.86 & 0.22 & 0.64 & 0.26 \\
\hline $\begin{array}{l}\text { All contro } \\
\text { turbines }\end{array}$ & 0.89 & 0.22 & 0.68 & 0.30 \\
\hline
\end{tabular}

$* 14 \mathrm{~K} 1 \& 14 \mathrm{~K} 2=$ south controls; $14 \mathrm{~L} 5 \& 14 \mathrm{~L} 6=$ north controls; $14 \mathrm{~K} 3,14 \mathrm{~K} 4$, $14 \mathrm{~L} 3,14 \mathrm{~L} 4=$ buffers; $14 \mathrm{KJ}-14 \mathrm{~L} 2=$ primary turbines. Anemometer $\mathrm{A}$ in front of $14 \mathrm{~K} 8$.

*:Calculated using equivalent mean speed from the performance curve (Figure 2-2). 
On the other hand, the energy production of the individual Row 14 primary turbines was much better correlated with Anemometer $A$ wind speed. The combined correlation coefficient for all seven turbines was 0.97 for both low- and high-RPM cases (Figures 2-6 and 2-7, respectively). Since Anemometer A data exist for all tests and are independent of Row 14 operational status, a "hypothetical" energy production for the primary turbines in that row could be calculated from the Anemometer $A$ wind data with sufficient accuracy for the wake analyses. 


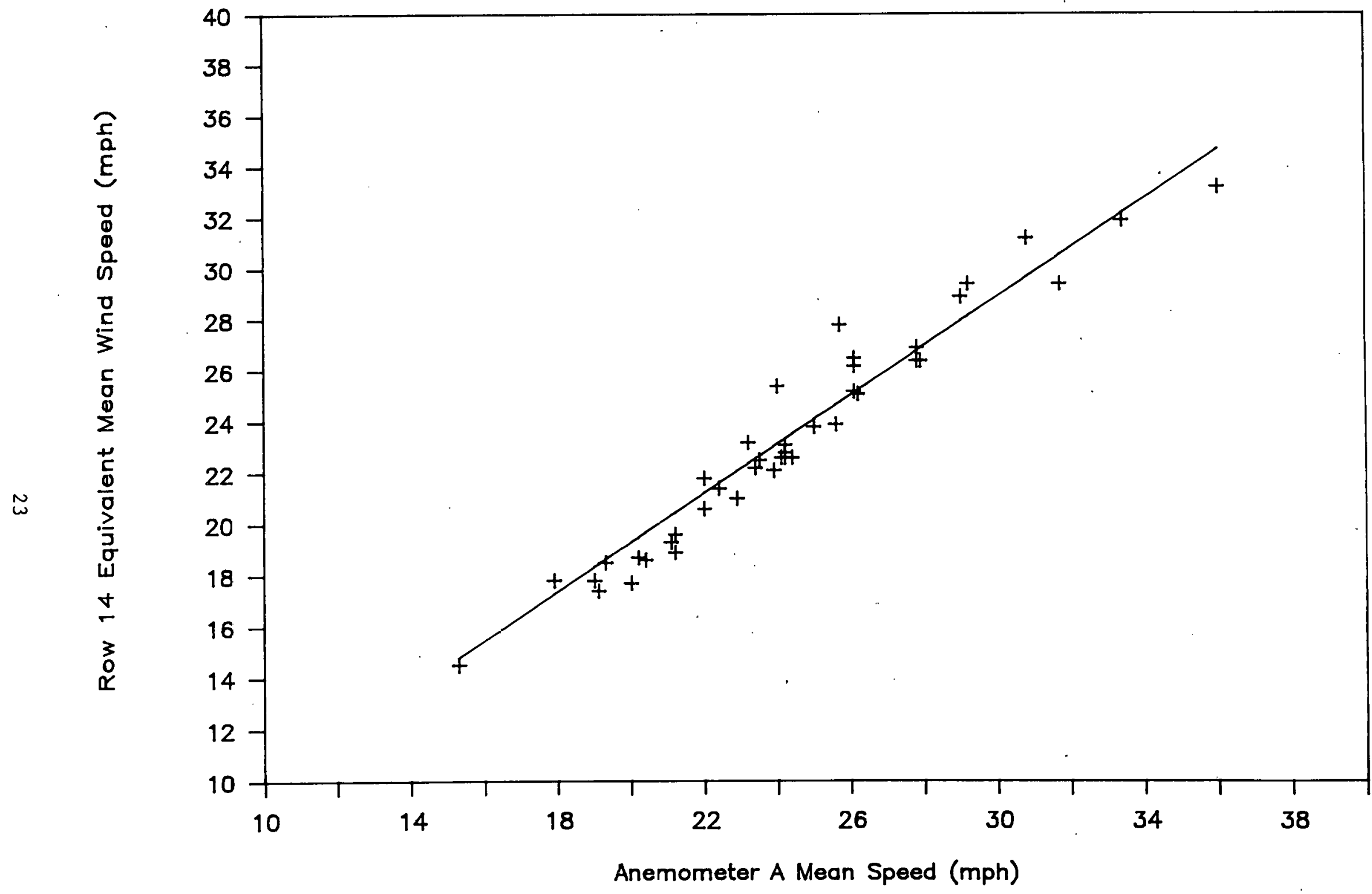

Figure 2-6. Row 14 Equivalent Mean wind Speed vs. Anemometer A Mean Wind Speed (Low-RPM Mode) 


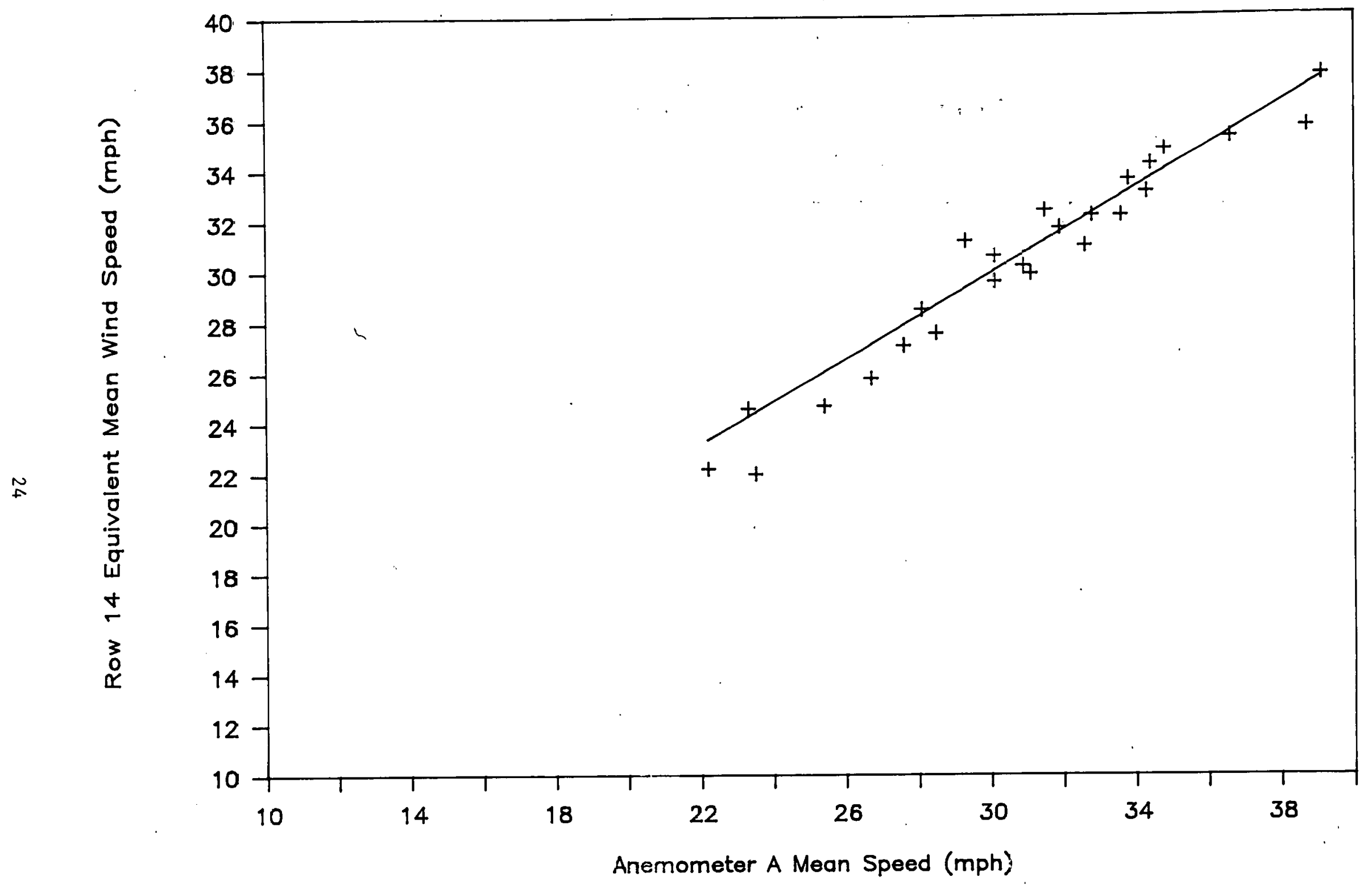

Figure 2-7. Row $\$ 4$ Equivalent Mean Wind Speed vs. Anemometer A Mean Wind Speed (High-RPM Mode) 


\subsection{RESULTS}

This section presents the overall results of the row-by-row wake tests, the special-scenario tests, and supplementary anemometer measurements. The relationships between several variables and wake effects are also examined.

The following nomenclature applies throughout this section:

- Turbine row or simply "row": refers to the primary turbines in the given row, except when buffer or control turbines are mentioned specifically.

- Wind data: refers to Anemometer Towers A-D. On Anemometer Tower B, measurement height is also given; e.g., B-170 for the 170-ft level. The mean speed is often abbreviated $\bar{V}$.

- Energy production (or $\bar{E}$ ): given in $\mathrm{kWh}$ per 15 minutes. Row means are given on a per-turbine basis.

- Mean power output: given in $\mathrm{kW}$.

- Test scenarios: as defined in Figure 2-5.

\subsection{Row-by-Row Scenario Tests}

The principal objective in these tests was to quantify the magnitude of wakeinduced losses in energy production from row to row and identify which variables influenced the degree of loss. As noted earlier, there was some concern at the beginning of this project that the turbines might be spaced too far apart for the measurements to prove anything conclusively.

The key assumption invoked to analyze the data is that all mean-speed and production data can be normalized by some measure of free-stream, ambient conditions at the upwind row. As discussed in Section 2.6, the best variables for this purpose were the mean wind speed at Anemometer A and the Row 14 energy production (primary turbines). The hypothetical energy production, based on Anemometer A data, was used when Row 14 turbines were shut off.

Scenarios A-D are classified as the row-by-row type. The following rows operated for each scenario:

- A-Rows $14,15,16$

- B--Rows 15,16

- C--Row 16

- D--none (only the control turbines). This scenario was not used because scenario $C$ provided essentially the same information

\subsubsection{Overall Statistics}

Mean (primary) row production is summarized in Table 3-1 by scenario. The data are paired by a given non-A scenario (at least one row shut off) and the Scenario A tests bracketing them (all rows on). All energy-production data 
Table 3-1. Mean Energy Production (Row-by-Row Tests)

Mean energy production ( $k$ Wh)

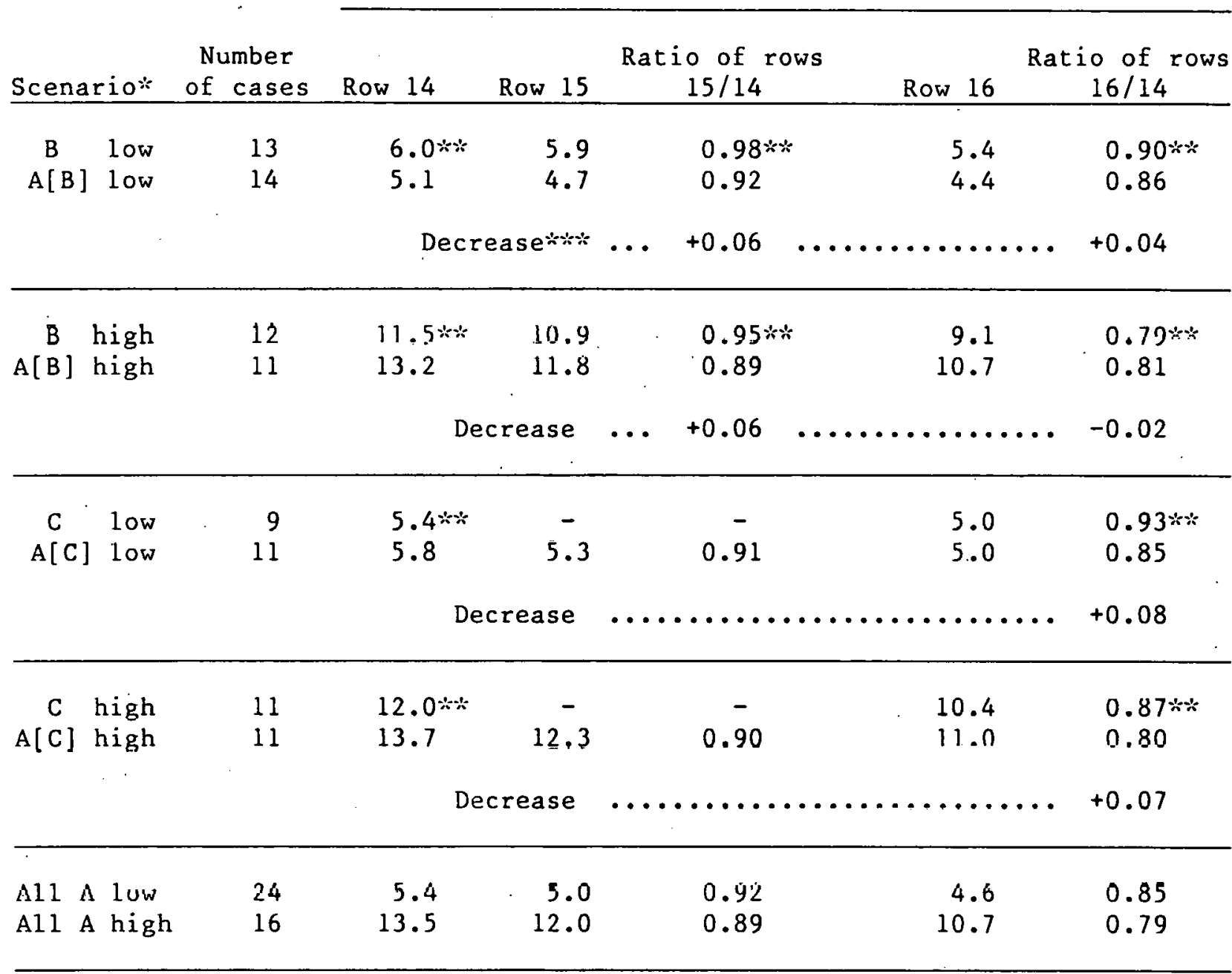

$\because A=$ Rows $14,15,16$ on; $B=$ Rows 15,16 on; $C=$ Row 16 on. $A[B]$ and $A[C]$ refer to Scenario A tests bracketing the B or C tests. Bracketing is defined as a test occurring sequentially within two test numbers. Low and high refer to the RPM mode of the turbines.

*:Hypothetical energy-production and energy production ratios, based on mean wind speed at Anemometer A. l'this is discussed in Section 2.6.

***:Decrease is the difference in energy production ratios (non-A minus bracketing-A). 
for Rows 15 and 16 are normalized by Row 14 production. This procedure was straightforward for Scenario A; for Scenarios B and C, hypothetical production was used as the normalization basis (see Section 2.6).

For the Scenario B tests (both low- and high-RPM), normalized Row 15 energy production was $6 \%$ higher than for the Scenario A tests bracketing them. For the Scenario C tests (again both RPMs), normalized Row 16 energy production was $7-8 \%$ higher than for the bracketing-A tests. Thus, energy production at the second row of the array increased $6 \%$ when the front row was shut off, and energy production at the third row increased $7-8 \%$ when the first two rows were shut off. By inference, these values should equal the magnitude of the wakeinduced losses in production, at least for the aggregate conditions of the test periods. The small incremental effect of shutting off two rows rather than one suggests that wake effects from a given row are minimal at 21 RD.

The anemometer data are summarized in Table 3-2 in a format similar to that of the energy-production results. They show the same trend, but with slightly smaller magnitude: 2-4\% in the C/A mean-speed ratios (Scenario B tests), and $4-5 \%$ for the D/A mean-speed ratios (Scenario C tests).

Two other items are worth mentioning. First, note the consistency in the normalized energy-production and wind-speed data for the various subsets of the Scenario A tests. Second, Row 15 and 16 normalized mean energy production over all Scenario A tests ( 0.92 and 0.85 , respectively) was reasonably close to that measured in spring 1986 [0.96 and 0.87 , respectively (Table 2-2)].

The statistical significance of the wake effects (i.e., whether the differences between the non-A and Scenario $A$ speed and energy data are real) has been addressed through the use of the Student's t-test (Table 3-3). Statistical significance refers to the mathematical probability that two different data sets came from the same population. Specifically, in Table 3-3, there are paired sets of data, each member of a pair having its own sample size, mean, and standard deviation. If the difference between means is "real" (i.e., wake effects really do exist), the Student's t-test would show a low probability that the two members of the pair came from the same population. In other words, the lower the significance level, the more likely that wake effects are real.

Significance levels based on energy production are $0.1 \%$ for the Scenario $B$, low-RPM pair and about $10 \%$ for the other three scenario pairs. Those based on anemometer data are better--about $0.1 \%$ for both low- and high-RPM Scenario B pairs and $5-10 \%$ for the Scenario $C$ pairs.

These significance levels and the gellecal intcrnal consistency of the data in Tables 3-1 and 3-2 indicate that wake-induced losses in energy production do indeed occur in this array.

\subsubsection{Ambient-Wind-Speed Influences}

Table 3-4 summarizes mean row energy-production and wind-speed data for Scenario A tests as a function of Anemometer A wind speed. For low-RPM operation, normalized energy production at Rows 15 and 16 (the values in parentheses that are ratios to Row 14 energy production) increased as Anemometer $A$ wind speed increased. However, normalized mean-wind-speed ratios at these 
Table 3-2. Mean Wind Speeds Measured by Anemometers A-D

(Row-by-Row Tests) *

Mean wind speed (mph) and mean speed ratios

\begin{tabular}{|c|c|c|c|c|c|c|c|c|c|}
\hline & & & & & & & & & \\
\hline Scena & rio** & of cases & A & $\mathrm{B}-80$ & $\mathrm{~B}-80 / \mathrm{A}$ & $\mathrm{C}$ & $\mathrm{C} / \mathrm{A}$ & $\mathrm{D}$ & $D / A$ \\
\hline $\begin{array}{c}B \\
A[B]\end{array}$ & $\begin{array}{l}\text { low } \\
\text { low }\end{array}$ & $\begin{array}{l}13 \\
14\end{array}$ & $\begin{array}{l}26.0 \\
24.0\end{array}$ & $\begin{array}{l}24.9 \\
22.5\end{array}$ & $\begin{array}{l}0.96 \\
0.94\end{array}$ & $\begin{array}{l}25.1 \\
22.3\end{array}$ & $\begin{array}{l}0.97 \\
0.93\end{array}$ & $\begin{array}{l}23.4 \\
21.7\end{array}$ & $\begin{array}{l}0.90 \\
0.90\end{array}$ \\
\hline & & & Decrease & ..... & +0.02 & ........ & +0.04 & ....... & 0 \\
\hline $\begin{array}{c}B \\
A[B]\end{array}$ & $\begin{array}{l}\text { high } \\
\text { high }\end{array}$ & $\begin{array}{l}12 \\
1.1\end{array}$ & $\begin{array}{l}30.3 \\
31.8\end{array}$ & $\begin{array}{l}28.6 \\
29.9\end{array}$ & $\begin{array}{l}0.94 \\
0.94\end{array}$ & $\begin{array}{l}28.6 \\
29.1\end{array}$ & $\begin{array}{l}0.94 \\
0.92\end{array}$ & $\begin{array}{l}26.6 \\
28.3\end{array}$ & $\begin{array}{l}0.88 \\
0.89\end{array}$ \\
\hline & & & Decrease & ....... & 0 & ......... & +0.02 & ...... & -0.01 \\
\hline $\begin{array}{c}\mathrm{C} \\
\mathrm{A}[\mathrm{C}]\end{array}$ & $\begin{array}{l}\text { low } \\
\text { low }\end{array}$ & $\begin{array}{r}9 \\
11\end{array}$ & $\begin{array}{l}24.9 \\
25.6\end{array}$ & $\begin{array}{l}23.7 \\
24.4\end{array}$ & $\begin{array}{l}0.95 \\
0.95\end{array}$ & $\begin{array}{l}23.7 \\
23.7\end{array}$ & $\begin{array}{l}0.95 \\
0.93\end{array}$ & $\begin{array}{l}23.4 \\
22.9\end{array}$ & $\begin{array}{l}0.94 \\
0.89\end{array}$ \\
\hline & & & Decrease & $\ldots \ldots$ & 0 & $\ldots \ldots \ldots$ & +0.02 & $\ldots \ldots$ & +0.05 \\
\hline $\begin{array}{c}\mathrm{C} \\
\mathrm{A}[\mathrm{C}]\end{array}$ & $\begin{array}{l}\text { high } \\
\text { high }\end{array}$ & $\begin{array}{l}11 \\
11\end{array}$ & $\begin{array}{l}31.1 \\
32.3\end{array}$ & $\begin{array}{l}29.3 \\
30.6\end{array}$ & $\begin{array}{l}0.94 \\
0.95\end{array}$ & $\begin{array}{l}29.5 \\
29.5\end{array}$ & $\begin{array}{l}0.95 \\
0.91\end{array}$ & $\begin{array}{l}28.6 \\
28.4\end{array}$ & $\begin{array}{l}0.92 \\
0.88\end{array}$ \\
\hline & $\cdot$ & & Decrease & $\ldots \ldots$ & -0.01 & $\ldots \ldots \ldots$ & +0.04 & $\ldots \ldots$ & +0.04 \\
\hline $\begin{array}{ll}\text { All } & \text { A } \\
\text { All } & \text { A }\end{array}$ & $\begin{array}{l}\text { A low } \\
\text { A high }\end{array}$ & $\begin{array}{l}24 \\
16\end{array}$ & $\begin{array}{l}24.6 \\
32.2\end{array}$ & $\begin{array}{l}23.2 \\
30.3\end{array}$ & $\begin{array}{l}0.94 \\
0.94\end{array}$ & $\begin{array}{l}22.8 \\
29.3\end{array}$ & $\begin{array}{l}0.93 \\
0.91\end{array}$ & $\begin{array}{l}22.0 \\
28.3\end{array}$ & $\begin{array}{l}0.89 \\
0.88\end{array}$ \\
\hline
\end{tabular}

*Anemometer A is 2 rotor diameters (RD) in front of Row 14; Anemometer B is 5 RD behind Row 14; Anemometers $C$ and $D$ are 2 RD in front of Rows 15 and 16, respectively (see Figure 2-1).

$* * A=$ Rows $14,15,16$ on; $B=$ Rows 15,16 on; $C=$ Row 16 on. $A[B]$ and $A[C]$ refer to Scenario A tests bracketing the $B$ or $C$ tests. Bracketing is defined as a test occurring sequentially withis lwo rcgt numbers. Low and high refer to the RPM-mode of the turbines. 
Table 3-3. Significance Level of Energy Production and Mean-Wind-Speed Differences (Row-by-Row Tests) $*$

\begin{tabular}{|c|c|c|c|c|c|}
\hline Scenario & $\begin{array}{l}\text { Number } \\
\text { of cases }\end{array}$ & Parameter & $\begin{array}{r}\text { Mean } \\
\text { value }\end{array}$ & $\begin{array}{r}\text { Standard } \\
\text { deviation } \\
\end{array}$ & $\begin{array}{c}\text { Significance } \\
\text { level }(\%)\end{array}$ \\
\hline B low & 13 & $\begin{array}{l}\bar{E} \text { ratio, Row } 15 / \text { hypo- } \\
\text { thetical Row } 14\end{array}$ & 0.98 & 0.05 & \\
\hline$A[B]$ low & 14 & $\bar{E}$ ratio, Row 15/Row 14 & 0.92 & 0.03 & 0.1 \\
\hline B high & 12 & $\begin{array}{l}\bar{E} \text { ratio, Row } 15 / \text { hypo- } \\
\text { thetical Row } 14\end{array}$ & 0.95 & 0.10 & \\
\hline$A[B]$ high & 11 & $\bar{E}$ ratio, Row $15 /$ Row 14 & 0.89 & 0.03 & 3 \\
\hline C low & 9 & $\begin{array}{l}\bar{E} \text { ratio, Row } 16 / \text { hypo- } \\
\text { thetical Row } 14\end{array}$ & 0.93 & 0.13 & \\
\hline$A[C]$ low & 11 & $\bar{E}$ ratio, Row 16/Row 14 & 0.85 & 0.09 & 20 \\
\hline C high & 11 & $\begin{array}{l}\bar{E} \text { ratio, Row } 16 / \text { hypo- } \\
\text { thetical Row } 14\end{array}$ & 0.87 & 0.13 & 13 \\
\hline$A[C]$ high & 11 & $\bar{E}$ ratio, Row $16 /$ Row 14 & 0.80 & 0.05 & ה \\
\hline B low & 13 & $\bar{v}$ ratio, anem. C/A & 0.97 & 0.01 & $<0.1$ \\
\hline$A[B]$ low & 14 & $\overline{\mathrm{V}}$ ratio, anem. C/A & 0.93 & 0.02 & \\
\hline B high & 12 & $\bar{V}$ ratio, anem. C/A & 0.95 & 0.02 & 0.3 \\
\hline$A[B]$ high & 11 & $\overline{\mathrm{V}}$ ratio, anem. $\mathrm{C} / \mathrm{A}$ & 0.91 & 0.03 & \\
\hline C low & 9 & $\overline{\mathrm{V}}$ ratio, anem. $\mathrm{D} / \mathrm{A}$ & 0.94 & 0.05 & 10 \\
\hline$A[C]$ low & 11 & $\overline{\mathrm{V}}$ ratio, anem. $\mathrm{D} / \mathrm{A}$ & 0.90 & 0.05 & \\
\hline C high & 11 & $\overline{\mathrm{V}}$ ratio, anem. $\mathrm{D} / \mathrm{A}$ & 0.92 & 0.03 & 5 \\
\hline$A[C]$ high & 11 & $\overline{\mathrm{V}}$ ratio, anem. $\mathrm{D} / \mathrm{A}$ & 0.88 & 0.05 & \\
\hline
\end{tabular}

*Sçenarios explained in Table-3-2. Student's t-test used to establish significance levels. 
rows ( $C / A$ and $D / A V$ ratios) were essentially independent of Anemometer $A$ wind speed. These seemingly different trends are actually not; they arise from the shape of the performance curve (Figure 2-2).

For high-RPM operation, both normalized mean energy production and wind speed at Rows 15 and 16 seemed to be independent of Anemometer $A$ wind speed, with one small exception: the normalized energy-production values were higher for winds above $35 \mathrm{mph}$ (only three cases), which also results from the shape of the performance curve.

Table 3-4. Mean Energy Production and Wind Speed as a Function of Ainemumeler A Wind-speed Class (Scenario A Tests)

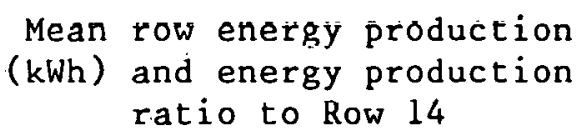

Mean wind speed (mph) and mean wind speed ratio to Anemometer A

Anem. A No. of

$\begin{array}{llllllllllllll}\overline{\mathrm{V}}, \mathrm{mph} & \text { cases } & 14 & 15 & 15 / 14 & 16 & 16 / 14 & \mathrm{~A} & \mathrm{~B} 80 & \mathrm{~B} 80 / \mathrm{A} & \mathrm{C} & \mathrm{C} / \mathrm{A} & \mathrm{D} & \mathrm{D} / \mathrm{A}\end{array}$

Low-RPM Mode

$\begin{array}{ccccccccccc}15-20 & 5 & 2.4 & 2.0(.85) & 1.9(.79) & 18.1 & 16.4(.91) & 16.5(.91) & 16.4(.91) \\ 20-25 & 17 & 4.3 & 3.9(.91) & 3.5(.81) & 22.5 & 20.8(.92) & 20.8(.92) & 19.8(.88) \\ 25-30 & 11 & 6.5 & 6.1(.94) & 5.7(.88) & 27.0 & 25.9(.96) & 25.1(.93) & 24.2(.90) \\ 30-35 & 4 & 8.4 & 7.9(.94) & 7.9(.94) & 33.0 & 31.8(.96) & 30.3(.92) & 30.1(.91)\end{array}$

High-RPM Mode

$\begin{array}{rrrrrrrrrrr}20-25 & 3 & 4.5 & 3.9(.87) & 3.5(.74) & 23.0 & 22.1(.96) & 21.0(.91) & 21.0(.91) \\ 25-30 & 6 & 8.4 & 7.2(.86) & 6.2(.74) & 27.6 & 25.8(.93) & 24.8(.90) & 24.1 & (.87) \\ 30-35 & 13 & 13.4 & 11.6(.87) & 10.2(.76) & 32.5 & 30.7(.94) & 28.9(.89) & 27.8(.86) \\ 35-40 & 3 & 18.7 & 17.3(.93) & 15.5(.83) & 38.1 & 34.2(.90) & 35.3(.93) & 33.2(.87)\end{array}$




\subsubsection{Vertical-Shear Influences}

Scenario A tests were used to evaluate the influence of vertical shear (the degree to which wind speeds increase with height above ground) on energyproduction patterns throughout the primary array.* Logic suggests that wakeinduced energy-production losses from row-to-row would be greater in weak shears, because there is less momentum aloft to replenish flow deficits created by the turbine wakes.

Table 3-5 presents mean row energy production stratified by vertical wind shear, specifically for the upper $25 \%$ and lower $25 \%$ of cases.** Note that mean Row 14 energy production was greater for the cases with the higher shears. Mean speeds at Anemometer A, not shown, were also greater. Because of the relationship between ambient wind speed and relative energy production throughout the array (Section 3.1.2), one must adjust for this phenomenon appropriately in order to interpret the table correctly.

The adjusted normalized mean row energy-production data were used as the basis for evaluating the influence of wind shear on wake.effects. In the low-RPM mode, Row 16 production showed the "expected" trend, with relatively higher values for the stronger shears than for the weaker, shears. On the other hand, Row 15 showed the opposite trend in the low-RPM mode, as did both rows in the high-RPM mode. The same trends are found even if one does not adjust the data for ambient wind speed.

Therefore, the measurements do not support the theory that more positive wind shear profiles reduce wake effects within the array. However, it should be kept in mind that the number of cases is small, so it is perhaps premature to conclude anything specific from the existing data base.

\subsubsection{Turbulence-Intensity Influences}

Numerical wake models have assumed that wake dissipation is highly dependent on transverse turbulence intensity (computed from wind-direction fluctuations). Wakes should decay over shorter downwind distances in higher turbulence, resulting in fewer wake losses at downwind.rows. This section first examines the turbulence levels themselves and then the energy-production statistics.

*Wind-shear characteristics themselves are treated, in more detail in Section $3: 3.1$.

**Note that wind shear is defined for this particular table as the ratio of mean wind speed at Anemometer $B(170 \mathrm{ft})$ to that at Anemometer $A$. The $80-\mathrm{ft}$ level of Anemometer $B$ is inappropriate for defining vertical shear in the Scenario A tests, because this level is in the wake of operating turbines in Row 14. 
Table 3-5. Mean Energy Production as a Function of Vertical Shear Class (Scenario A Tests)

Mean Energy Production (kWh)

\begin{tabular}{|c|c|c|c|c|c|c|c|c|}
\hline \multirow[b]{2}{*}{ RPM } & \multirow[b]{2}{*}{$\begin{array}{c}\text { Shear } \\
\text { category* }\end{array}$} & \multirow[b]{2}{*}{$\begin{array}{l}\text { Mean } \\
\text { shear* }\end{array}$} & \multirow[b]{2}{*}{$\begin{array}{l}\text { Number } \\
\text { of cases }\end{array}$} & & & & & \\
\hline & & & & Row 14 & Row 15 & $\begin{array}{c}\bar{E} \text { ratio } \\
15 / 14\end{array}$ & Row 16 & $\begin{array}{c}\bar{E} \text { ratio } \\
16 / 14\end{array}$ \\
\hline $\begin{array}{l}\text { Low } \\
\text { Low }\end{array}$ & $\begin{array}{l}\text { Upper } 25 \% \\
\text { Lower } 25 \%\end{array}$ & $\begin{array}{l}1.18 \\
0.99\end{array}$ & $\begin{array}{l}9 \\
9\end{array}$ & $\begin{array}{l}5.0 \\
3.7\end{array}$ & $\begin{array}{l}4.6 \\
3.4\end{array}$ & $\begin{array}{l}0.92 \\
0.92\end{array}$ & $\begin{array}{l}4.3 \\
2.9\end{array}$ & $\begin{array}{l}0.86 \\
0.78\end{array}$ \\
\hline $\begin{array}{l}\text { II igh } \\
\text { High }\end{array}$ & $\begin{array}{l}\text { Upper } 25 \% \\
\text { Lower } 25 \%\end{array}$ & $\begin{array}{l}1.16 \\
1.04\end{array}$ & $\begin{array}{l}6 \\
6\end{array}$ & $\begin{array}{r}9.3 \\
12.9\end{array}$ & $\begin{array}{r}7.8 \\
11.7\end{array}$ & $\begin{array}{l}0.84 \\
0.91\end{array}$ & $\begin{array}{r}6.7 \\
10.1\end{array}$ & $\begin{array}{l}0.72 \\
0.78\end{array}$ \\
\hline
\end{tabular}

Adjustment of above data for differences in ambient (Anemometer A) wind speed between the upper and lower quartiles:

Row 15

Row 16

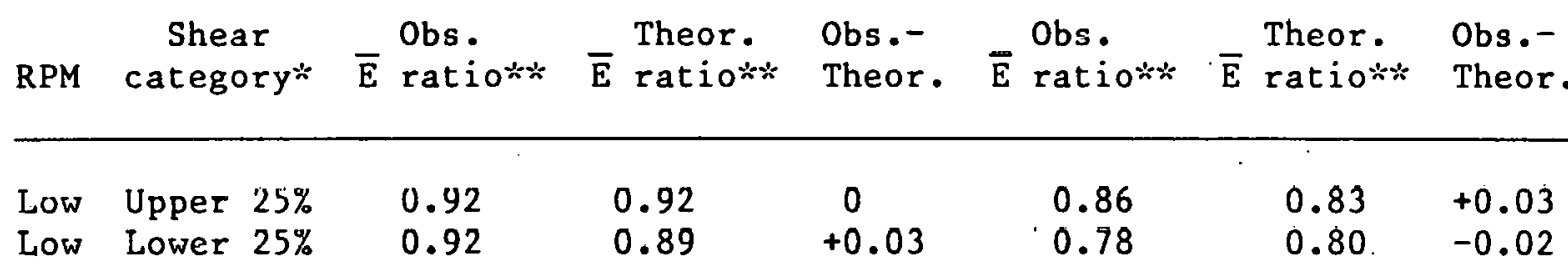

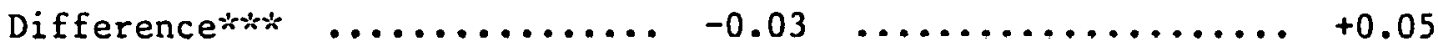

$\begin{array}{llllllll}\text { High } & \text { Upper 25\% } & 0.84 & 0.87 & -0.03 & 0.72 & 0.74 & -0.02 \\ \text { High } & \text { Lower } 25 \% & 0.91 & 0.87 & +0.04 & 0.78 & 0.76 & +0.02\end{array}$

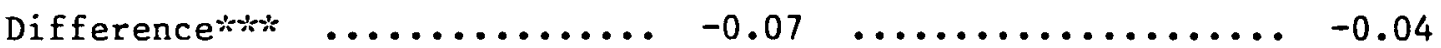

*Shear is defined as mean speed at 170-ft level of Anemometer Tower $B$ divided by mean speed at the $80-\mathrm{ft}$ level of Anemometer $A$.

*: The observed $\bar{E}$ ratio is from the upper part of the table. The theoretical ratio is interpolated from Table 3-4 and is based on ambient wind speed only (i.e., not broken down by wind shear).

W*:According to theory, the difference between the upper and lower quartiles should be a positive number; in other words, relative energy production within the array would be higher when there is a stronger positive shear profile. 
The poor quality of the wind-direction data precluded reliable calculations of transverse turbulence intensity. Therefore, turbulence intensity levels were calculated from the wind speed data using the formula:

$$
\mathrm{IT}_{(\mathrm{s})}=\operatorname{sigma} \mathrm{V} / \overline{\mathrm{V}}
$$

where $I_{(s)}$ is the speed turbulence intensity, sigma $V$ is the standard deviation of the wind speed, and $V$ is the mean speed.

This turbulence variable is broadly interchangeable with transverse turbulence intensity, both being one-dimensional representations of the same twodimensional flow field.

Table 3-6 presents mean turbulence intensity at all RM Young anemometers for the Scenario. A and $C$ tests. (Recall that all Anemometers are free of wake influences in Scenario $C$, whereas only Anemometers $A$ and $B-170$ are free of wakes in Scenario A.) Three important comments can be made about these data:

- Mean turbulence intensity at Rows 15 and 16 (Anemometers $C$ and D) was virtually the same whether the upwind turbine rows were operating (Scenario A) or not (Scenario C). Even at 5 RD (Anemometer B-80), "mean" turbulence levels were not significantly different at high RPM than they were at low RPM.

- The range of the mean turbulence intensity at all $80-\mathrm{ft}$ anemometers was small (0.14-0.16) for all scenario/RPM combinations (except B-80 anemometer for $B$ low-RPM), indicating uniformity of turbulence levels across the anemometer network.

- There was a consistently lower turbulence intensity at the 170-ft level than at the $80-\mathrm{ft}$ levels.

The first two findings are of particular interest because they conflict with traditional assumptions about turbulence within wind turbine arrays. It has typically been assumed that incremental turbulence created by wakes persists sufficiently to increase turbulence at turbine rows embedded within the array above ambient levels. But at the 10-1l RD spacing of this array, no such effect was observed.

The Scenario A tests were sorted by wind speed turbulence intensity (Anemometer A), and mean row energy production was calculated for the upper and lower quartiles (Table 3-7), following the same analysis format as used to investigate wind shear influences in the previous section. There seems to be little difference in normalized energy production between the high- and lowturbulence cases at Rows 15 and 16 , even when the data are adjusted for the ambient-wind-speed effect (Table 3-4). In fact, the largest difference $(-3 \%$ for Row 16, low-RPM) has the opposite sign from what the theories predict. 
Table 3-6. Mean Speed Turbulence Intensity*

\begin{tabular}{ccccccc} 
& & \multicolumn{5}{c}{ Anemometer } \\
\cline { 3 - 6 } Scenario & RPM & A & B-80 & B-170 & C & D \\
\hline & & & & & & \\
A & Low & 0.15 & 0.17 & 0.12 & 0.16 & 0.15 \\
C & Low & 0.15 & 0.14 & 0.11 & 0.15 & 0.15 \\
& & & & & & \\
A & High & 0.14 & 0.15 & 0.11 & 0.15 & 0.14 \\
C & High & 0.14 & 0.14 & 0.11 & 0.14 & 0.14 \\
\hline
\end{tabular}

*Defined as standard deviation/mean.

Table 3-7. Mean Energy Production as a Function of Speed lurbulence Intensity Class (Scenario A Tests)

Mean Row Energy Production Ratio to Row 14

Turb. Mean IT, Row 14 Obs. Theor. Obs.- Obs. Theor. Obs.RPM category Anem. A $\bar{E}$ (kWh) 15/14 15/14\% Theor. 16/14 16/14* Theor.

\begin{tabular}{llllllllll}
\hline Low & Upper 25\% & 0.19 & 5.3 & 0.94 & 0.93 & +0.01 & 0.88 & 0.85 & +0.03 \\
Low Lower 25\% & 0.12 & 4.8 & 0.92 & 0.92 & 0.0 & 0.89 & 0.83 & +0.06
\end{tabular}

Dillerenceds

$+u . u 1 \quad \ldots \ldots \ldots \ldots \ldots \ldots+0.03$

$\begin{array}{lllrllllll}\text { High } & \text { Upper } 25 \% & 0.16 & 9.8 & 0.90 & 0.87 & +0.03 & 0.78 & 0.75 & +0.03 \\ \text { High } & \text { Lower } 25 \% & 0.13 & 14.9 & 0.89 & 0.88 & +0.01 & 0.78 & 0.77 & +0.01\end{array}$

Difference**

$+0.02$

$+0.02$

*The theoretical ratio is interpolated from Table 3-4 and is based on ambient wind speed only (i.e., not broken down by turbulence intensity).

$\because$ According to theory, the difference between the upper and lower quartiles should be a positive number; in other words, relative energy production within the array would be higher in more turbulent conditions. 
Therefore, it must be concluded that no evidence was found in these measurements to support an inverse relationship between turbulence intensity levels and wake effects. The small sample sizes preelude a more emphatic conclusion; there indeed may be such an effect.

\subsubsection{Diurnal Influences}

Scenario A, low-RPM cases were used to evaluate differences in energyproduction patterns due to diurnal variations. Diurnal variations could potentially be important since dramatic differences in atmospheric conditions can occur between night and day. These differences correspond to differences in atmospheric stability, turbulence, and shear. However, the analysis presented did not attempt (because of limited resources available) to distinguish between these differences, but merely shows the gross effects seen between night and day operation at the test site. The results are shown in Table 3-8. Correcting for the ambient wind speed effect on normalized energy production at Rows 15 and 16 , both the daytime and nighttime cases matched the overall means within $1 \%$. This suggests that there is no diurnal influence on wake effects in this array.

\subsection{Special-Scenario Tests}

The special scenarios were of two types:

- Turbines brought on-line sequentially in front of a row of operating turbines (scenarios E, F, G, I)

- Turbines brought on-line sequentially in front of a single turbine (scenarios $\mathrm{H}, \mathrm{J}$ ).

There were at most six sequences of any given scenario/RPM combination, and often no more than three left after screening out incomplete or invalid results. The special scenarios therefore do not provide a very large data base for in-depth analysis. Mean individual turbine energy production for all subscenarios is presented in Appendix B.

Table 3-8. Mean Energy Production as a Function of Time-of-Day Class (Scenario A, Low-RPM Tests)

Mean Row Energy Production (kWh) and Ratio to Row 14

\begin{tabular}{|c|c|c|c|c|c|c|c|c|c|c|}
\hline $\begin{array}{l}\text { Hours } \\
\text { (PDT) }\end{array}$ & $\begin{array}{l}\text { Number } \\
\text { of cases }\end{array}$ & 14 & 15 & $\begin{array}{l}\text { Obs. } \\
15 / 14\end{array}$ & $\begin{array}{l}\text { Theor. } \\
15 / 14 \%\end{array}$ & $\begin{array}{l}\text { Obs.- } \\
\text { Theor. }\end{array}$ & 16 & $\begin{array}{l}\text { Obs. } \\
16 / 14\end{array}$ & $\begin{array}{l}\text { Theor. } \\
16 / 14 \%\end{array}$ & $\begin{array}{l}\text { Obs.- } \\
\text { Theor }\end{array}$ \\
\hline $08-18$ & 17 & 4.2 & 3.8 & 0.91 & 0.91 & 0.0 & 3.4 & 0.81 & 0.81 & 0.0 \\
\hline $20-02$ & 20 & 6.0 & 5.5 & 0.92 & 0.93 & -0.01 & 5.2 & 0.87 & 0.86 & +0.01 \\
\hline
\end{tabular}

*The theoretical ratio is interpolated from Table 3-4 and is based on ambient wind speed only (i.e., not broken down by Limé of day). 
The typical analysis technique applied to these special scenarios was to compare energy-production changes in the key row most affected by wakes from turbines being brought on-line during the scenario sequence. Certain turbines remained completely free of wakes throughout a sequence, some were affected by wakes during an entire sequence, and others were affected during just part of a sequence.

An example will serve to illustrate the analysis technique. The Scenario G, low-RPM sequence was run six times. All Row 16 turbines operate during the entire three-part sequence. In $G 1$, the first part of the sequence, turbine $15 \mathrm{~K} 8$ also runs. $15 \mathrm{~K} 7$ and $15 \mathrm{~K} 9$ are added in $\mathrm{G} 2$, and $15 \mathrm{~K} 6$ and $15 \mathrm{~K} 10$ are added in G3. Row 16 turbines are subject to wakes in the following manner*:

- $16 \mathrm{~K} 4,16 \mathrm{K5}, 16 \mathrm{~K} 11$, and $16 \mathrm{~K} 12$ are completely free of wakes during the entire sequence (note buffer turbines included for analysis here)

- $16 \mathrm{~K} 8$ is affected by Row 15 wakes during the entire sequence

- $16 \mathrm{~K} 6,16 \mathrm{~K} 7,16 \mathrm{Kg}$, and $16 \mathrm{Kl} 10$ are affected by wakes during just some of the sequence.

Table 3-9 summarizes pertinent mean-speed and energy-production statistics for the scenario sequence. Note the use of the four outer turbines in Row 16 completely free of wakes to normalize production data at inner turbines in the row. Normalized energy production at these inner turbines decreases as Row 15 turbines are brought on-line relative to the outer turbines. This decrease is presumably due to wakes; the percentage losses agree fairly well with the $6 \%$ figure determined in Table 3-1 for one upwind row of turbines.

Some of the key findings in the special-scenario test analyses are as follows:

- Apparent wake effects were found in Scenarios E, F, and G, using the technique described above. These effects were reasonably well defined from Row 15 to kow 16 but essentially undiscernible from Row 14 to Row 15 . This is peculiar, because Rows 14 and 15 are closer together and thus would be expected to show greater wake effects.

- For each scenario, apparent wake effects were equally well defined (or poorly detined) for high- and low-RPM test modes.

- No evidence of horizontal wake growth was found extending to turbines in a downwind row adjacent to the principally affected turbine(s). For example, if turbine $15 \mathrm{~K}^{\prime} \mathrm{\prime} s$ wake was seen to impact $16 \mathrm{~K} 8$, no impact was ohserved at $16 \mathrm{Kl}$ or $16 \mathrm{~kg}$.

*Wind directions were perpendicular to the rows, according to observations made during these tests. 
- It was impossible to analyze scenarios $H$ and $J$ with any confidence, because only one turbine operated in the downwind row. There was simply too much natural variability in the energy-production data to identify a meaningful pattern.

\subsection{Other Results}

The anemometer data lend themselves to other analyses ancillary to array wake evaluation, but pertinent to the study. Some of these are presented here.

\subsubsection{Wind Shear at Anemometer Tower B}

The wind-shear ratio at this tower is defined as the ratio of winds at $170 \mathrm{ft}$ to those at $80 \mathrm{ft}$. The mean wind-shear ratio seems to be relatively independent of ambient (Anemometer A) wind speed (Table 3-10). The overall mean shear ratio is 1.14 when Row 14 turbines are shut down, corresponding to a vertical power law exponent of 0.17 . This value is slightly higher than the often-quoted value of $1 / 7$ for flat terrain. The highest and lowest individual wind-shear ratios based on the 15 -minute tests were 1.29 and 1.02 , respectively, corresponding to power law exponents of 0.34 and 0.03 . Thus, no negative wind shears were observed at this tower during the testing periods.

The mean wind-shear ratio was $3 \%$ higher when Row 14 turbines were operating. This is because the 80-ft level of Tower B is only 5 RD downwind of Row 14 and clearly in the turbine wakes when that row is operating. The lower wind speed at the $80-\mathrm{ft}$ level results in a higher wind-shear ratio.

The frequency distribution of the wind shear ratio at Anemometer Tower $B$ appears to have a normal distribution (Table 3-11).

Table 3-9. Analysis of Scenario G Sequence (Low-RPM Mode)*

\begin{tabular}{|c|c|c|c|c|c|c|c|}
\hline \multirow[b]{2}{*}{ Scenariontrir } & \multirow{2}{*}{$\begin{array}{l}\text { Number } \\
\text { of cases }\end{array}$} & \multirow{2}{*}{$\begin{array}{l}\text { Anem. C } \\
\text { V (mph) }\end{array}$} & \multirow{2}{*}{$\begin{array}{l}\mathrm{C} / \overline{\mathrm{A}} \mathrm{V} \\
\text { ratio }\end{array}$} & \multirow{2}{*}{$\begin{array}{c}\bar{E}(\mathrm{kWh}) \\
\text { outer } \\
\text { group }\end{array}$} & \multicolumn{3}{|c|}{$\begin{array}{l}\text { Mean Energy Production Ratio to } \\
\text { Outer Group in Row } 16 \% *\end{array}$} \\
\hline & & & & & $16 \mathrm{~K} 8$ & $16 \mathrm{~K} 7,8,9$ & $16 \mathrm{~K} 6,7,8,9,10$ \\
\hline G1 & 6 & 25.6 & 0.98 & 5.1 & 1.17 & 1.13 & 1.14 \\
\hline G2 & 6 & 25.1 & 0.94 & 5.2 & 1.06 & 1.09 & 1.10 \\
\hline c.3 & 6 & 24.7 & 0.95 & 4.9 & 1.08 & 1.07 & 1.07 \\
\hline
\end{tabular}

*Background data for this analysis is in Appendix B.

**outer group includes $16 \mathrm{~K} 4,16 \times 5,16 \mathrm{~K} 11$, and $16 \mathrm{~K} 12$.

***:Scenario description: Row 14 off during all parts of sequence; Row 16 (including buffer turbines) on during all parts of sequence. $15 \mathrm{~K} 8$ also operates in Gl; $15 \mathrm{~K} /, 15 \mathrm{~K} 8$, and $15 \mathrm{~K} 9$ operate during G2; $15 \mathrm{~K} 6,15 \mathrm{~K} 7,15 \mathrm{~K} 8$, $15 \mathrm{~K} 9,15 \mathrm{~K} 10$ operate during $\mathrm{G} 3$. 
Table 3-10. Mean Wind-Shear Ratios (Anemometer Tower B)

Row 14 Shut Down

Anem. A Number $\bar{V}$ ratio, Std. dvtn.

$\overline{\mathrm{V}}(\mathrm{mph})$ of cases 170'/80' of $\dot{\vec{V}}$ ratio

$15-20$

15

0.04

1.12

0.06

1.16

0.04

1.14

0.02

1.12

0.02

7

1.14

0.05

75

1.17

0.06

134 of case

$\overline{\mathrm{V}}$ ratio, $170^{\prime} / 80^{\prime}$

Row 14 Operating
1.11

1.14

0.05

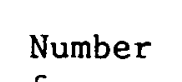

Std. dvtn. of $\bar{V}$ ratio

$\begin{array}{lll}7 & 1.18 & 0.07 \\ 26 & 1.17 & 0.08 \\ 20 & 1.17 & 0.05 \\ 18 & 1.16 & 0.04 \\ 4 & 1.16 & 0.02\end{array}$

Table 3-11. Frequency Distribution of Mean Wind-Shear. Ratios (Row 14 Turbines Shut Down)

\begin{tabular}{cc}
$\begin{array}{c}\text { Tower B } \\
\text { ratio } \\
170 \% / 80^{\prime}\end{array}$ & $\begin{array}{c}\text { Number of } \\
\text { occurrences }\end{array}$ \\
\hline $1.00-1.04$ & 4 \\
$1.05-1.09$ & 18 \\
$1.10-1.14$ & 43 \\
$1.15-1.19$ & 48 \\
$1.20-1.24$ & 17 \\
$1.25-1.29$ & 4 \\
Total & 134 \\
\hline
\end{tabular}




\subsubsection{Vertical Growth of the Wake}

The intermediate measurement levels on the 170-ft tower facilitated analysis of wake growth in the vertical. In particular, mean-wind-speed ratios of the $110-\mathrm{ft}$ level of Tower B to Anemometer A and to the 170-ft level of Tower B were compared for cases with Row 14 operating (possible wake impact on 110-ft level) and Row 14 shut down (no wakes). The results are summarized in Table 3-12.

There was no significant difference in these mean-wind-speed ratios as a function of Row 14 status. It is therefore tentatively concluded that wake effects at the 110-ft level of Anemometer Tower B, corresponding to a vertical growth angle of 4 degrees, are negligible.

\subsubsection{Special Comparison of Anemometers B (80 ft) and C}

Mean speed ratios $B-80 / A$ and $C / A$ are given in Table 3-13 as a function of Row 14 operational status (on or of $f$ ). Both the $B$ and $C$ anemometers showed a statistically significant $(<0.1 \%$ level) reduction in mean speed ratio when Row 14 was operating, presumably because of wake effects.

However, the magnitude of the mean wind-speed reductions is peculiar. Anemometer B at $5 \mathrm{RD}$ downwind shows a $2 \%$ decrease, whereas Anemometer $\mathrm{C}$ at 8 RD shows a $5 \%$ decrease. This is reversed from what wake theories predict; it is not known why this happened.

The impact of wakes at Anemometer $B$ is clearly seen from the standard deviations of the individual mean speed ratios. The standard deviation at Anemometer $B$ is much higher when Row 14 is operating, indicating a variable impart at. 5 RD. Note that the standard deviation at Anemometer $C$ is the same regardless of Row $14^{\prime}$ s operational status. 
Table 3-12. Analysis of Wake Effects at $110 \mathrm{ft}$ (Anemometer Tower B)

\begin{tabular}{|c|c|c|c|c|c|c|c|}
\hline RPM & $\begin{array}{l}\text { Row } 14 \\
\text { status }\end{array}$ & $\begin{array}{l}\text { Number } \\
\text { of cases }\end{array}$ & $\underset{\bar{V}}{A n e m} \cdot A$ & $\bar{V}^{B-110}(m p h)$ & $\begin{array}{l}\bar{V} \text { ratio, } \\
\text { B110/A }\end{array}$ & $\bar{V}(\mathrm{mph})$ & $\begin{array}{l}\bar{V} \text { ratio, } \\
\text { B110/B17C }\end{array}$ \\
\hline Low & off & 35 & 24.1 & 24.3 & 1.01 & 26.2 & 0.93 \\
\hline \multirow[t]{2}{*}{ Low } & on & 37 & 24.3 & 24.8 & 1.02 & 26.5 & 0.94 \\
\hline & & & Difference*** & $\ldots \ldots \ldots$ & -.01 & $\ldots \ldots \ldots \ldots$ &.+.01 \\
\hline $\mathrm{High}$ & of $f$ & 28 & 30.0 & 30.2 & 1.01 & 32.5 & 0.43 \\
\hline \multirow[t]{2}{*}{$\mathrm{High}$} & on & 24 & 30.8 & 31.0 & 1.01 & 33.8 & 0.92 \\
\hline & & & Difference** & $\ldots \ldots \ldots \ldots$ & 0 & $\ldots \ldots \ldots \ldots \ldots$ & $\cdot+.01$ \\
\hline
\end{tabular}

*RM Young sensor.

*Ideally, a positive difference represents the wake effect at the $110-\mathrm{ft}$ level of Tower $B$. These values are so small, however, that it has been concluded that there is no measurable effect.

Table 3-13. Relative Mean Wind-Speed

Losses Due to Row. 14 Wakes

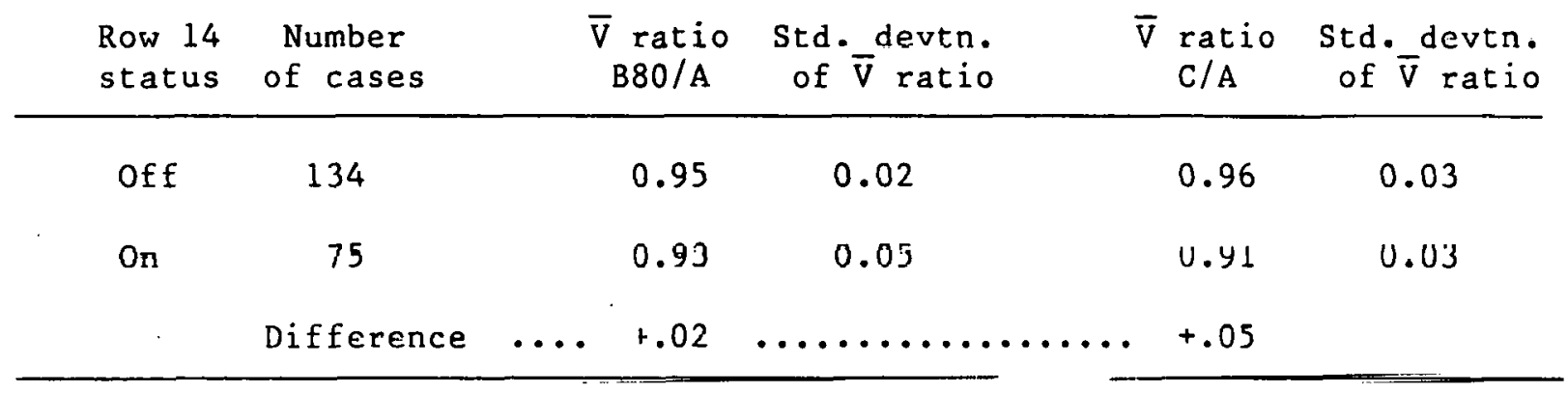




\subsection{CONCLUSIONS AND RECOMMENDATIONS}

The existence of wake-induced losses in energy production has been confirmed for the Fayette 95-IIS wind turbine array (2.8 x 10+ rotor-diameter spacing). The measurements indicated losses of about $6 \%$ for turbines 10 RD downwind, and a cumulative loss of $7 \%-8 \%$ for turbines downwind of two rows. These figures are specific to the conditions present during the study and should be treated as approximate. To fully understand the nature and magnitude of the wake effects, more sampling is needed. However, the test methodology was sound and can be recommended to other investigators for future research.

Percentage wake losses at low-RPM operation decrease with increasing ambient wind speed, but at high-RPM operation, these losses are mostly independent of ambient conditions. These relationships are largely an artifact of the turbine performance curve, as relative wind-speed losses due to wakes do not vary with ambient wind speed at either mode of operation.

Many investigators have assumed that the degree of wake-induced energy production losses is affected significantly by variations in ambient atmospheric conditions, most notably stability, shear, and turbulence. For example, in the Altamont Pass area during the summer months, these conditions vary significantly from night to day. However, the data collected during this study do not establish statistical relationships between these factors and wake effects. If such relationships do occur, they are apparently too small to discern above the noise level of the energy-production data. Also, a more detailed analysis including a sophisticated partitioning of the data might support other conclusions, but this level of analysis was beyond the scope of the present study.

Horizontal wake growth from an individual turbine sufficient to impact energy production at more than one turbine in the next downwind row was not found in the special scenario tests. Also, no conclusive evidence was found for vertical growth of the wake to one $\mathrm{RD}$ above hub height at 5 RD downwind.

The anemometers supporting the second and third rows of the array were located at 8 and 9 RD downwind of the first and second rows, respectively. Mean turbulence levels at these distances were identical regardless of whether the upwind rows were operating or not. In other words, there was no cumulative increase of turbulence throughout the array, which contradicted what was expected. For example, the presence of the machines tends to increase the ambient and terrain-induced turbulence through the addition of surface roughness. In addition, the operation of the machines mechanically induces turbulence. However, the results of this study indicate that any turbulence generated by the machines appears to decay completely by 8-9 RD downwind from a given tow.

The natural spatial variation of mean wind speed (at $45 \mathrm{ft}$ above ground) exceeded $20 \%$, which is surprising considering that there was only a 40-ft difference between the turbines having the highest and lowest elevations.

The project was successful in meeting its primary objectives, especially in view of its unprecedented nature. The methodology, software, and hardware can be adapted to other wind farms. 
The following are recommended for further studies of array wake effects:

- Run wake models for this specific array to investigate their ability to reproduce observed conditions. The wake models would have to be modified to handle complex terrain and other nonuniform factors.

- Perform a field measurement study like this one on more densely spaced arrays, containing both Fayette and other types of wind turbines.

- Because commercial wind farms are generally located in more rugged terrain than that of this study (its flatness was one of the prime reasons for its selection), a study similar to this one should be conducted for complex rerrain.

- This study addressed only one fixed array; so, to optimize array spacing, wake effects should be documented for a variety of spacing configurations. A flexible array could be developed so that a small but meaningful group of turbines could be moved to various downwind distances behind a fixed row. The guyed turbine tower used by Fayette would facilitate such moves at relatively little expense. 


\subsection{REFERENCES}

Baker, R. W., and S. N. Walker, 1985. Wake Velocity Measurements at the Goodnoe Hills MOD-2 Site (a Summary of 1982 and 1984 Findings). Portland, Oregon. Bonneville Power Administration Report 84-15.

Buck, J. W., and D. S. Renne, 1985. Observations of the Wake Characteristics at the Goodnoe Hills MOD-2 Array. Richland, Washington. Battelle Pacific Northwest Laboratory. Report PNL-5565.

Doran, J. C., and K. R. Packard, 1982. Comparison of Model and the Observations of the Wake of a MOD-OA Wind Turbine. Richland, Washington. Battelle Pacific Northwest Laboratory. Report PNL-4433.

Eberle, W. R., 1981. Wind Flow Characteristics in the Wakes of Large Wind Turbines, Vol. 1--Analytical Model Development. U.S. Department of Energy, Washington, D.C. Report DOE/NASA/0029-1.

Lissaman, P. B. S., G. W. Gyatt, and A. D. Zalay, 1982. Numerical Modeling Sensitivity Analysis of the Performance of Wind Turbine Arrays. Richland, Washington. Battelle Pacific Northwest Laboratory. Report PNL-4183.

Renne, D. S., and J. W..Buck, 1985. Measurement and Analysis of the Wake of a DAF 500-kW Vertical Axis Wind Turbine. Rosemead, California. Southern California Edison Company. Report SCE 85-RD-9. 


\section{APPENDIX A}

\section{SAMPLE OPERATIONAL AND ANALYSIS GRAPHICS FOR AN INDIVIDUAL 15-MINUTE TEST}

The procedures, displays, and graphics used for editing a 15-minute wake test are shown in this appendix. Test $\$ 52$, a Scenario B test, was conducted at 0133 hours PDT on 27 August 1986. Each chart (as it appears on the computer screen) is discussed below.

A. Performing diagnostics--this chart is automatically displayed after the data acquisition system is powered up. Turbines are displayed in a geographical format. ( 14 WO1 and 14 W02 are the data interface hoards.) "OK" means communication is successfully, established, in this case with all units. Aftcr the operator types in name, the next screen (following) appears.

B. Main menu--the operator chooses from the 1 ist. F1, F2, etc., are the function keys used to select the 'next test option.' Current time and wind velocity data are updated at one-second intervals.

C. On the screen, the test operator can select the next test scenario by depressing the appropriate function key (e.g., F1 for scenario A).

D. RPM field map--the operator chose F2 (Scenario B). Several things happen after the choice is made. First, signals go out to turn off or start up turbines, or both, as appropriate. The RPM display then automatically appears on the screen. In the example, primary and buffer turbines in Row 14 are now off; the others are all at the proper RPM. The test is started by depressing the F1 key. This display is updated continuously during the test.

E. Data collection log--manually filled in by operator befure, duritig, and after the test.

F. Condensed example of information recorded for each test--this is a sample of the data file as written onto the hard disk of the Sperry IT computer in the test trailer. The operator reviews immediately after lest finishes.

G. Formatted printout of results--15-minute energy production given in map format; mean wind velocities for anemometers given at bottom in geographic format [Anemometer $A$ on the left, then B (170-ft data above $80 \mathrm{ft}$ ), then $C$ and $D J$. This is used for more refincd cditing. 


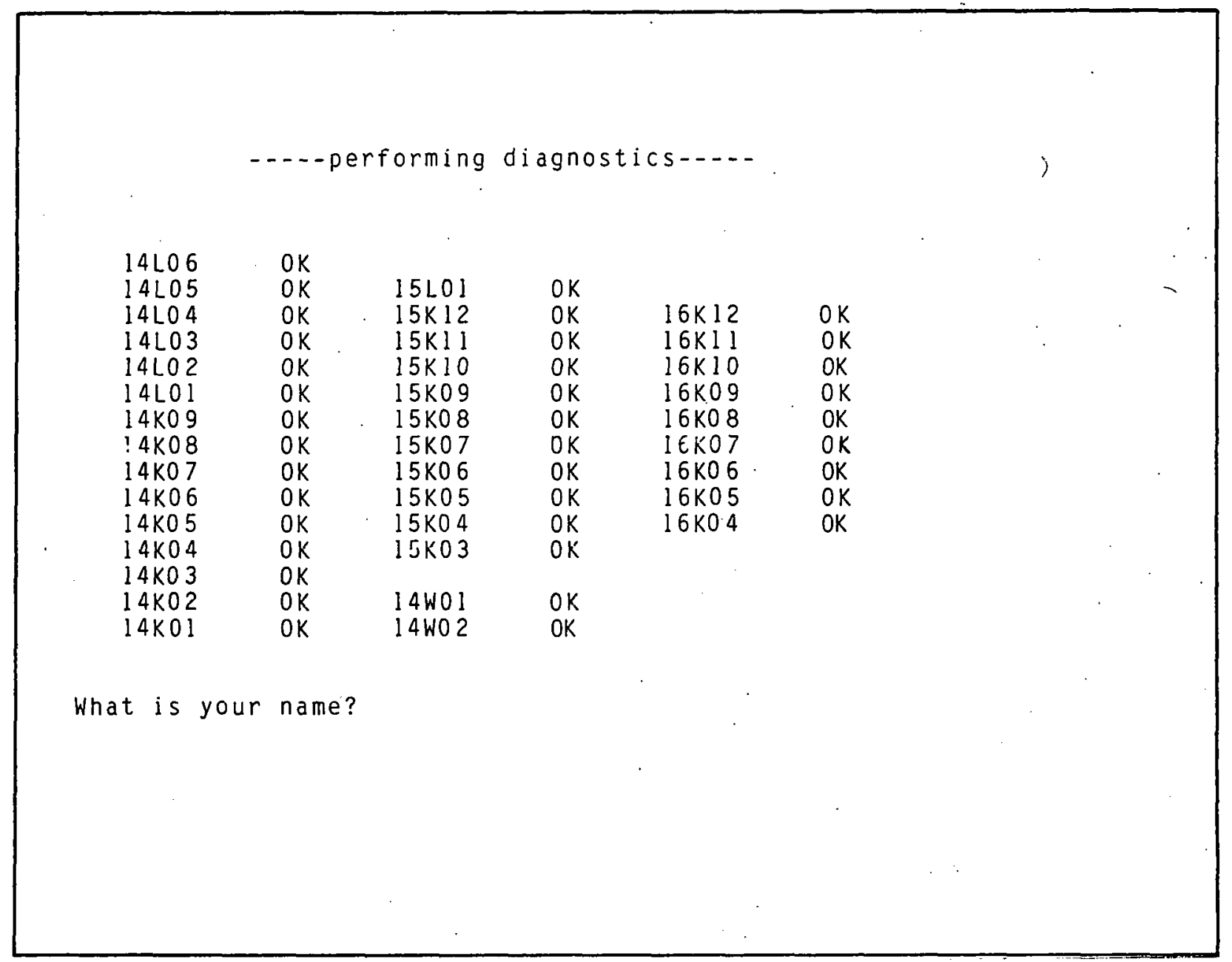

Chart A. 


$\begin{array}{ll}\text { Fl } & \text { Select next test scenario } \\ \text { F2 } & \text { Display RPM field map } \\ \text { F3 } & \text { Display data from one turbine } \\ \text { Esc } & \text { Exit program }\end{array}$

\begin{tabular}{|c|c|c|c|c|}
\hline We & Aug. & 7 & $: 30: 30$ & 1986 \\
\hline $\begin{array}{l}\text { A } \\
B 00 \\
B 170 \\
C \\
D\end{array}$ & $\begin{array}{l}: 24.7 \\
\vdots \quad 20.1 \\
: \quad 33.6 \\
: \quad 19.9 \\
: 19.3\end{array}$ & $\begin{array}{l}\mathrm{mph} / \\
\mathrm{mph} / \\
\mathrm{mph} / \\
\mathrm{mph} / \\
\mathrm{mph} /\end{array}$ & $\begin{array}{l}230.1 \\
224.1 \\
214.0 \\
225.4 \\
283.0\end{array}$ & $\begin{array}{l}\text { deg } \\
\text { deg } \\
\text { deg } \\
\text { deg } \\
\text { deg }\end{array}$ \\
\hline
\end{tabular}


-.--select next test scenario-..- ESC to exit

Fl....All machines $0 N$

F2... ROW 14 OFF, row 15 ON, row 16 ON

F3.... Row 14 OFF, row 15 OFF, row $160 \mathrm{~N}$

F4....All primary turbines OFF

F5....16K06-16K1.0 ON add $15 \mathrm{K07}, 15 \mathrm{KO9} O \mathrm{~N}$ add $14 K 08 \quad O N$

F6....16K08, $16 \mathrm{Kl} 0,16 \mathrm{Kl} 2$ $\begin{array}{llll}\text { add } & 15 K 08 & 0 N \\ \text { add } & 15 K 06,15 K 10 & 0 N\end{array}$ add $14 K 08 \quad 0 N$ add I $4 K 06,14 K L O I \quad O N$

F7... 15K08, all row 16 ON add, I5K07 l. add $15 \mathrm{KO} 6,15 \mathrm{KlO} \quad \mathrm{ON}$

F8....15K08, 16K08 ON (on lst $15 \mathrm{~min}$ ) add 15K07, 15K09 ON. (on 2nd $15 \mathrm{~min}$ ) add 16K06, 15KI0 ON (on 3rd $15 \mathrm{~min}$ )

F9....14K08, all row 15, $16 \mathrm{ON}$ (on lst $15 \mathrm{~min}$ ) add $14 \mathrm{KO}, 14 \mathrm{KOg}$ ON (on 2nd $15 \mathrm{~min}$ ) add 14K06, 14LOL ON (on 3rd $15 \mathrm{~min}$ )

F10..14K08, 15K08, 16KU8 oN (on lst $15 \mathrm{~min}$ ) add 14K07, 14KO9 ON (on 2nd $15 \mathrm{~min}$ ) add 14K06, 14LOl ON (on 3rd $15 \mathrm{~min}$ )

Chart C. 


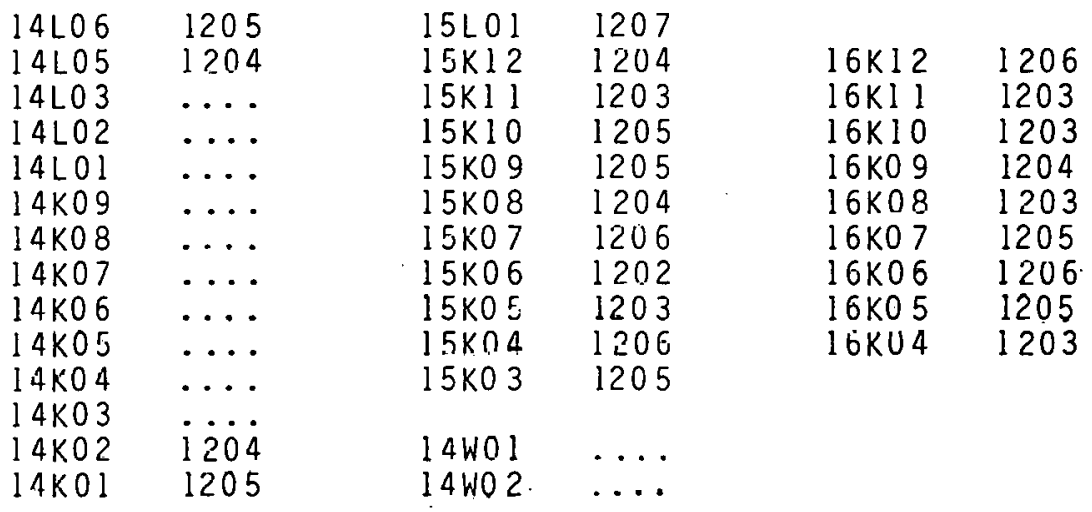

Fl Start test

F2 Stop test

F3 Aboard test

ESC Exit to main menu

\begin{tabular}{|c|c|c|c|c|}
\hline Wed $\mathrm{Au}$ & 27 & $01: 3$ & $: 45$ & 1986 \\
\hline $\begin{array}{ll}\text { A } & : \\
\text { B8 0 } & \vdots \\
\text { B } 170 & \vdots \\
\text { C } & \vdots \\
\text { D } & \vdots\end{array}$ & $\begin{array}{l}26.0 \\
26.0 \\
32.0 \\
26.8 \\
24.2\end{array}$ & $\begin{array}{l}\text { mph/ } \\
m p h / \\
m p h / \\
m p h / \\
m p h /\end{array}$ & $\begin{array}{l}235.8 \\
227.6 \\
224.7 \\
232.4 \\
239.3\end{array}$ & $\begin{array}{l}\text { deg } \\
\text { deg } \\
\text { deg } \\
\text { deg } \\
\text { deg }\end{array}$ \\
\hline
\end{tabular}

Chart D. 
TEST HUMBER: 52

TEST START/STOP TIMES: $8 / 27 / 86$

$01: 33: 30$

TEST DONE BY: R Simon

TEST SCENARI0: F2. (ROW M II.)

HTG OPERATION MODE: LOW speed

WTG'S NOT RESPONDING: none

WTG'S NOT OPERATING:

PRINT SNAPSHOT OF FIELD RPM BEFORE TEST START AND ATTACH HERE TO:

ADOITIONAL COMMENTS: 14 LOl took 1 min for RPM to go to 0 -

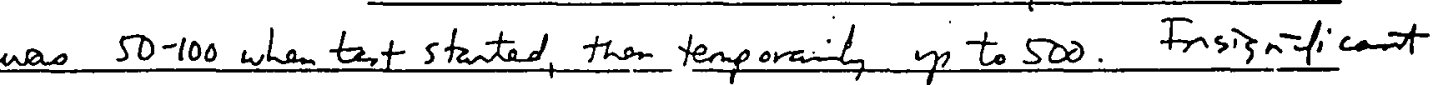
with respect to aralysir Anoma $\bar{V}=263$

TOHER B HINDOMETER READINGS

\begin{tabular}{|c|c|c|c|c|c|c|c|c|}
\hline \multirow[b]{2}{*}{ HEI GHT } & \multirow[b]{2}{*}{ START } & \multirow[b]{2}{*}{ COUNT } & \multirow[b]{2}{*}{ STOP } & \multirow[b]{2}{*}{ COUNT } & \multirow[b]{2}{*}{$\triangle$ COUNT } & \multirow{2}{*}{$\begin{array}{l}(\text { COUNT } \div) \\
\text { OFFSET } \\
\end{array}$} & \multirow[b]{2}{*}{ AVG W.S. } & AER B RM \\
\hline & & & & & & & & AVG W.S. \\
\hline $80^{\prime}$ & & 817 & & 193 & 376 & 1.000 & 25.1 & 25.0 \\
\hline $110^{\circ}$ & & 413 & $\because$ & 314 & 401 & $.99 \%$ & 26.8 & $x$ \\
\hline $140^{\circ}$ & & 533 & & 966 & 433 & .984 & 29.3 & $x$ \\
\hline $170^{\circ}$ & & 636 & & 107 & 471 & .982 & 320 & 30.3 \\
\hline
\end{tabular}

SCAN DATA FOR DATA QUALITY: COMMENTS: OK 
DATE IESTT CONDUCTED

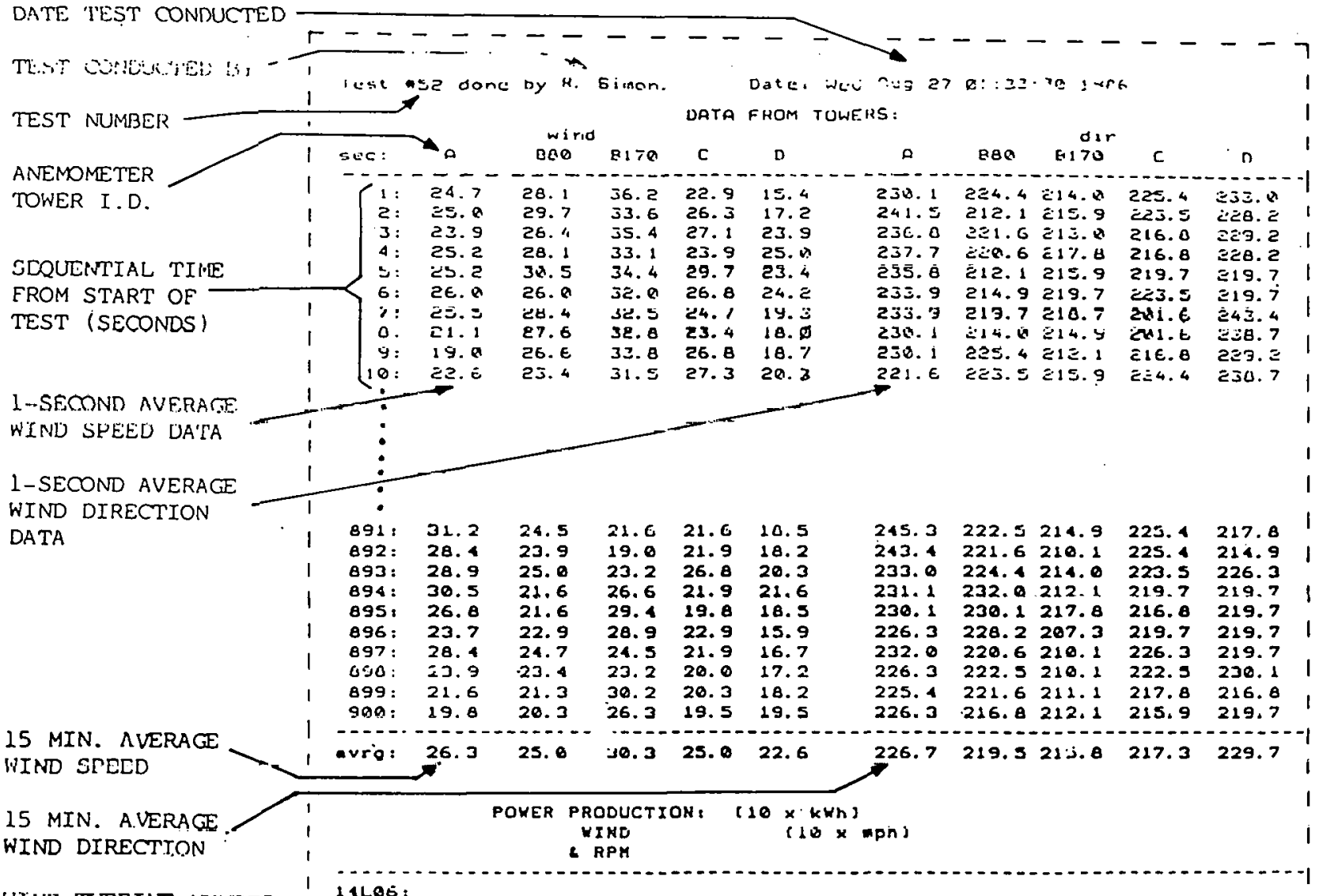

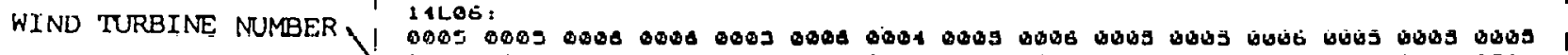
$\begin{array}{lllllllllllllll} & \end{array}$ IN $1 / 10$ th $\mathrm{KWH}$

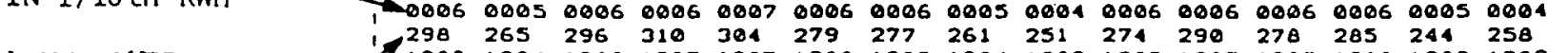
I-MN. AVERAGE WIND 120812041206120712071206120512041203120512071205120612021203 SFEED FROM CONTROL AINEMOMETER IN $1 / 10$ th $\mathrm{MPH}$ I-MN. AVERAGE WTG. GENERATOR SPEED (RPM)

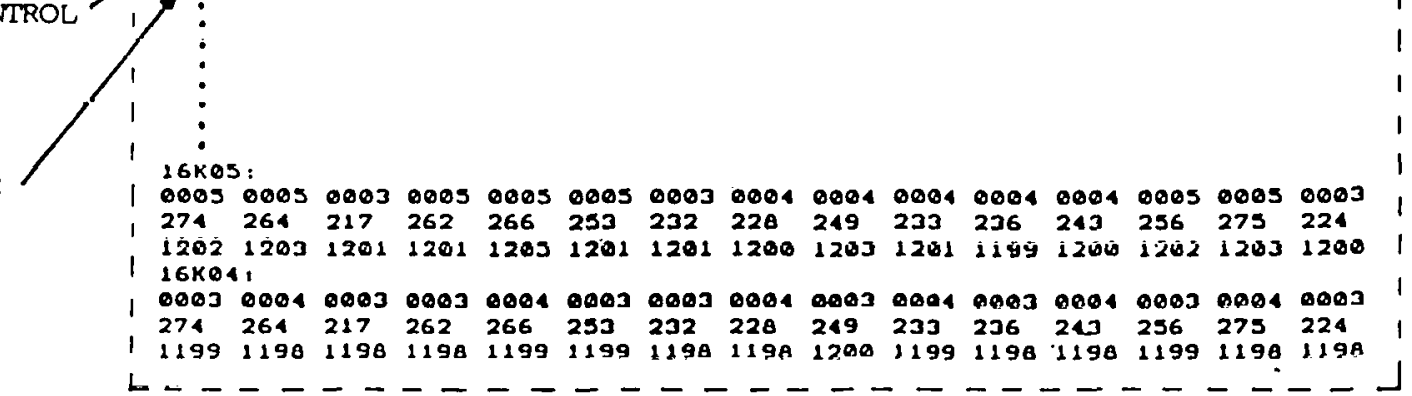



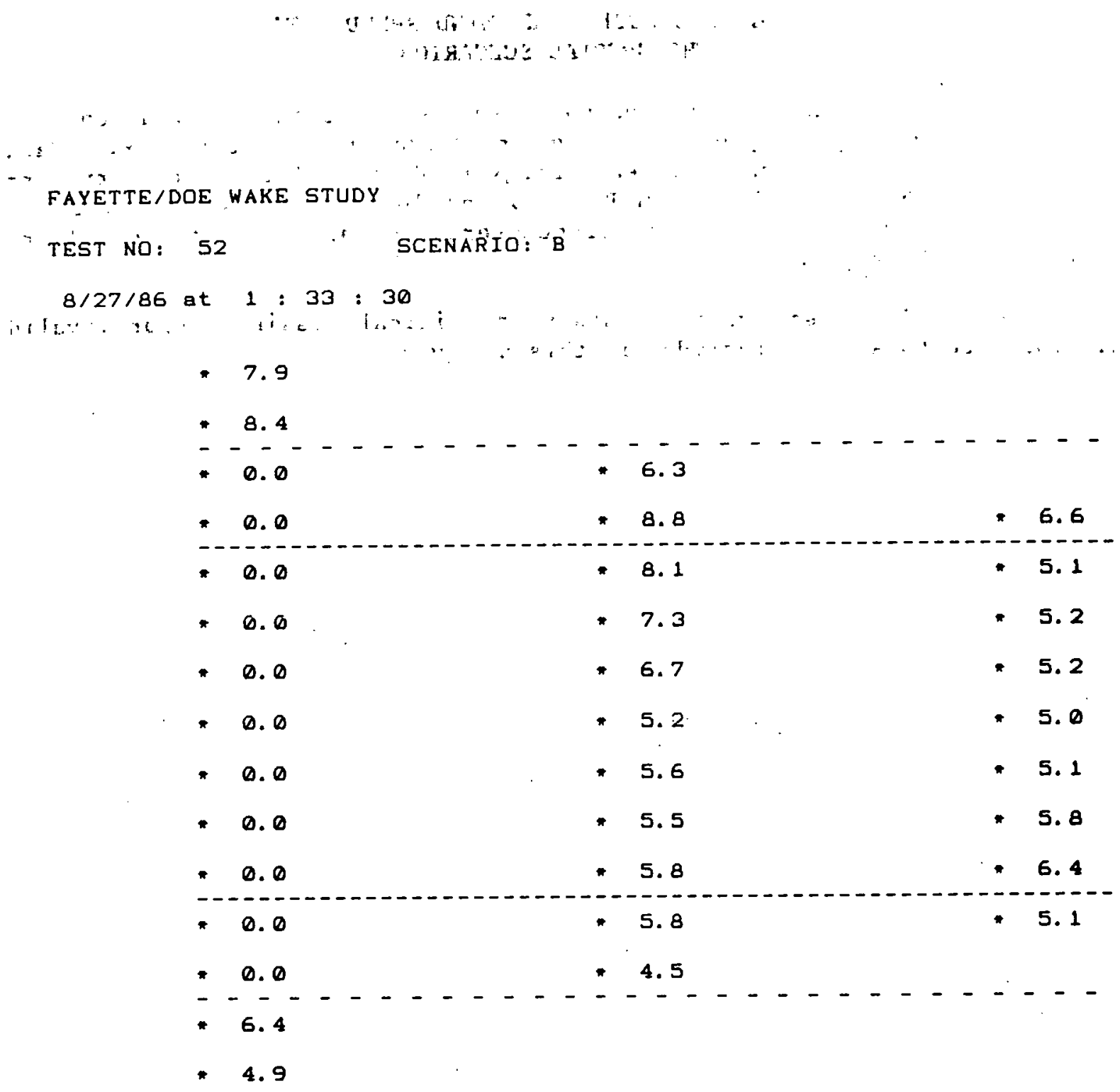

30.30

$2: 5.80$

- 26.3

25.00

0226. 7

219.5

- 25.0

0217.3

- 22.6

0229.7

$09-30-1986$

Chart G. 


\section{APPENDIX B}

\section{MEAN ENERGY-PRODUCTION AND WIND-SPEED DATA}

FOR THE SPECIAL SCENARIOS

All data for each scenario subsequence have been tabulated; mean energyproduction and mean wind-speed data are presented in this appendix. Data within the dashed lines represent mean energy production for the primary turbines. Certain buffer turbines in Rows 15 and 16 are included outside the dashed lines. Mean wind speeds for Anemometers $A-D$ (all at $80-f t$ level) are given from left to right.

An effort was made to screen out tests with critical missing and/or invalid data. Those tests are not included in this analysis. 


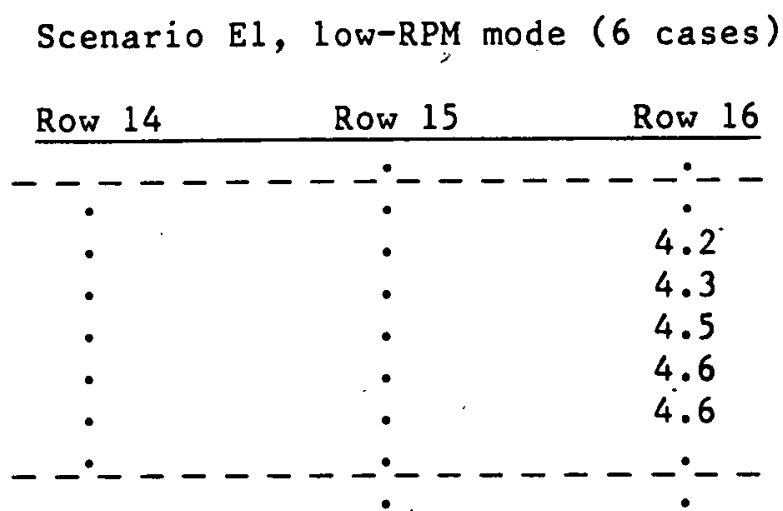

$\begin{array}{lllll}\text { Anemometer } \bar{V}(\mathrm{mph}) & 23.6 & 22.6 & 22.7 & 22.3\end{array}$

Scenario E2, 10W-RPM mode (6 cases)

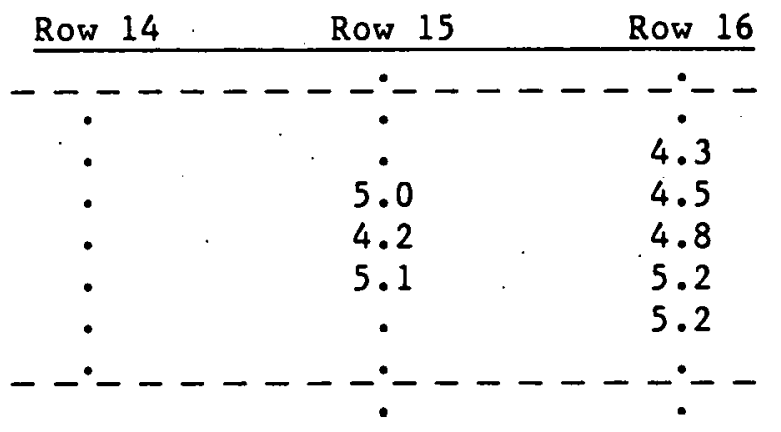

$\begin{array}{lllll}\text { Anemometer } \bar{V}(\mathrm{mph}) & 24.7 & 23.8 & 24.0 & 22.7\end{array}$

Scenario EJ, low-RPM mude (6 cases)

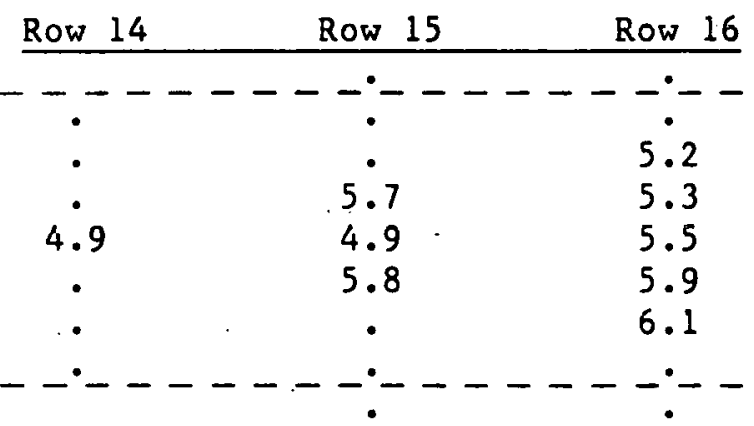

Anemometer $\bar{V}(\mathrm{mph}) .26 .7 \quad 24.8 \quad 25.5 \quad 24.3$

See page 52 for an explanation of these tables. 
Scenario E1, high-RPM mode (1 case)

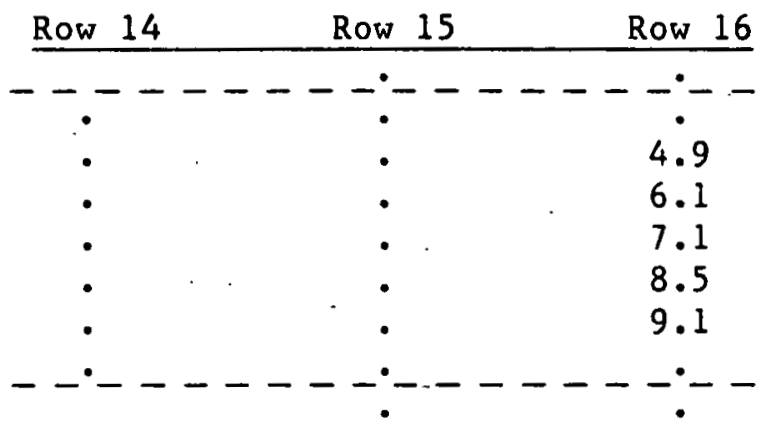

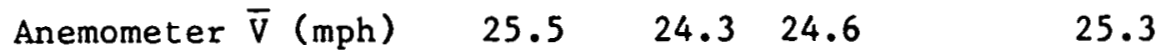

Scenario E2, high-RPM mode (1 case)

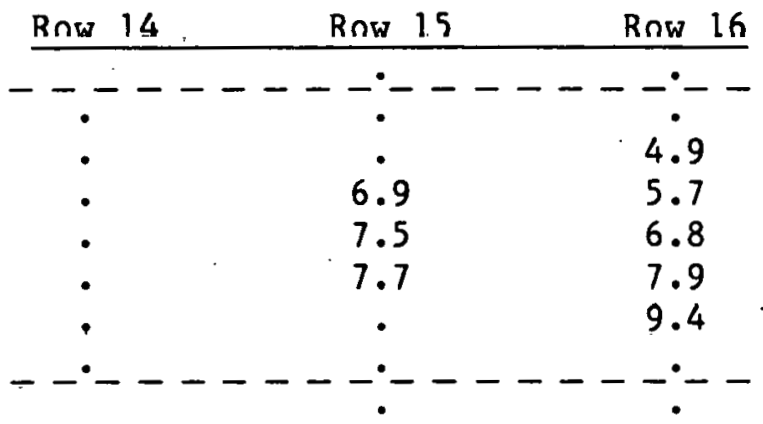

Anemometer $\overline{\mathrm{V}}(\mathrm{mph}) \quad 26.2 \quad 25.2 \quad 25.5 \quad 25.0$

Scenario E3, high-RPM mode (1 case)

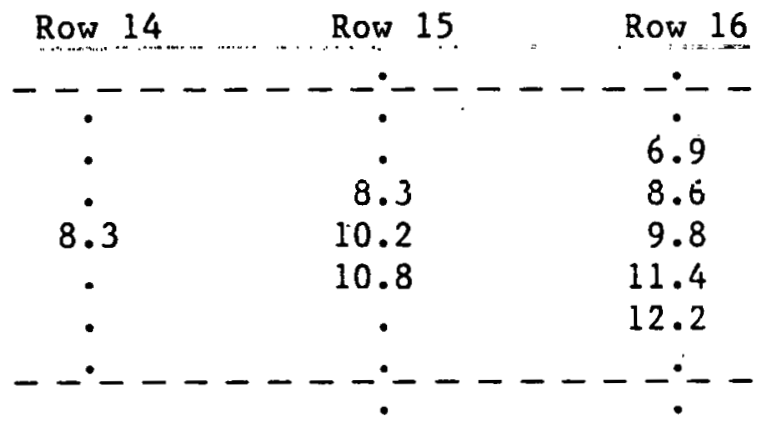

Anemometer $\bar{V}(\mathrm{mph}) \quad 27.5 \quad 27.2 \quad 28.0 \quad 28.0$

See page 52 for an explanation of these tables. 


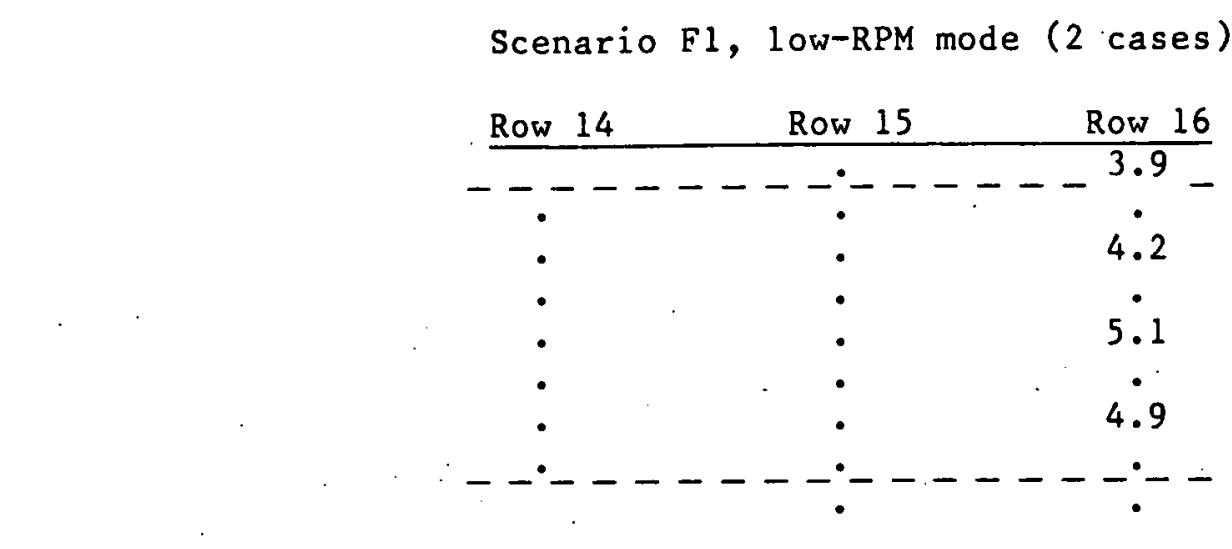

Anemometer $\bar{V}(\mathrm{mph}) \quad 23.8 \quad 23.1 \quad 23.6 \quad 23.3$

Scenario F2, low-RPM mode (2 cases)

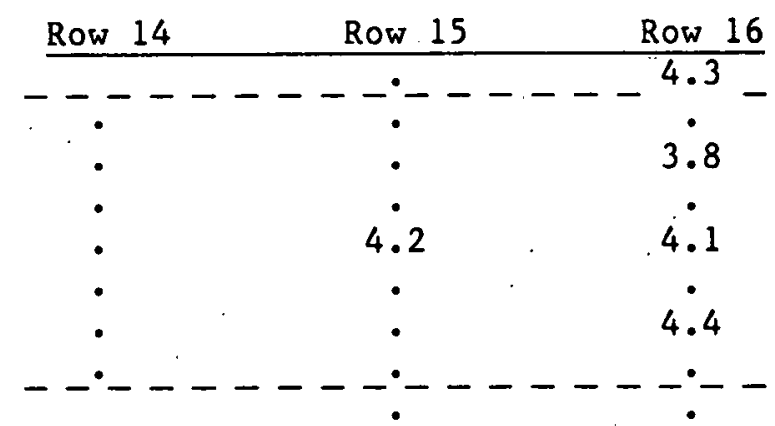

Anemometer $\bar{V}(\mathrm{mph}) \quad 23.2 \quad 22.1 \quad 22.3 \quad 21.5$

Scenario F3, lnw-RPM mode (2 cases)

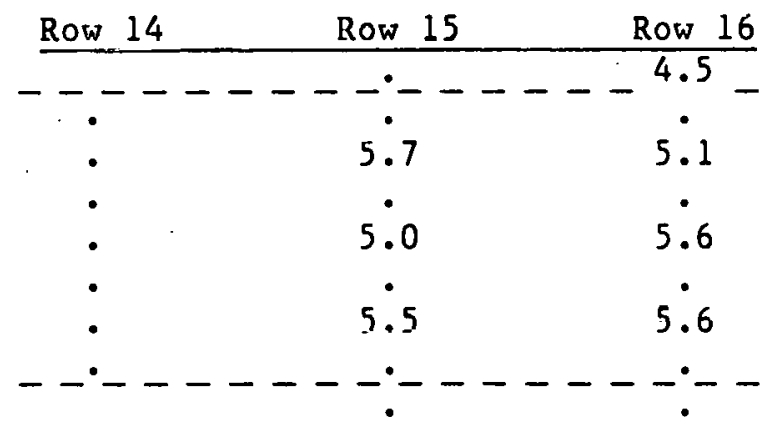

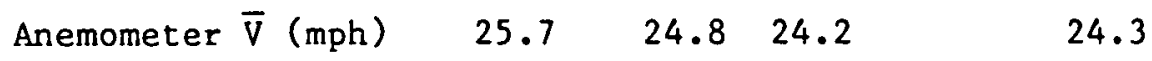

See page 52 for an explanation of these tables. 
Scenario F4, low-RPM mode ( 2 cases)

\begin{tabular}{|c|c|c|}
\hline Row 14 & Row 15 & Row 16 \\
\hline $\begin{array}{c}--- \\
\dot{\cdot}\end{array}$ & $\begin{array}{l}-\dot{-0} \\
6.0\end{array}$ & $\begin{array}{l}5.3 \\
5.4\end{array}$ \\
\hline 5.6 & 5.5 & 5.9 \\
\hline • & 5.9 & 6.4 \\
\hline$--^{\circ}-$ & $-\because$ & - \\
\hline
\end{tabular}

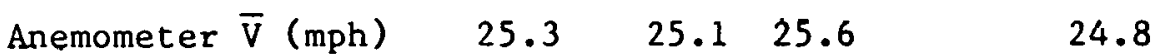

Scenario F5, low-RPM mode ( 2 cases)

\begin{tabular}{|c|c|c|}
\hline Row 14 & Row 15 & Row 16 \\
\hline--7 & $-\cdot-1$ & -4.9 \\
\hline 5.4 & 5.8 & 4.8 \\
\hline ( & * & • \\
\hline 5.4 & 4.9 & 5.7 \\
\hline 5.7 & 5.9 & 6.0 \\
\hline--- & $-:$ & $-\therefore$ \\
\hline
\end{tabular}

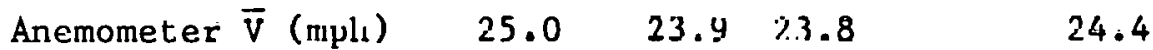

See page 52 for an explanation of these tables. 
Scenario Fl, high-RPM mode (2 cases)

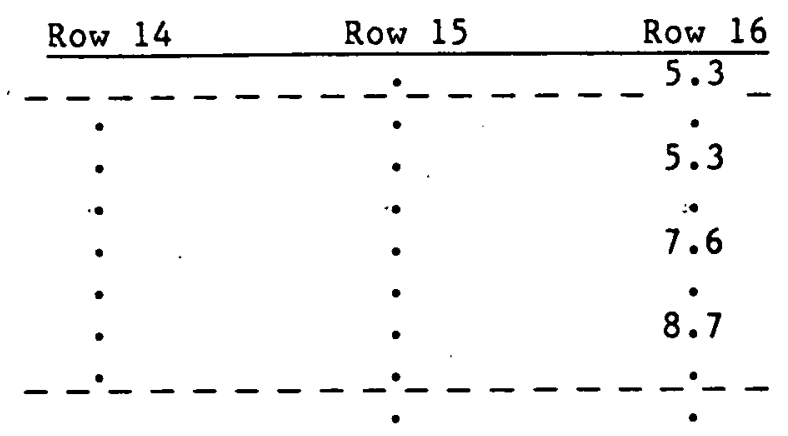

$\begin{array}{lllll}\text { Anemometer } \overline{\mathrm{V}}(\mathrm{mph}) & 25.9 & 25.1 & 25.7 & 25.7\end{array}$

Scenario F2, high-RPM mode (2 cases)

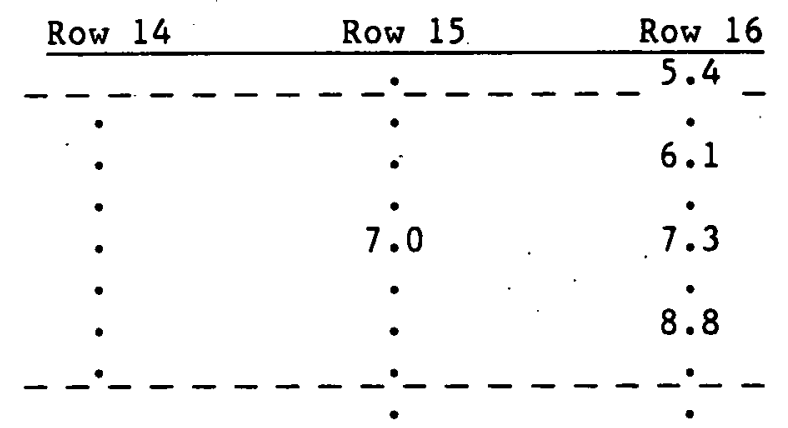

$\begin{array}{lllll}\text { Anemometer } V(\mathrm{mph}) & 26.4 & 24.5 & 24.8 & 25.6\end{array}$

Scenario F3, high-RPM mode (2 cases)

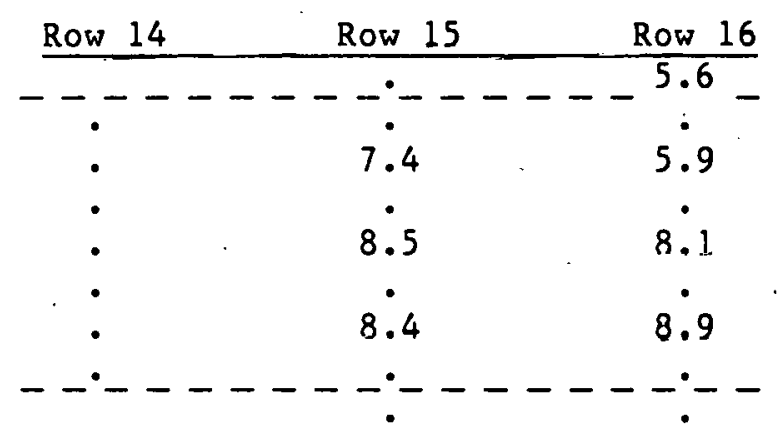

Anemometer $\bar{V}(\mathrm{mph}) .27 .1 \quad 26.1 \quad 26.3 \quad 26.5$

See page 52 for an explanation of these tables. 


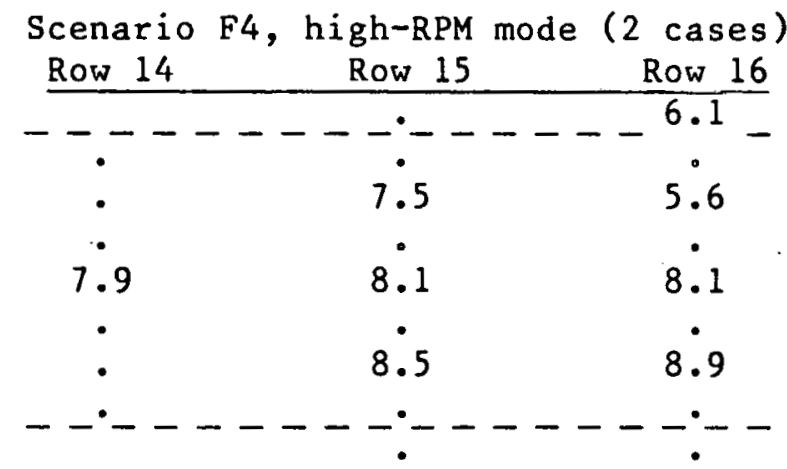

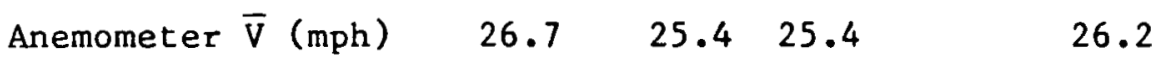

Scenario F5, high-RPM mode (2 cases)

\begin{tabular}{|c|c|c|}
\hline Row 14 & Row 15 & Row 16 \\
\hline$\frac{---}{8.1}$ & $\begin{array}{l}-\dot{-} \\
7.3\end{array}$ & $\begin{array}{c}5.4 \\
4.7\end{array}$ \\
\hline 7.8 & 6.9 & 6.4 \\
\hline 7.0 & 6.6 & 7.1 \\
\hline$--\cdot$ & $\because-$ & $-\div$ \\
\hline
\end{tabular}

Anemumeter $\vec{V}(\mathrm{mph}) \quad 26.2 \quad 24.7 \quad 24.1 \quad 24.1$

See page 52 for an explanation of these tables. 


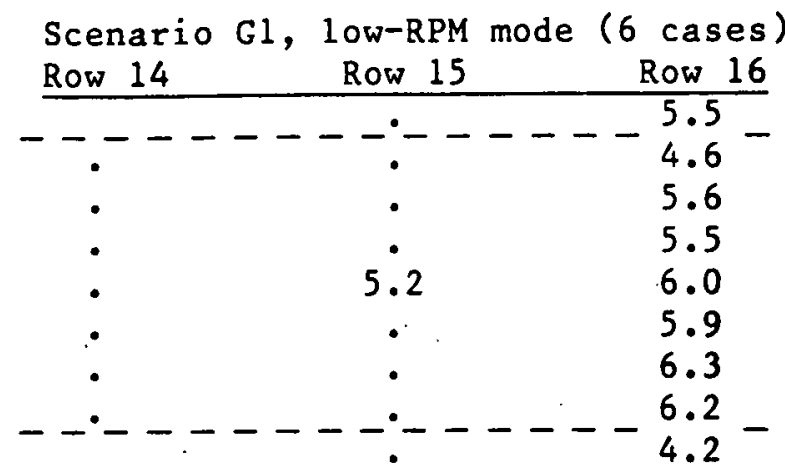

Anemometer $\overline{\mathrm{V}}(\mathrm{mph}) \quad 26.9 \quad 25.5 \quad 25.6^{\circ} \quad 25.0$

Scenario G2, low-RPM mode (6 cases)

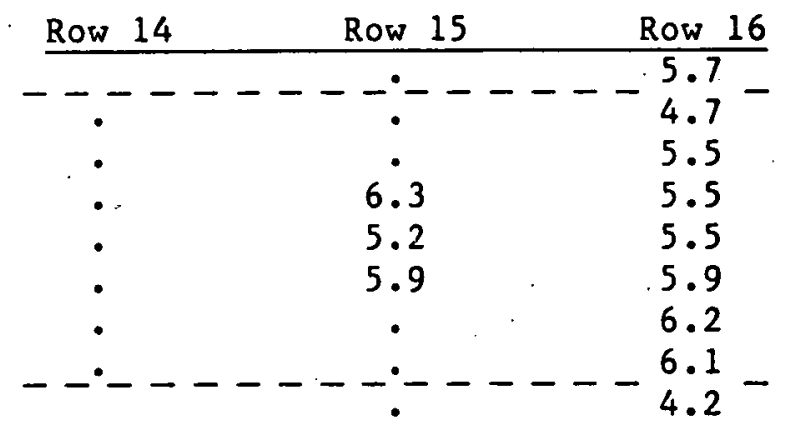

Anemometer $\bar{V}(\mathrm{mph}) \quad 26.4 \quad 25.0 \quad 25.1 \quad 23.5$

Scenario G3, low-RPM mode ( 6 cases)

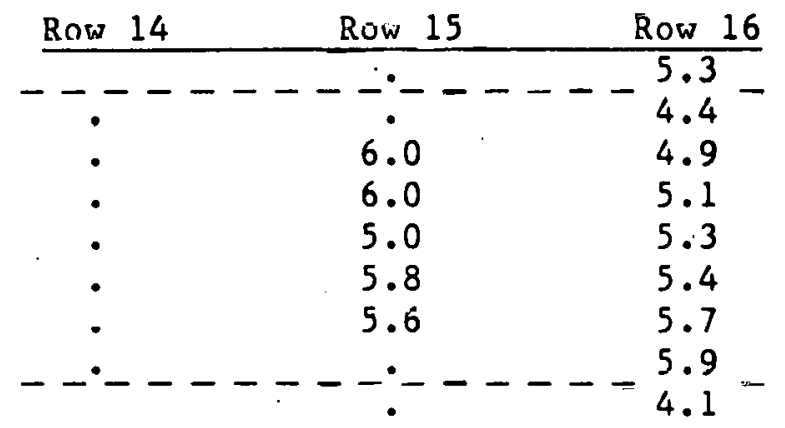

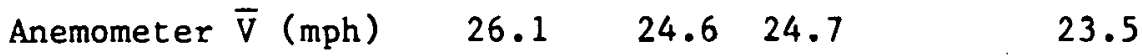

See page 52 for an explanation of these tables. 
Scenario G1, high-RPM mode ( 3 cases)

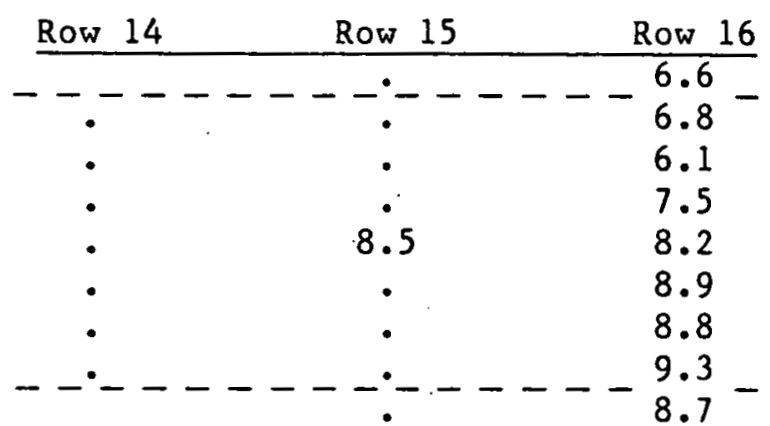

Anemometer $\bar{V}(\mathrm{mph}) \quad 26.5 \quad 25.4 \quad 26.0 \quad 26.0$

Scenario G2, high-RPM mode ( 3 cases)

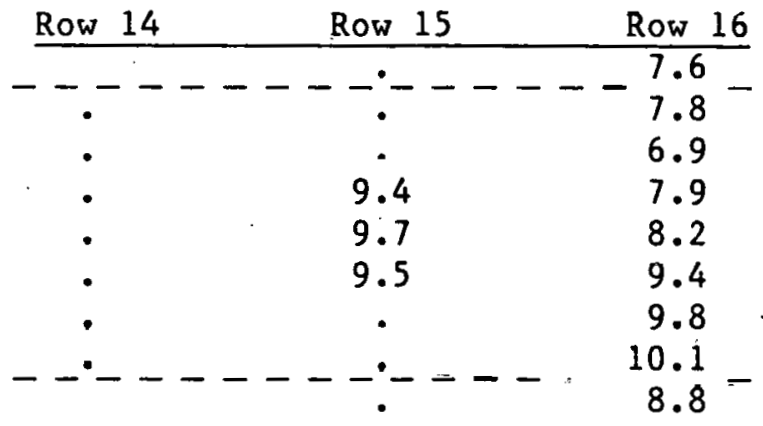

Anemometer $\overline{\mathrm{V}}(\mathrm{mph}) \cdot 28.0 \quad 27.0 \quad 27.2 \quad 25.8$

Scenario G3, high-RPM mode ( 3 cases)

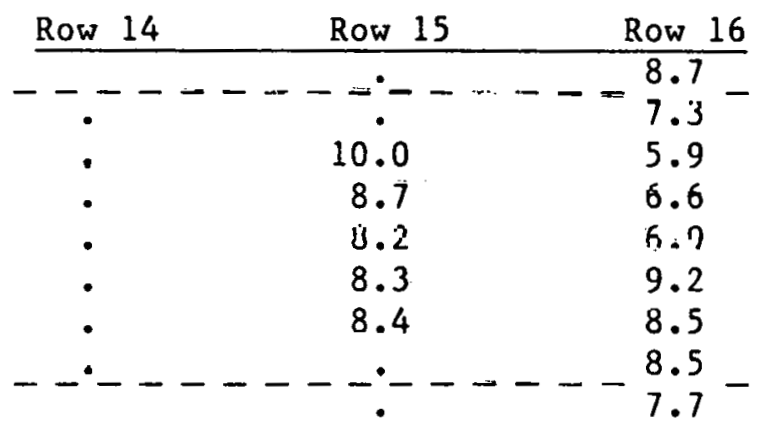

$\begin{array}{lllll}\text { Anemometer } \overline{\mathrm{V}}(\mathrm{mph}) & 27.7 & 26.2 & 25.7 & 24.4\end{array}$

See page 52 for an explanation of these tables. 


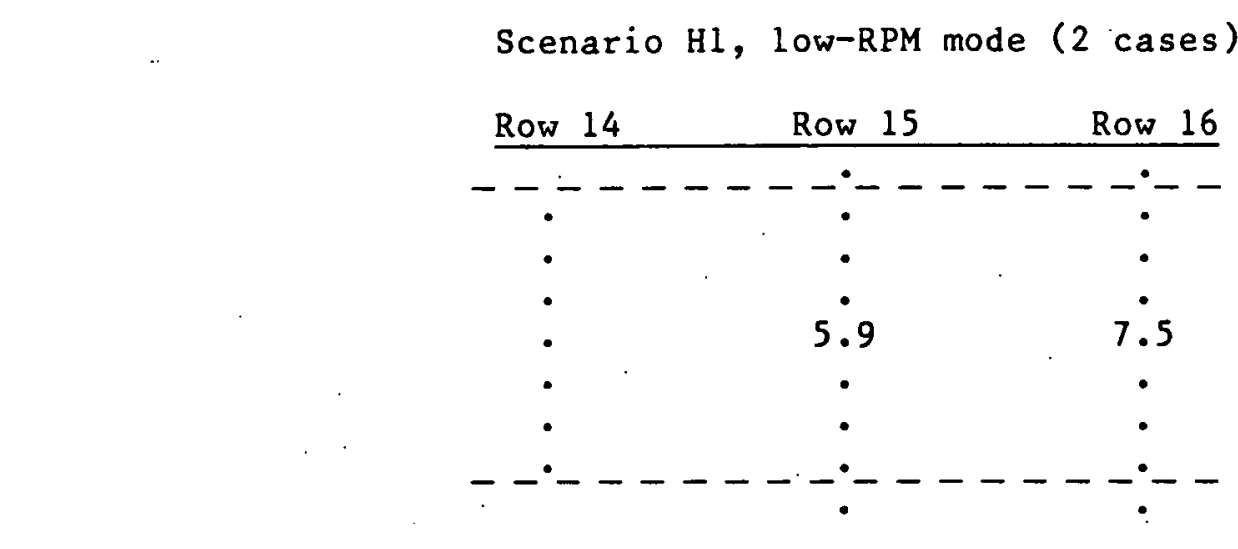

Anemometer $\vec{V}(\mathrm{mph}) \quad 28.5 \quad 27.8 \quad 28.1 \quad 28.2$

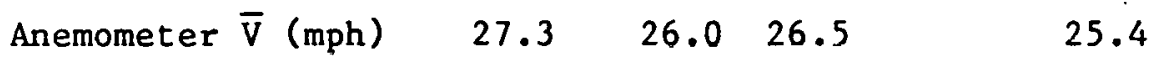

Anemometer $\bar{V}(\mathrm{mph}) \quad 26.4 \quad 25.2 \quad 25.4 \quad 24.3$

See page 52 for an explanation of these tables. 
Scenario Hl, high-RPM mode (2 cases)

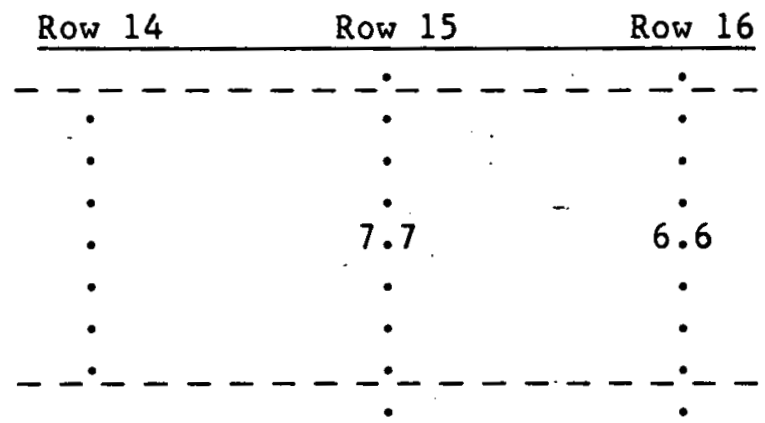

Anemometer $\bar{V}(\mathrm{mph}) \quad 26.7 \quad$. 23.1. 24.I." 24.2

Scenario $\mathrm{H} 2$, high-RPM mode (2 cases)

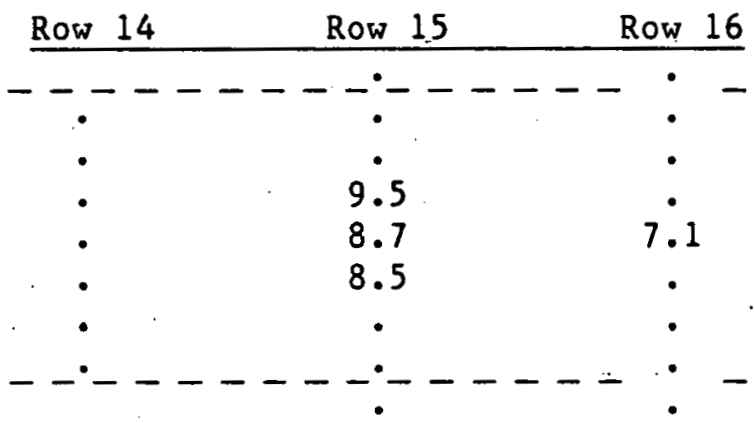

$\begin{array}{lllll}\text { Anemometer } \bar{V}(m p h) & 28.6 & 26.9 & 26.3 & 24.8\end{array}$

Scenario H3, high-RPM mode ( 2 cases)

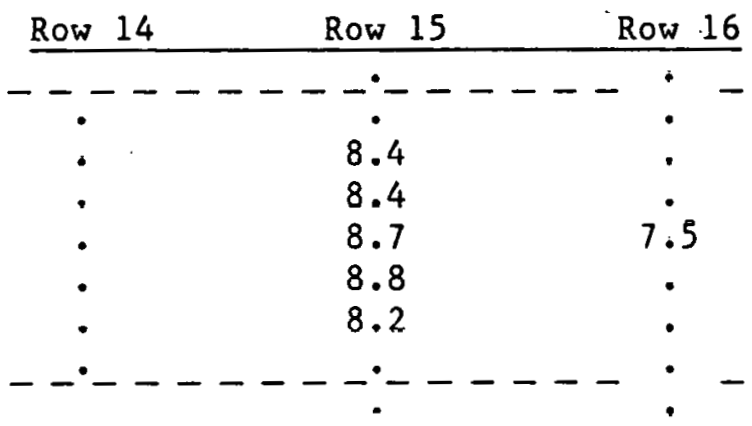

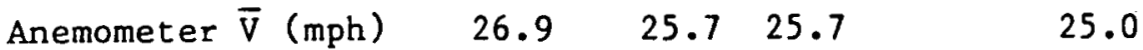

See page 52 for an explanation of these tables. 


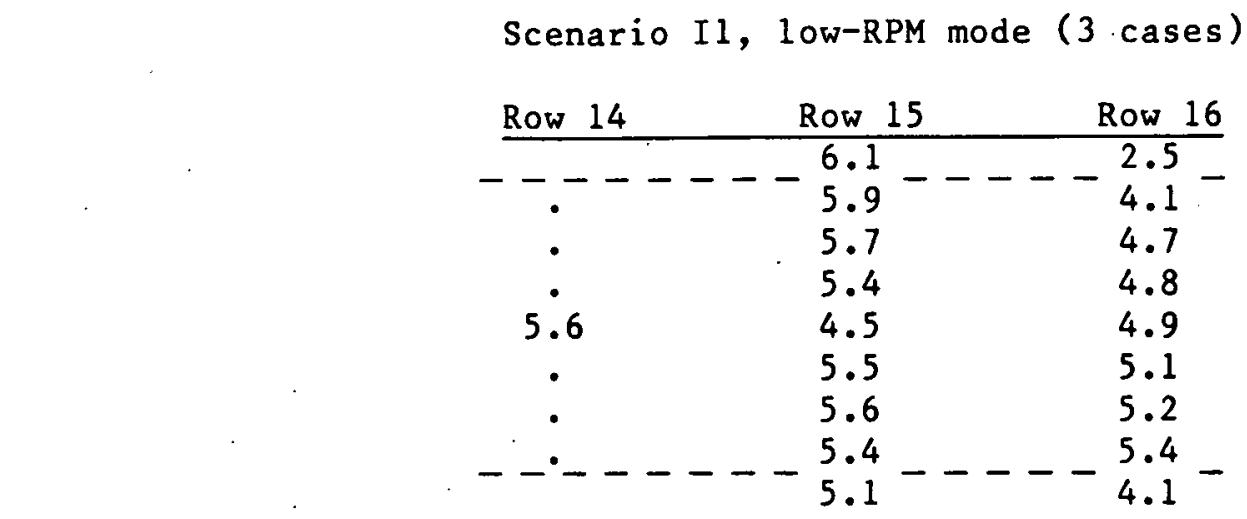

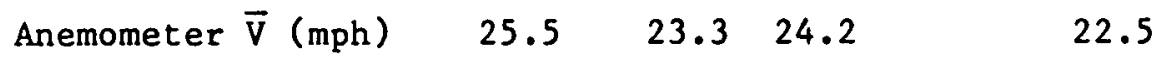

Scenario I2, low-RPM mode (5 cases)

\begin{tabular}{|c|c|c|}
\hline Row 14 & Row 15 & Row 16 \\
\hline--- & 4.7 & 2.2 \\
\hline & 4.7 & 3.4 \\
\hline 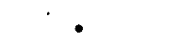 & 4.6 & 3.8 \\
\hline 4.7 & 4.5 & 4.1 \\
\hline 4.7 & 3.8 & 4.1 \\
\hline 4.6 & 4.4 & 4.2 \\
\hline • & 4.7 & 4.2 \\
\hline & $\begin{array}{r}4.6 \\
4.4\end{array}$ & $\begin{array}{r}4.5 \\
3.7\end{array}-$ \\
\hline
\end{tabular}

$\begin{array}{lllll}\text { Anemometer } \bar{V}(\mathrm{mph}) & 23.6 & 21.1 & 21.5 & 20.9\end{array}$

Scenario I3, low-RPM mode ( 3 cases).

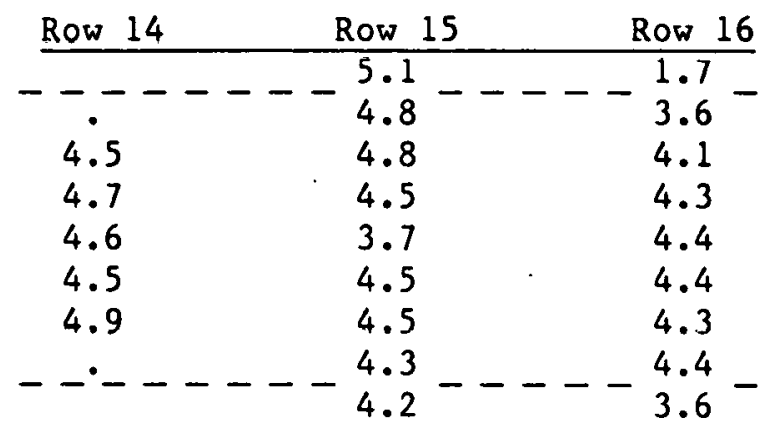

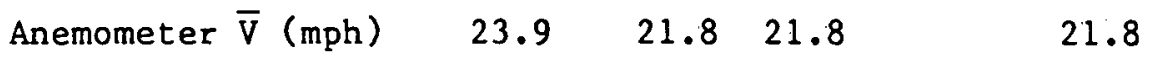

See page 52 for an explanacion of chese cables. 
Scenario Il, high-RPM mode ( 0 cases)

Scenario I2, high-RPM mode (1 case)

\begin{tabular}{|c|c|c|}
\hline \multicolumn{3}{|l|}{ Row 14} \\
\hline--- & 5.9 & 2.2 \\
\hline & 4.9 & 2.3 \\
\hline 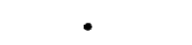 & 3.1 & 1.5 \\
\hline 4.9 & 2.5 & 1.6 \\
\hline 5.2 & 2.7 & 1.8 \\
\hline 3.8 & 3.4 & 2.8 \\
\hline - & 5.0 & 3.1 \\
\hline$-\cdot-$ & 3.9 & 3.5 \\
\hline
\end{tabular}

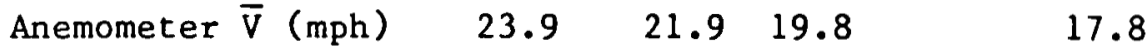

Scenario I3, high-RPM mode (1 case)

\begin{tabular}{ccc} 
Row 14 & Row 15 & Row 16 \\
\hline$--1-$ & 3.9 & 0.9 \\
3.2 & 1.9 & 1.5 \\
3.0 & 1.5 & 0.7 \\
3.3 & 2.3 & 1.1 \\
2.2 & 2.1 & 1.8 \\
2.0 & 2.7 & 2.3 \\
$--.0-----2.6$ & 1.9 \\
- & $0.0---$ & 3.4
\end{tabular}

Anemometer $\bar{V}(\mathrm{mph}) \quad 21.1 \quad 19.4 \quad 18.0 \quad 18.8$

See page 52 for an explanation of these tables. 
Scenario J1, low-RPM mode (3 cases)

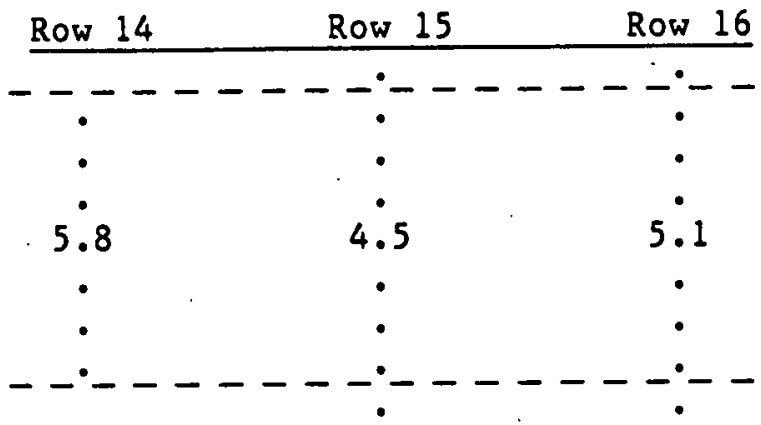

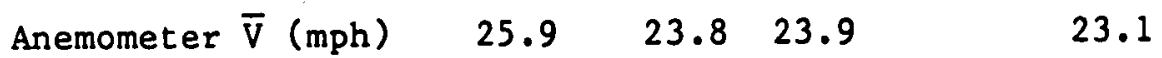

Scenario J2, 10w-RPM mode ( 2 cases)

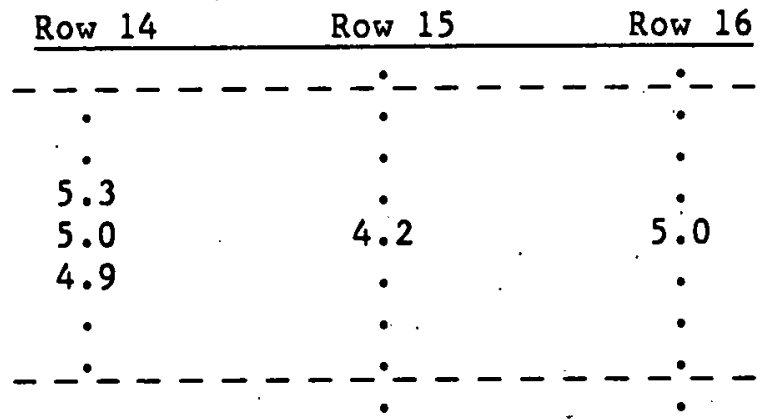

$\begin{array}{lllll}\text { Anemometer } \bar{V}(\mathrm{mph}) & 24.4 & 23.3 & 23.0 & 22.8\end{array}$

Scenario J3, low-RPM mode (2 cases)

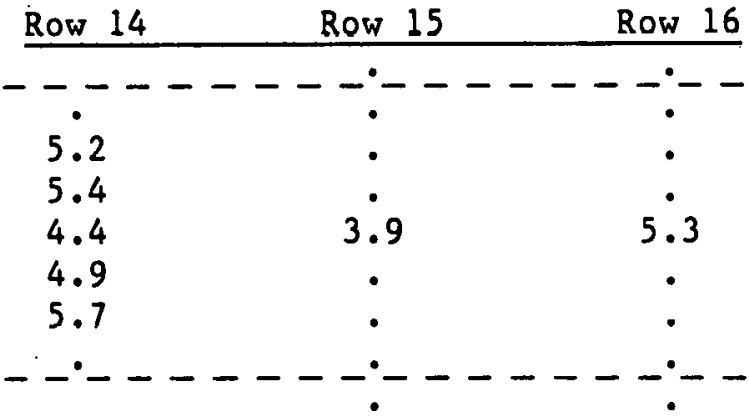

Anemometer $\bar{V}(\mathrm{mph}) \quad 25.0 \quad 24.4 \quad 23.4 \quad 24.6$

See page 52 for an explanation of these tables. 
SEP

STR -3186

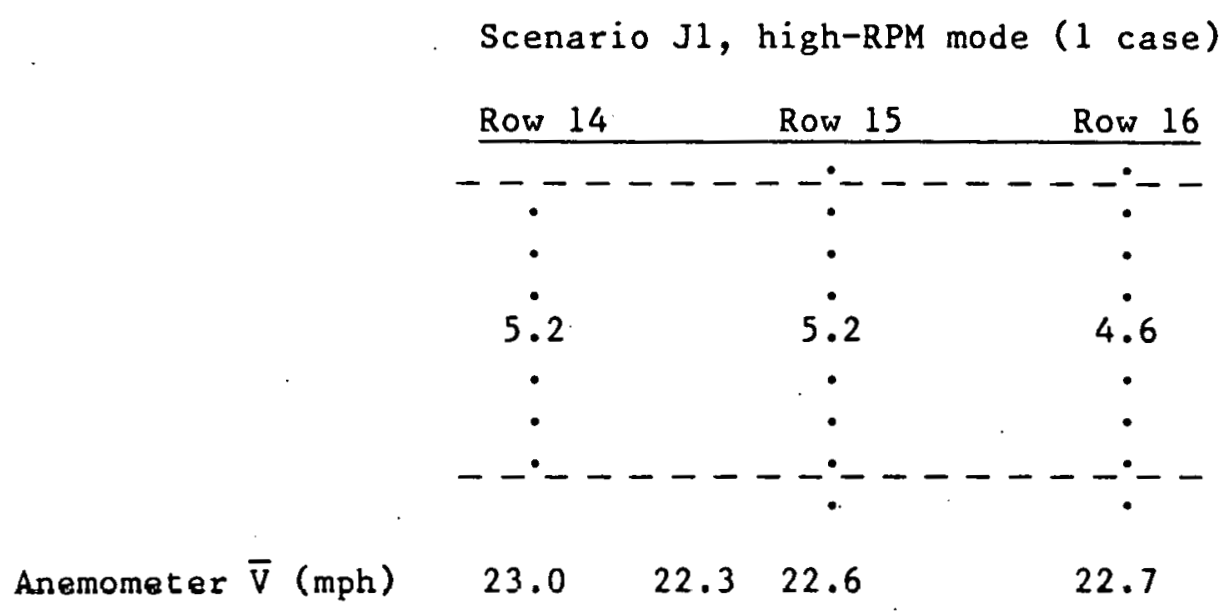

Scenario J2, high-RPM mode (1 case)

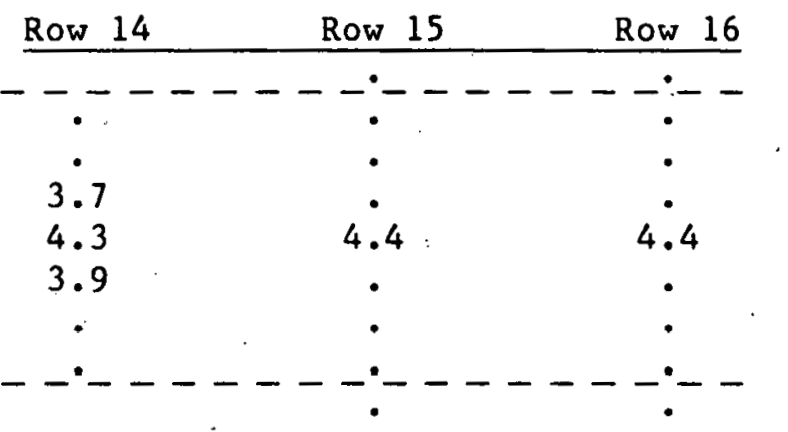

Anemometer $\overline{\mathrm{V}}(\mathrm{mph}) \quad 22.3 \quad 21.3 \quad 20.9 \quad \cdots \quad 22.3 \quad$

Scenario J3, high-RPM mode (0 cases)

See page 52 for an explanation of these tables.

66 


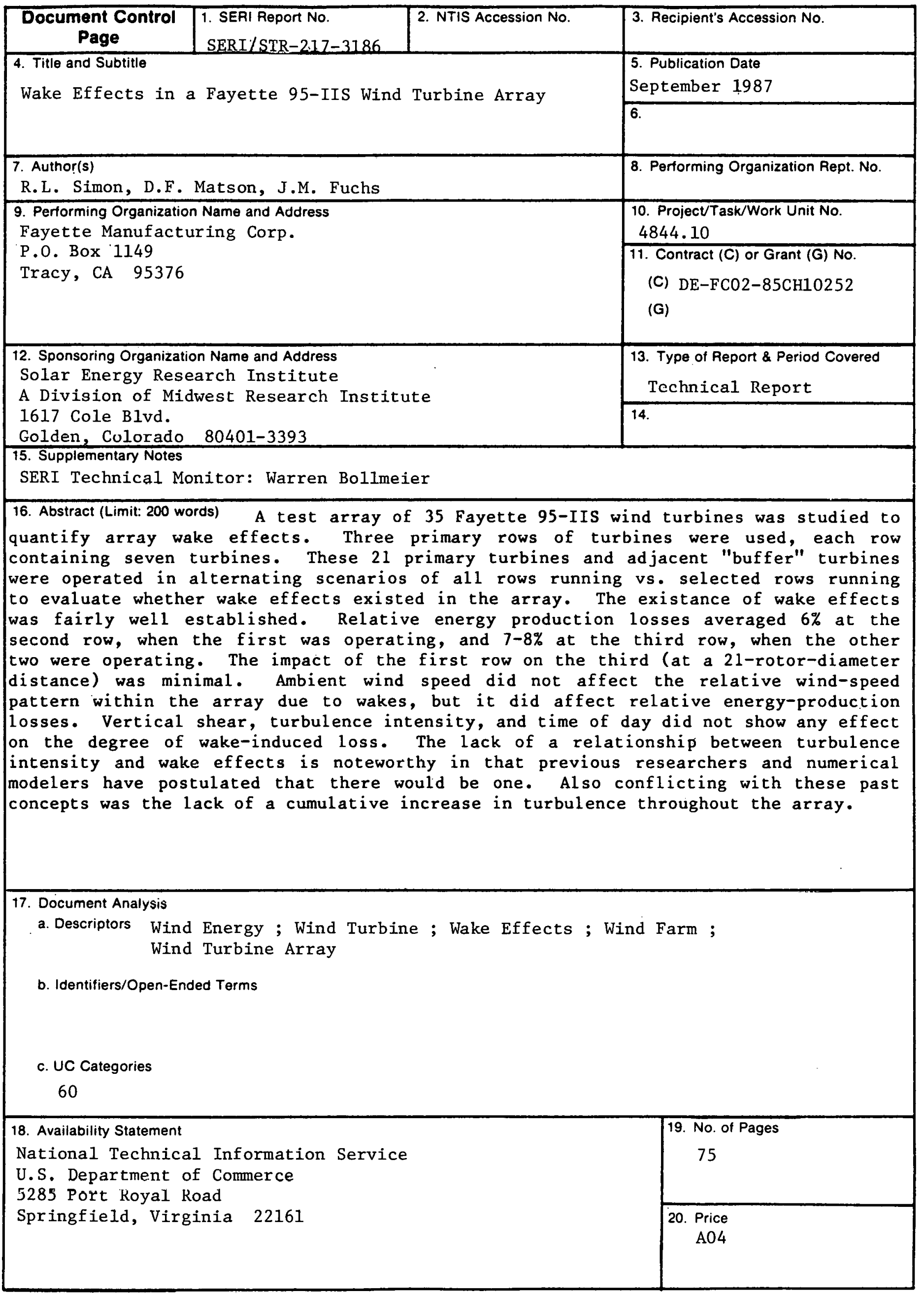

